\title{
The demographic and geographic impact of the COVID pandemic in Bulgaria and Eastern Europe in 2020
}

\author{
Antoni Rangachev ${ }^{1,2}$, Georgi K. Marinov³, and Mladen Mladenov ${ }^{4}$ \\ ${ }^{1}$ Department of Mathematics, University of Chicago, Chicago, IL 60637, USA \\ ${ }^{2}$ Institute of Mathematics and Informatics, Bulgarian Academy of Sciences, Sofia 1113, Bulgaria \\ ${ }^{3}$ Department of Genetics, Stanford University, Stanford, CA 94305, USA \\ ${ }^{4}$ Premier Research, Morrisville, NC 27560, USA
}

\begin{abstract}
Background: The COVID-19 pandemic followed a unique trajectory in Eastern Europe compared to other heavily affected regions, with most countries there only experiencing a major surge of cases and deaths towards the end of 2020 after a relatively uneventful first half of the year. However, the consequences of that surge have not received as much attention as the situation in Western countries. Bulgaria, even though it has been one of the most heavily affected countries, has been one of those neglected cases.
\end{abstract}

Methods: We use mortality and mobility data from Eurostat, official governmental and other sources to examine the development and impact of the COVID-19 pandemic in Bulgaria and other European countries.

Results: We find a very high level of excess mortality in Eastern European countries measured by several metrics including excess mortality rate (EMR), P-scores and potential years of life lost. By the last metric Eastern Europe emerges as the hardest hit region by the pandemic in Europe in 2020. With a record EMR at $\sim 0.25 \%$ and a strikingly large and mostly unique to it mortality rate in the working age demographics, Bulgaria emerges as one of the most affected countries in Eastern Europe. The high excess mortality in Bulgaria correlates with insufficient intensity of testing and with delayed imposition of "lockdown" measures. We also find major geographic and demographic disparities within the country, with considerably lower mortality observed in major cities relative to more remote areas (likely due to disparities in the availability of medical resources). Analysis of the course of the epidemic revealed that individual mobility measures were predictive of the eventual decline in cases and deaths. However, while mobility declined as a result of the imposition of a lockdown, it already trended downwards before such measures were introduced, which resulted in a reduction of deaths independent of the effect of restrictions.

Conclusions: Large excess mortality and high numbers of potential years of life lost are observed as a result of the COVID pandemic in Bulgaria, as well as in several other countries in Eastern Europe. Significant delays in the imposition of stringent mobility-reducing measures combined with a lack of medical resources likely caused a substantial loss of life, including in the working age population.

\section{Introduction}

The SARS-CoV-2 virus and COVID-19, the disease it causes $^{1 / 3}$, have emerged as the most acute public health emergency in a century. The novel coronavirus spread rapidly before significant efforts at containment were implemented in much of the world, resulting in devastating early outbreaks in the United States and Western Europe, starting in late February and early March of 2020.

Some combination of lockdown measures, imposed in response to surging infections, voluntary changes in behavior, and the onset of the summer season is thought to have caused the major decline in COVID-19 cases in Europe in the summer of 2020. However, winter in the Southern hemisphere, during which large epidemics developed in South Africa and South America, together with the well-documented seasonality of common-cold coronaviruses ${ }^{4}$, strongly suggested that a major second wave was to be expected in Europe with the arrival of winter ${ }^{5}$, and when it eventually arrived expectation turned into reality. 
During the early months of the pandemic, a dichotomy emerged between countries in Western and Eastern Europe (with the possible exception of Russia). Western Europe was heavily affected - by June 2020 official COVID mortality reached 600 to 800 deaths per million (DPM) in countries such as Spain, Italy, the UK, Belgium, France, and Sweden, with excess mortality rates even higher 6 [10. In contrast, most Eastern European countries registered relatively few deaths, possibly because of much earlier implementation of social distancing measures relative to the development of the outbreak.

This dichotomy disappeared during the second wave at the end of 2020, with both countries in Western and Eastern Europe officially registering a large number of COVIDrelated fatalities, as well as in some cases considerably larger excess mortality. However, the development of the pandemic in Eastern Europe has so far generally received much less attention than that in the West even though multiple countries in the region were heavily affected by it. We show this using multiple excess mortality measures, which quantify the pandemic-related loss of life and allow for standardized comparisons between countries.

Among Eastern European countries, Bulgaria has emerged as perhaps the most heavily affected by the pandemic as suggested by excess mortality analysis ${ }^{6}$. Here we analyze the development and impact of the pandemic on Bulgaria, in the broader European context, across demographic groups within the country, and for its regional subdivisions, as well as the influence of human mobility changes and government-imposed quarantine measure on the course of the pandemic. We use these analyses to identify correlate factors likely responsible for particularly high unexplained excess mortality in certain settings.

\section{Methodology}

\section{Data Sources}

All-cause mortality data for European countries, as well as NUTS-3 (Nomenclature of Territorial Units for Statistics) regions in Bulgaria, was obtained from Eurostat $\frac{11 \mid 12}{2}$. The data presented in the datasets is sex- and age-stratified, with age groups split in increments of 5 years. Since not all countries submit data at the same time and in the same manner, only countries that have consistent weekly data for the period 2015-2020 (inclusive) were analyzed.

Country-level population data at the beginning of 2020 was collected through Eurostat $\frac{13}{13}$, but was further supplemented by population data from the United Nations' UNdata Data Service ${ }^{14}$. We further elaborate on this topic in the subsequent section on Potential Years of Life Lost (PYLL) and Working Years of Life Lost (WYLL) estimates.

Life expectancy values at different ages were obtained from three separate sources. We acquire the full life tables for Bulgaria through the country's National Statistical Institute $^{15}$, and for Czechia through the country's Statistical Office 1 . Abridged life tables for all European countries were obtained from the World Health Organization's open data platform 17 . This dataset is partitioned by age, in increments of 5 years.

COVID-related mortality and testing data for Bulgaria was collected through the resources available from the Min-

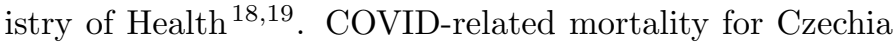
was acquired from Czech Ministry of Health official website tracking the pandemic $\underline{20}$.

\section{Data Availability}

All datasets and associated code can be found at https: //github.com/Mlad-en/COV-BG.git.

\section{Excess mortality and P-scores}

To calculate excess mortality across countries as well as across Bulgarian regions, we analyze the mortality observed between week 10 and 53 of 2020 and compare it to the mean mortality between the same period for the previous five years (2015-2019). We derive this mean both on a weekly and aggregate total basis. We then establish a $95 \%$ confidence interval for this mean. This range is used to calculate excess mortality as:

\section{Excess Mortality $=$ Mortality $_{2020}-$ Mean Mortality}

This calculation is done both as a sex- and age-stratified metric, as well as an aggregated total. To normalize excess mortality across countries, we calculate excess mortality per total population. To do this, we use population data from Eurostat for 2020.

Based on the excess mortality ranges we also compute a $\mathrm{P}$-score value for each country/region. A P-score value is defined as "the percentage difference between the number of deaths in 2020[...] and the average number of deaths in the same period-week or month over the years 2015-2019."21]

We calculate the P-score as follows:

$$
P:=\frac{\text { Mortality }_{2020}-\text { Mean Mortality }}{\text { Mean Mortality }} * 100
$$

We also calculate the ratio between excess mortality and official COVID-19-attributed mortality. Due to the demonstrably low testing in Bulgaria ${ }^{22}$ and other countries, this allows us to estimate under-reported COVID-19 fatalities. We also use the total positive tests per region reported at the end of 2020 to compute a Case Fatality Ratio (CFR) which estimates the proportion of COVID-19 fatalities among confirmed cases.

\section{Potential Years of Life Lost (PYLL), Aged-Standardized Years of life lost Rate (ASYR), and Working Years of Life Lost (WYLL) estimates}

Potential Years of Life Lost (PYLL) is a metric that estimates the burden of disease on a given population by looking at premature mortality. It is derived as the difference 
medRxiv preprint doi: https://doi.org/10.1101/2021.04.06.21254958; this version posted April 10, 2021. The copyright holder for this preprint (which was not certified by peer review) is the author/funder, who has granted medRxiv a license to display the preprint in perpetuity.

It is made available under a CC-BY-NC-ND 4.0 International license .

A

\begin{tabular}{|c|c|c|c|c|c|}
\hline Country & $\begin{array}{l}\text { Average } \\
\text { Mortality }\end{array}$ & $\begin{array}{c}\text { Mortality } \\
\text { (2020) }\end{array}$ & Population & $\begin{array}{c}\text { Excess } \\
\text { mortality }\end{array}$ & P-score \\
\hline \multirow{6}{*}{$\begin{array}{l}\text { Spain } \\
\text { Poland } \\
\text { Slovenia } \\
\text { Belgium } \\
\text { Czechia } \\
\text { Italy }\end{array}$} & 336,932 & 418,959 & \begin{tabular}{|l|}
$47,332,614$ \\
\end{tabular} & \begin{tabular}{ll|}
82,027 \\
\end{tabular} & 24.3 \\
\hline & 329,989 & 410,313 & $37,958,138$ & 80,324 & 24.3 \\
\hline & 16,395 & 20,260 & $2,095,861$ & 3,865 & 23.6 \\
\hline & 89,076 & 108,337 & \begin{tabular}{|l|}
$11,522,440$ \\
\end{tabular} & 19,261 & 21.6 \\
\hline & 91,116 & 110,437 & \begin{tabular}{|l|}
$10,693,939$ \\
\end{tabular} & 19,321 & 21.2 \\
\hline & 523,664 & 632,791 & $59,641,488$ & 109,127 & 20.8 \\
\hline \multirow{4}{*}{$\begin{array}{c}\text { Bulgaria } \\
\text { Switzerland } \\
\text { Romania } \\
\text { Malta }\end{array}$} & 88,784 & 106,136 & $6,951,482$ & 17,352 & 19.5 \\
\hline & 54,563 & 64,647 & $8,606,033$ & 10,084 & 18.5 \\
\hline & 213,927 & 253,027 & $19,328,838$ & 39,100 & 18.3 \\
\hline & 2,826 & 3,332 & 514,564 & 506 & 17.9 \\
\hline \multirow{2}{*}{$\begin{array}{l}\text { Luxembourg } \\
\text { Netherlands }\end{array}$} & 3,405 & 3,973 & 626,108 & 568 & 16.7 \\
\hline & 122,940 & 142,890 & $17,407,585$ & 19,950 & 16.2 \\
\hline \multirow{2}{*}{$\begin{array}{c}\text { Portugal } \\
\text { Montenegro }\end{array}$} & 88,458 & 102,505 & $10,295,909$ & 14,047 & 15.9 \\
\hline & 5,295 & 6,116 & 621,873 & 821 & 15.5 \\
\hline \multirow{2}{*}{$\begin{array}{l}\text { Slovakia } \\
\text { France }\end{array}$} & 43,723 & 50,147 & $5,457,873$ & 6,424 & 14.7 \\
\hline & \begin{tabular}{|l|l|}
492,698 \\
\end{tabular} & 564,198 & $67,320,216$ & 71,500 & 14.5 \\
\hline \multirow{2}{*}{$\begin{array}{l}\text { Austria } \\
\text { Hungary }\end{array}$} & 66,271 & \begin{tabular}{ll|}
75,824 \\
\end{tabular} & $8,901,064$ & 9,553 & 14.4 \\
\hline & 105,603 & 119,020 & $9,769,526$ & 13,417 & 12.7 \\
\hline \multirow{2}{*}{$\begin{array}{l}\text { Croatia } \\
\text { Cyprus }\end{array}$} & 42,923 & 48,394 & $4,058,165$ & 5,471 & 12.7 \\
\hline & 4,718 & 5,285 & 888,005 & 567 & 12 \\
\hline \multirow{2}{*}{$\begin{array}{l}\text { Lithuania } \\
\text { Sweden }\end{array}$} & 32,907 & 36,797 & $2,794,090$ & 3,890 & 11.8 \\
\hline & 73,036 & 80,720 & $10,327,589$ & 7,684 & 10.5 \\
\hline \multirow{2}{*}{$\begin{array}{l}\text { Greece } \\
\text { Estonia }\end{array}$} & 99,509 & 108,019 & $10,718,565$ & 8,510 & 8.6 \\
\hline & 12,643 & 13,410 & $1,328,976$ & 767 & 6.1 \\
\hline \multirow{2}{*}{$\begin{array}{l}\text { Denmark } \\
\text { Finland }\end{array}$} & 44,156 & 45,815 & $5,822,763$ & 1,659 & 3.8 \\
\hline & 44365.8 & 46023 & 5525292 & 1657.2 & 3.7 \\
\hline \multirow{3}{*}{$\begin{array}{l}\text { Latvia } \\
\text { Norway }\end{array}$} & 23424.6 & 24093 & 1907675 & 668.4 & 2.9 \\
\hline & 33429.6 & 33521 & 5367580 & 91.4 & 0.3 \\
\hline & 477 & 1876 & 364134 & -2 & -0.1 \\
\hline
\end{tabular}

all ages total P-score
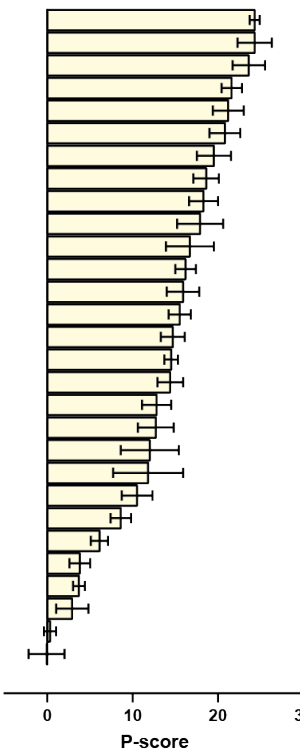

all ages females $\mathbf{P}$-score

B

Country Average Mortality Population Excess P-score \begin{tabular}{c|c|c|c|c|c|} 
& Mortality & \multicolumn{2}{c}{ (2020) } & \multicolumn{4}{c}{ mortality } \\
\cline { 2 - 6 } Slovenia & 8,285 & 10,364 & $1,044,795$ & 2,079 & 25.1 \\
\cline { 2 - 6 } & 165,789 & 206754 & $24,133,301$ & 40,975 & 24.7 \\
\hline
\end{tabular} \begin{tabular}{|c|c|c|c|c|c|}
\hline \multirow{2}{*}{ Spain } & 165,789 & 206,764 & $24,133,301$ & 40,975 & 24.7 \\
\cline { 2 - 7 } & 158,479 & 194,943 & $19,584,757$ & 36,464 & 23 \\
\hline
\end{tabular} \begin{tabular}{l|c|c|c|c|c|}
\multirow{3}{*}{ Poland } & 158,479 & 194,943 & $19,584,757$ & 36,464 & 23 \\
\cline { 2 - 7 } & 45,287 & 55,253 & 5841,215 & 9,966 & 22 \\
\hline
\end{tabular} \begin{tabular}{|c|c|c|c|c|c|}
\hline \multirow{2}{*}{ Belgium } & 45,287 & 55,253 & $5,841,215$ & 9,966 & 22 \\
\cline { 2 - 7 } & 44,723 & 53,442 & $5,421,943$ & 8719 & 19.5 \\
\hline
\end{tabular} \begin{tabular}{c|c|c|c|c|c|}
\multirow{3}{*}{ Czechia } & 44,723 & 53,442 & $5,421,943$ & 8,719 & 19.5 \\
\cline { 2 - 6 } & 271,894 & 323,781 & $30,591,392$ & 51,887 & 19.1
\end{tabular} Italy Portugal

Bulgaria

Malta

witzerland

Switzerland

Luxembourg

France

Slovakia

Hungary

Netherlands

Lithuania

Austria

Montenegro

Cyprus

Sweden

Estonia

Latvia

Finland

enmark

Iceland

Norway

\begin{tabular}{|c|c|c|}
\hline 41,894 & 323,781 & $30,591,392$ \\
\hline 43,912 & 51,543 & $5,435,932$ \\
\hline
\end{tabular}

\begin{tabular}{|c|c|c|c|c|}
\hline 42,599 & 49,823 & $3,581,836$ & 7,224 & 17 \\
\hline 1,389 & 1,625 & 248,802 & 236 & 17 \\
\hline
\end{tabular}

\begin{tabular}{|c|c|c|}
\hline 1,38925 & 1,625 & 248,802 \\
\hline
\end{tabular}

\begin{tabular}{|c|c|c|c|c|}
\hline 72,663 & $4,337,170$ & 4,585 & 16.3 \\
\hline
\end{tabular}

\begin{tabular}{|c|c|c|}
\hline 1,670 & 1,929 & $9,868,177$ \\
\hline 111,44
\end{tabular}

\begin{tabular}{|c|c|c|c|c|}
\hline 246,071 & 281,202 & $31,787,547$ & 259 & 15.5 \\
\hline
\end{tabular}

\begin{tabular}{|c|c|c|c|c|}
\hline 21,278 & 24,276 & $2,792,523$ & 2,998 & 14,3 \\
\hline
\end{tabular}

\begin{tabular}{|c|c|c|c|c|}
\hline 53,852 & 60,931 & $5,088,736$ & 7,079 & 13.1 \\
\hline
\end{tabular}

\begin{tabular}{|c|c|c|c|c|}
\hline 62,985 & 71,188 & $8,759,554$ & 8,203 & 13 \\
\hline 21,803 & 24,468 & 2086515 & 2,655 & 12, \\
\hline
\end{tabular}

\begin{tabular}{|l|l|l|l|l|}
\hline 21,803 & 24,468 & $2,086,515$ & 2,665 & 12.2 \\
\hline 16,803 & 18,798 & $1,489,736$ & 1,995 & 119 \\
\hline
\end{tabular}

\begin{tabular}{|c|c|c|}
34,317 & 38,321 & $4,522,292$ \\
\hline 2,529 & 2,817 & 314,318 \\
\hline
\end{tabular}

\begin{tabular}{|l|l|l|l}
\hline$, 2,529$ & 2,817 & 314,318 \\
\hline 2,227 & 2,468 & 453,534 \\
\hline
\end{tabular}

\begin{tabular}{|l|l|l|}
\hline 48,738 & 53,328 & $5,503,077$ \\
\hline 37,398 & 40,434 & $5,131,775$ \\
\hline
\end{tabular}

\begin{tabular}{|c|c|c|c|c|}
\hline 398 & 40,434 & $5,50,077$ & 4,590 & 9.4 \\
\hline
\end{tabular}

\begin{tabular}{|c|c|c|c|c|}
\hline 6,644 & 7,084 & 699,699 & 440 & 6.6 \\
\hline
\end{tabular}

\begin{tabular}{|c|c|c|}
\hline 12,358 & 12,864 & $1,026,719$ \\
\hline
\end{tabular}

\begin{tabular}{|c|c|c|c|c|c|}
\hline 686458 & 7,084 & 699,699 & 40 & 6.6 \\
\hline
\end{tabular}

\begin{tabular}{|c|c|c|}
\hline 21873.2 & 22340 & 2925845 \\
\hline 919.2 & 910 & 177193 \\
\hline 17159 & 16947 & 2661018 \\
\hline
\end{tabular}

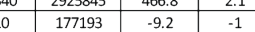

\begin{tabular}{|c|c|c|c|c|}
\hline 17159 & 16947 & 2661018 & -212 & -1.2 \\
\hline
\end{tabular}
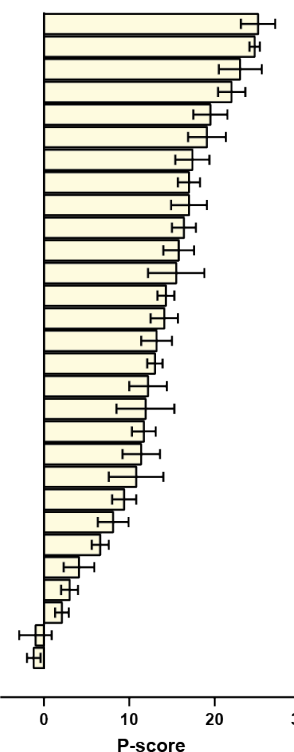

all ages males $\mathrm{P}$-score

C

Country Average Mortality Population Excess P-score

\begin{tabular}{c|c|c|c|c|c|}
\multirow{3}{*}{ Poland } & 171,510 & 215,370 & $18,373,381$ & 43,860 & 25.6 \\
\cline { 2 - 6 } & 171,433 & 212,96 & $23,99,31$ & 41,053 & 24 \\
\hline
\end{tabular}

\begin{tabular}{|c|c|c|c|c|c|}
\multirow{3}{*}{ Spain } & 171,143 & 212,196 & $23,199,313$ & 41,053 & 24 \\
\cline { 2 - 6 } & 46,393 & 56,995 & $5,271,996$ & 10,602 & 229 \\
\hline
\end{tabular}

\begin{tabular}{c|c|c|c|c|c|}
\cline { 2 - 6 } Czechia & 46,393 & 56,995 & $5,271,996$ & 10,602 & 22.9 \\
\cline { 2 - 7 } & 251,770 & 309,01 & $29,05,096$ & 57,220 & 227 \\
\hline
\end{tabular}

Italy

Slovenia

$\rightarrow$ Bulgaria

\begin{tabular}{|r|r|r|r|r|}
\hline 46,185 & 56,313 & $3,369,646$ & 10,128 & 21.9 \\
\hline
\end{tabular}

\begin{tabular}{|c|c|c|c|c|c|c|}
\hline Belgium & 43,789 & 53,084 & $5,681,225$ & 9,295 & 21.2 \\
\cline { 2 - 7 } & 26,485 & 31,94 & 4288,863 & 5,49 & 20.8 \\
\cline { 2 - 6 } & &
\end{tabular}

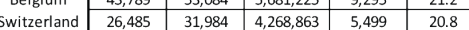

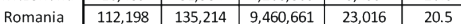

\begin{tabular}{|c|c|c|c|c|c|}
\cline { 2 - 7 } Netherlands & 59,955 & 71,702 & $8,648,031$ & 11,747 & 19.6 \\
\hline
\end{tabular}

Montenegro

Luxembourg

Austria

Slovakia

France
Portugal

Croatia

Cyprus

sweden

Hungary

Lithuania

Greece

Estonia

Denmark

Finland

Latvia

Iceland

\begin{tabular}{|c|c|c|c|c|}
\hline 2,766 & 3,299 & 307,555 & 533 & 19.3 \\
\hline 1,437 & 1707 & 265,762 & 270 & 188 \\
\hline
\end{tabular}

\begin{tabular}{|l|l|l|l|l|}
\hline 1,437 & 1,707 & 265,762 & 270 & 18.8 \\
\hline 1,735 & 2,044 & 314,964 & 309 & 17.8 \\
\hline
\end{tabular}

\begin{tabular}{|l|l|l|l|l|}
\hline $2,4,355$ & 25,871 & $2,6378,772$ & 5,550 & 17.4 \\
\hline
\end{tabular}

\begin{tabular}{|l|l|l|l|l|}
\hline $2,, 45$ & 25,871 & $2,665,350$ & 3,426 & 15.3 \\
\hline 246,626 & 282,996 & $32,532,669$ & 36,370 & 14.7 \\
\hline
\end{tabular}

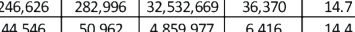

\begin{tabular}{|l|l|l|l|l|}
\hline 21,120 & 23,926 & $1,971,650$ & 2,806 & 13.3 \\
\hline
\end{tabular}

\begin{tabular}{|c|c|c|c|c|}
\hline 2,491 & 2,817 & 434,471 & 326 & 13.1 \\
\hline
\end{tabular}

\begin{tabular}{|c|c|c|c|c|}
\hline 35,638 & 40,286 & $5,195,814$ & 4,648 & 13 \\
\hline
\end{tabular}

\begin{tabular}{|l|l|l|l|l|}
\hline 51,752 & 58,089 & $4,680,790$ & 6,337 & 12.2 \\
\hline 16,105 & 17,999 & $1,304,354$ & 1,894 & 11.8 \\
\hline 50,771 & 54,691 & $5,25,488$ & 3,920 & 7.7 \\
\hline
\end{tabular}

\begin{tabular}{|c|c|c|c|c|}
\hline 16,105 & 17,999 & $1,304,354$ & 1,894 & 11.8 \\
\hline 50,771 & 54,691 & $5,215,488$ & 3,920 & 7.7 \\
\hline 5,999 &, 326 & 629,277 & 327 & 5.5 \\
\hline
\end{tabular}

\begin{tabular}{|c|c|c|}
\hline 50,711 & 54,691 & $5,215,488$ \\
\hline 5,999 & 6325 & 62,277 \\
\hline
\end{tabular}

\begin{tabular}{|c|c|c|c|c|}
\hline 5,999 & 6,326 & 629,277 & 327 & 5.5 \\
\hline 22,283 & 23,475 & $2,896,918$ & 1,192 & 5.4 \\
\hline
\end{tabular}

\begin{tabular}{|l|l|l|l|l|}
\hline 22180.2 & 23173 & 2728262 & 992.8 & 4.5 \\
\hline 16270.6 & 16574 & 2706562 & 303.4 & 1.9 \\
\hline
\end{tabular}

\begin{tabular}{|c|c|c|c|c|}
\hline 11066.6 & 11229 & 880956 & 162.4 & 1.5 \\
\hline
\end{tabular}

\begin{tabular}{c|c|c|}
\hline 11066.6 & 11229 & 880956 \\
\hline 958.8 & 966 & 186941 \\
\hline
\end{tabular}
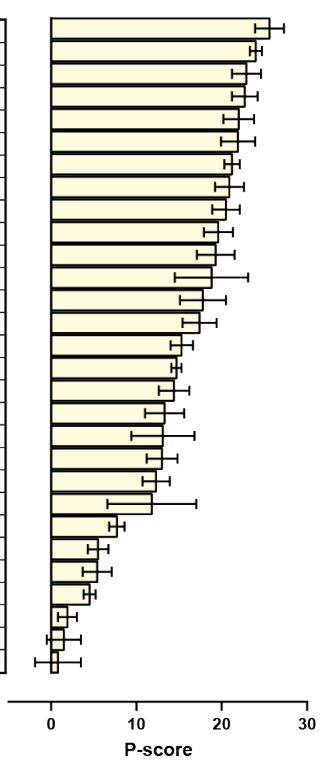

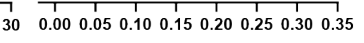
EMR (\%)
Figure 1: Excess mortality in Bulgaria and other EU countries in 2020. (A) Overall P-scores and excess mortality (in deaths per million; DPM) for all ages in Bulgaria (highlighted in red) and other EU countries; (B) P-scores and excess mortality for females of all ages; (C) P-scores and excess mortality for males of all ages. 



Figure 2: Ratio between excess mortality and official COVID-attributed deaths in European countries in 2020. Note that the high EMR/PFR ratios for 2020 in countries like Finland and Estonia might be an artifact of overall low both excess and COVID-attributed mortality.

between a person's age at the time died and the expected years of life for people at that age in a given country. As such, the metric attributes more weight to people that have died at a younger age.

We compute the PYLL across countries by taking the positive all-cause excess mortality for all ages groups (in Eurostat they are aggregated at 5 year intervals). We use the abridged life expectancy tables by the WHO (also aggregated at 5 year intervals) and calculate a total and average PYLL value for all countries. To be more precise, for an age interval $[x, x+4]$ and sex $s$ (if no sex is specified we assume it's for both sexes) define by $\operatorname{ED}([x, x+4], s)$ the excess deaths and by $\operatorname{LE}([x, x+4], s)$ the life expectancy. Then the potential years of life lost are computed as

$$
\operatorname{PYLL}([x, x+4], s)=\operatorname{ED}([x, x+4], s) * \operatorname{LE}([x, x+4], s) .
$$

The total PYLL is computed by summing over all age intervals. In our computations we take into account the margin of error for each $\operatorname{ED}([x, x+4], s)$.

A limitation on this approach is the upper-boundary aggregation value for the two datasets. The all-cause mortality dataset's upper boundary is $90+$, while the WHO's abridged life tables only go up to the $85+$ age bracket. To account for this, we attribute the life expectancy of the 85+ age group to the 85-89 mortality group. We have further excluded the $90+$ mortality group from our analysis. This is further elaborated on in the Limitations subsection, where we also provide a way of correcting for this exclusion.

Two countries for which we have the exact ages and sex for each reported COVID-19 fatality are Bulgaria and Czechia. We also have full life tables (increments of one year) for both countries provided by their respective statistical institutes. This allows us to compute and compare the PYLLs for each country based on excess mortality data and official data for COVID-19 fatalities.

Finally, we standardize PYLL values across countries by diving the total sum value by the population and normalizing it per 100,000 people:

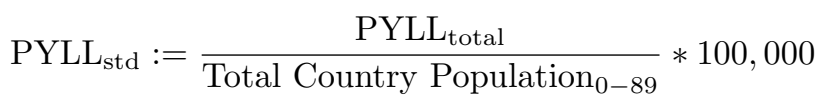

The data for country-level populations in Eurostat has a similar limitation in the upper boundary of the age distribution (a cut-off at 85+). To mitigate this limitation, we supplement the population data from Eurostat for ages 
medRxiv preprint doi: https://doi.org/10.1101/2021.04.06.21254958; this version posted April 10, 2021. The copyright holder for this preprint (which was not certified by peer review) is the author/funder, who has granted medRxiv a license to display the preprint in perpetuity.

It is made available under a CC-BY-NC-ND 4.0 International license .

A

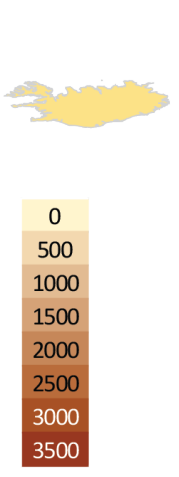

B

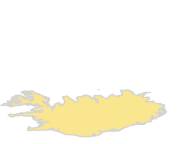

C

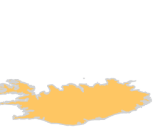

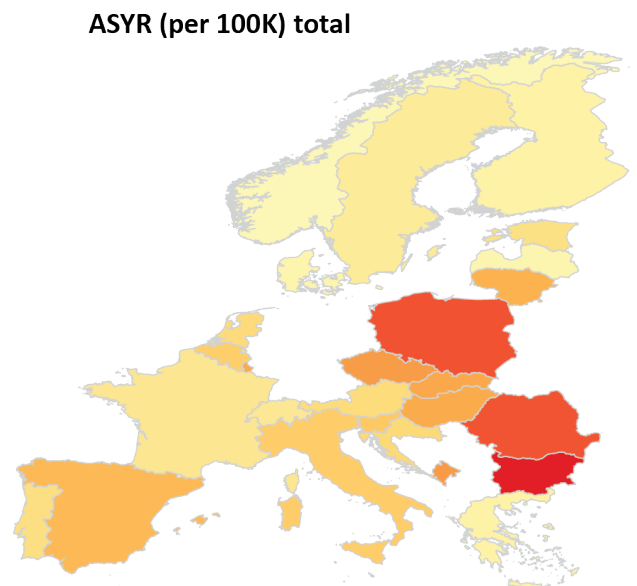

ASYR (per 100K) female

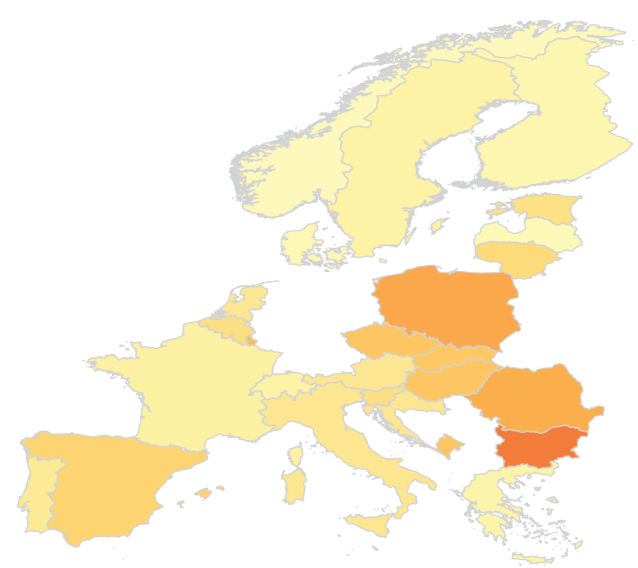

ASYR (per 100K) male

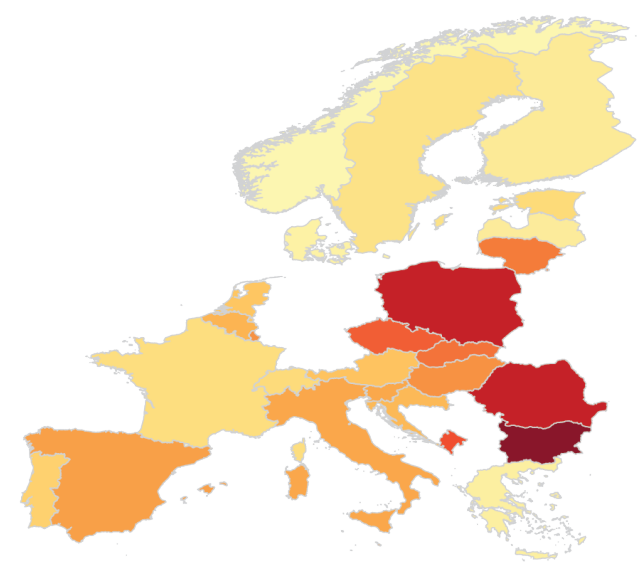

D

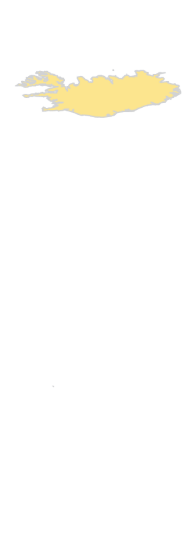

E

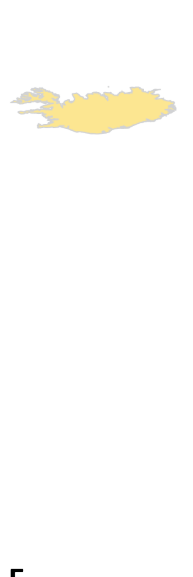

F

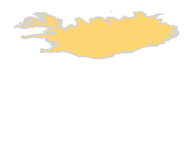

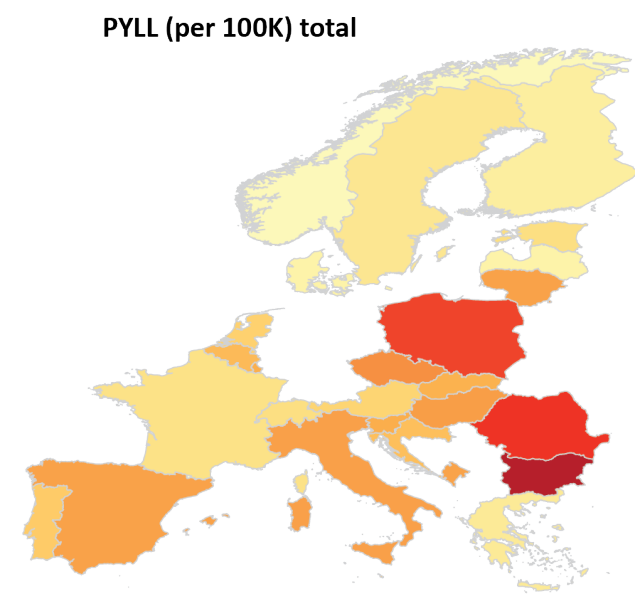

PYLL (per 100K) female

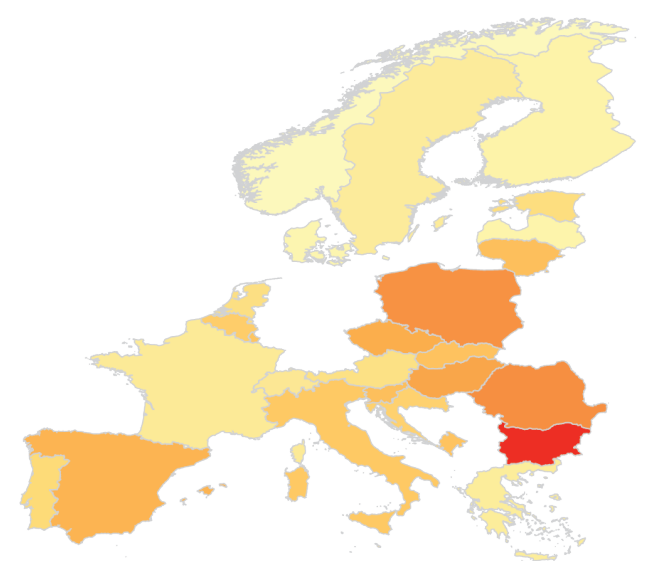

PYLL (per 100K) male

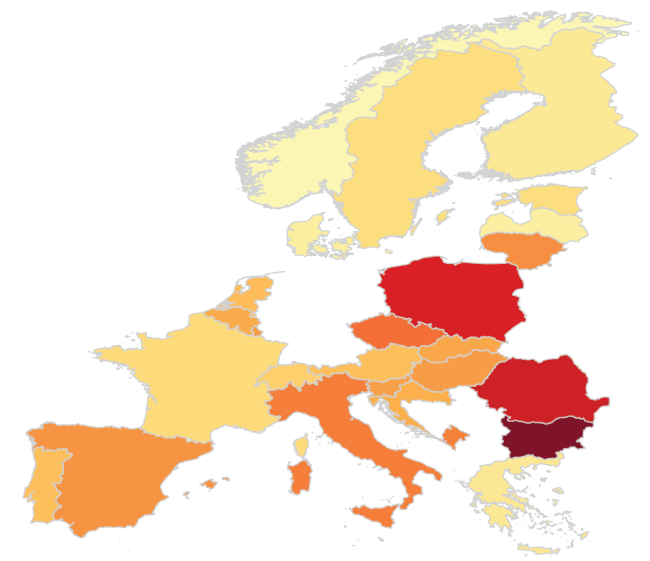

Figure 3: Geographic distribution of excess mortality-based ASYR and PYLL values for European countries in 2020. Shown are the total (per 100K people) values. (A) ASYR values for the whole population; (B) ASYR values for females; (C) ASYR values for males; (D) PYLL values for the whole population; (E) PYLL values for females; (F) PYLL values for males.

0-84 with population size data for the 85-89 age group from the UNdata Data Service.

To compare the impact of the pandemic across European populations with different age structures we compute the Age-Standardized Years of Life Lost Rate (ASYR) 23124 . Let $([x, x+4], s)$ be an age interval for a sex $s$ in a stan- dard life expectancy table for a given population. Denote by $P([x, x+4], s)$ the population size of $([x, x+4], s)$. Define the PYLL rate for $([x, x+4], s)$ as

$$
\operatorname{PYLL}_{\text {rate }}([x, x+4], s):=\frac{\operatorname{PYLL}([x, x+4])}{P([x, x+4], s)} * 100,000
$$


medRxiv preprint doi: https://doi.org/10.1101/2021.04.06.21254958; this version posted April 10, 2021. The copyright holder for this preprint (which was not certified by peer review) is the author/funder, who has granted medRxiv a license to display the preprint in perpetuity. It is made available under a CC-BY-NC-ND 4.0 International license.

A

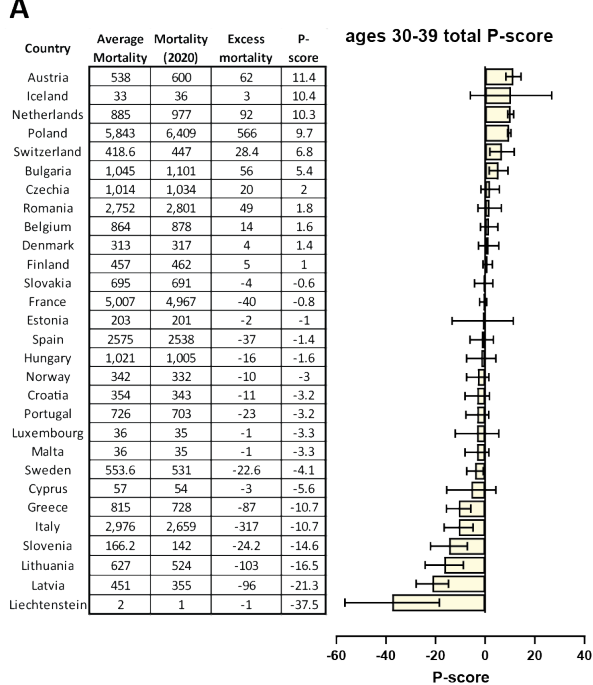

D

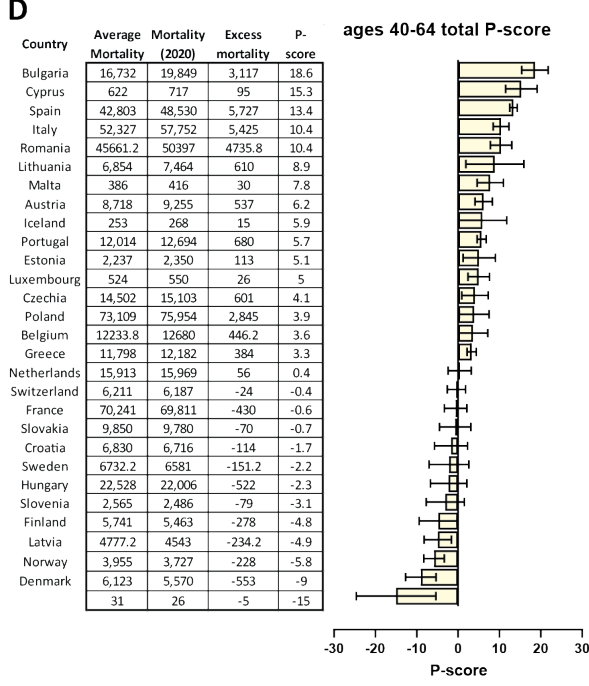

B

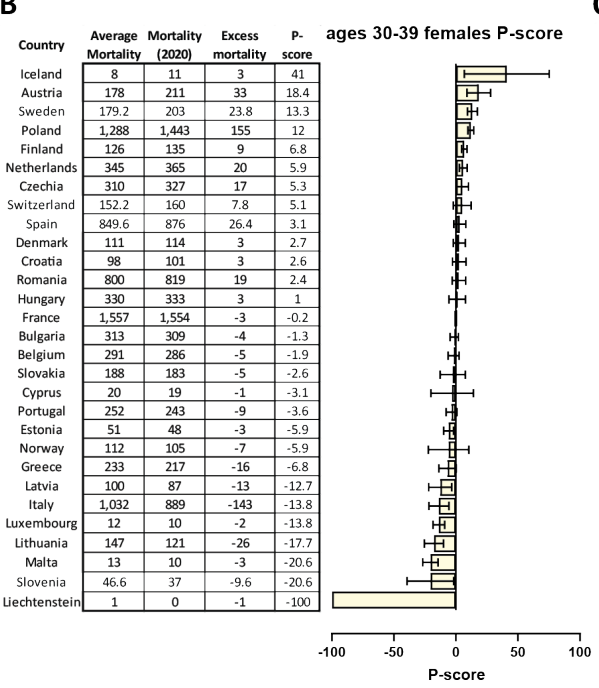

E

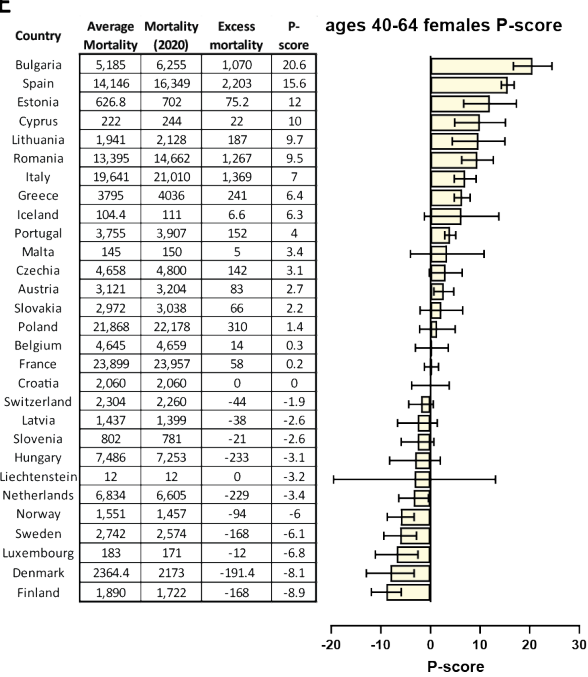

C

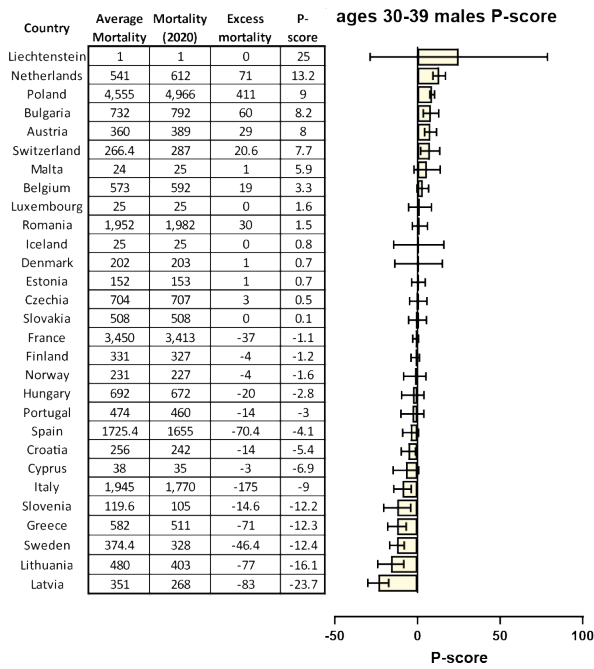

$\mathbf{F}$

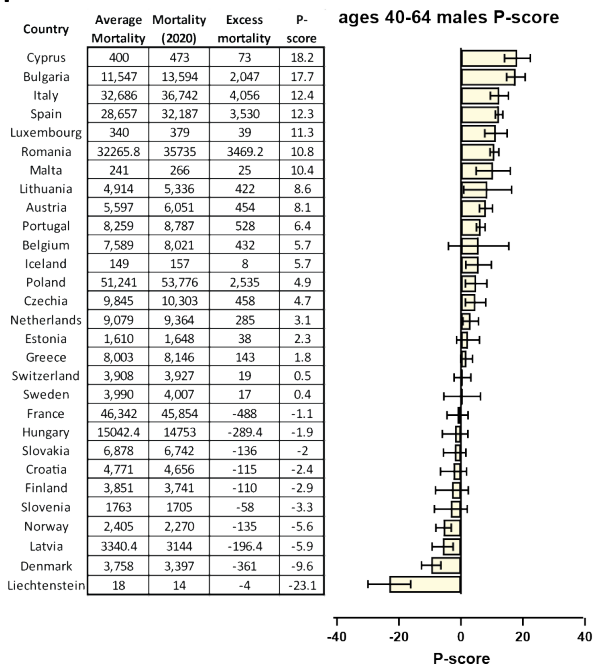

Figure 4: Excess mortality in working age populations in Bulgaria and other EU countries in 2020. (A) $\mathrm{P}$-scores for the overall population in ages 30-39; (B) P-scores for females in ages 30-39; (C) P-scores for males in ages 30-39; (D) P-scores for the overall population in ages 40-64; (E) P-scores for females in ages 40-64; (F) P-scores for males in ages $40-64$.

For the 2013 European Standard Population (ESP) denote by $W([x, x+4], s)$ the weight of $([x, x+4], s)$ in the standard population. Define

$$
\operatorname{ASYR}(s):=\sum \operatorname{PYLL}_{\text {rate }}([x, x+4], s) * W([x, x+4], s)
$$

where the sum is taken over all age intervals. For a given population of sex $s$ this measure is interpreted as the years of life lost per 100,000 people (of sex $s$ ) if the population has the same age distribution as the ESP. ASYR allows for comparison of the pandemic impact on EU countries having different age distributions. Finally, we derive total, average and total standardized WYLL value approximations. To accomplish this, we first assume a common retirement age at 65 and thus exclude excess mortality for all age groups over 65 . To calculate the remaining years of working life, we further assume a mean age for each age group, e.g. for the age interval $60-64$ we assume a mean age at 62.5 years. This would leave this group with approximately 2.5 years until retirement. Limitations on this approach are discussed in the subsequent Limitations subsection.

\section{Stringency index and Mobility data}

Metrics of population mobility were obtained from the Google COVID-19 Community Mobility Reports 25 . These datasets contain data on how visits and length of stay at different places change compared to a baseline by generating anonymized metrics from data of Google users who have switched on "Location History" on their mobile devices.

To quantify governmental pandemic-response measures across countries, we used the Oxford COVID-19 Govern- 
ment Response Tracker ${ }^{26}$, which systematically collects information on several different common policy responses that governments have taken to mitigate the effects of the pandemic 27 . This allows a comparison of governmental measures between over 180 countries worldwide.

\section{Limitations}

Each of the presented data sources and approaches to analysis have their own limitations. Below we discuss each one in detail.

\section{Limitation of scope}

The current time frame that is analyzed creates a hard boundary between week 10 and week 53 of 2020 . The exit conditions of different countries at these boundaries, however, are not equal. Some countries experienced subsequent surges in January 2021 and later months. Thus the current research provides a snapshot of the effects of the pandemic up to the end of 2020, not the totality of its effects.

\section{Limitation of Data}

All cause mortality figures for 2020 are still provisional for most EU countries, so they are subject to readjustment in future time. Even so, they can provide a good estimate of the effect of COVID-19 in different countries up to this point.

\section{Limitation of Excess mortality and P-scores}

Our mean mortality calculations do not account for population changes in the 2015-2019 period. For example, Bulgaria has one of the highest negative growth rates in the world. Between 2015 and 2020 Bulgaria's population has decreased by around 250,000 or approximately $6.5 \%$ per year 28 . The country also has a negative net migration and has seen approximately 25,000 people leave its borders in the last five years ${ }^{29}$

Since the P-score metric we compute is derived from the excess mortality figures we calculate for each individual country, this metric also suffers from the issues we outline for excess mortality.

\section{Limitations of PYLL/ASYR/WYLL}

Since PYLL, ASYR and WYLL data only take into account fatalities, these metrics do not provide information about any worsened quality of life of surviving individuals, reduced life expectancy of these individuals and working capacity. Metrics such as Disability-Adjusted Life Years (DALY), Quality-adjusted life year (QALY) and Healthy Years of Life (HALE) metrics may illuminate further the total disease burden on the European population, however, obtaining the necessary information for these measurements is not yet possible.
As mentioned before, due to data availability limitations from Eurostat in our computations of PYLLs and ASYRs we excluded the $90+$ group. Given that countries like France, Italy and Spain have significant excess mortality in this age group, we also present a computation of the ASYRs including the $90+$ age by assuming 4 years of life expectancy (the average life expectancy for the $90+$ age group for the European population is 4.74, according to the UNdata Data Service) in Supplementary Tables 4 and 5 . By linear interpolation, 4 is approximately the life expectancy for the age interval $[90,94]$ assuming that the average age of deaths for this interval is in the range 92.7 - 93 (the average age of the COVID-19 fatalities above 90 years of age is 92.7 in Czechia and 92.1 in Bulgaria, and likely it's higher in Western countries which overall have higher life expectancy).

This rough approximation gives an upper bound of how large the ASYRs can go. It leads to $5 \%-14 \%$ and $14 \%-22 \%$ increase in the ASYRs for the (0-89) population of Eastern and Western European countries, respectively, but it does not yield a decrease between the inequalities of the countries from the two groups or any significant change in their ranks (see Supplementary Fig. 3 and Supplementary Table 5).

The WYLL measure we present has some additional limitations. The first comes from the assumption that retirement age across European countries is 65 . While it is most often assumed as a standard between European countries, there is actually some variation between individual member states 30 . Furthermore, we assume that the mean age of people who have died in a given age group is the middle of the given range, e.g. for the age group 60-64 - mean age $=$ 62.5. It may well be a fact that a majority of the fatalities are concentrated in the upper part of the age bracket. However, since we do not have data about the different causes of mortality, but rather an aggregate total, we cannot be certain that this trend will hold true for all age groups and across different countries.

\section{Google COVID-19 Community Mobility Reports}

Bulgaria is below the EU average when it comes to use of mobile devices in the 16-74 age group. Still, a majority of the population within that group $(\sim 64 \%)$ utilized mobile devices to access the internet in $2019^{31}$. However, it is possible that there might be a skew towards the younger half of this age range of users who are supplying data.

\section{Results}

\section{Mortality during the COVID pandemic in Bulgaria}

We analyzed overall excess mortality patterns in Bulgaria for the year 2020 and compared it to data for other European Union (EU) countries for the same period. We focus on excess mortality rather than officially registered COVID deaths because limited testing and varying standards for 
official reporting of COVID deaths can result in large disparities between public figures for COVID-related mortality and the actual burden the disease has imposed on the population ${ }^{6}$. While some of the excess deaths are caused by the collapse of healthcare services during peak moments of COVID waves, when a particularly large discrepancy between official COVID deaths and excess deaths is observed, this is likely mostly due to underreporting of COVID deaths due to insufficient testing and other irregularities.

In total, we estimate that 17,352 lives have been lost in Bulgaria in 2020 in excess of the baseline from previous years (Figure 1A). This amounts to an EMR of 2,496 DPM, or $\sim 0.25 \%$, for the year and ranks the country as the most highly affected within the EU (Figure 1A; Supplementary Table 1, according to P-scores Spain, Poland and Belgium rank higher). COVID mortality is in most countries higher in males than in females ${ }^{32}$, and this is also what is observed in Bulgaria and most other EU countries (Figure 1B-C; Supplementary Tables 2 33. For females, an EMR of $2,178 \mathrm{DPM}$ is observed (P-score of 18.79), compared to an EMR of 3,198 DPM for males (P-score of 23.99) across all ages.

These observed EMR values are much higher than the officially reported COVID-attributed population fatality rate (PFR), by a factor of $\sim 2.3 \times$. Examination of the EMR/PFR ratios in Europe showed that excess deaths are higher than official COVID death tolls in most countries (Figure 22). However, a clear dichotomy emerges between Eastern and Western Europe, with the EMR/PFR ratio being considerably higher in countries in Eastern Europe such as Bulgaria, Romania, Poland, Slovakia, Lithuania, and others.

These estimates and geographic patterns are in agreement with other recent analyses of excess mortality $33 / 34$

\section{Loss of life as a result of the COVID pandemic}

We next examined the impact of the pandemic in terms of years of life lost using the PYLL and ASYR metrics based on excess mortality (Figure 3). Both metrics paint a similar picture, which is also consistent with the raw excess mortality measures.

Using standardized ASYR and PYLL values (per 100,000 population; Supplementary Figures 2A-C and 17, we find that the highest total loss of life among the examined countries occurred in Bulgaria, for both males and females, followed by Romania, Poland, Hungary and Czechia. This higher loss of life burden in Eastern European countries is explained not only by their high EMRs but also by a large numbers of deaths in younger age groups. In Bulgaria and Romania, $28 \%$ and $29 \%$ of excess deaths, respectively, are of people under the age of 70 . In Poland, $13 \%$ of the excess deaths are of people in the age ingerval $65-69$ and $42 \%$ of the excess deaths are of people under 75 . Moreover, $18 \%$ of all excess deaths in Bulgaria are of people under the age of 65, in particular in the 40-64 age group (Supplementary Figure 4). Calculation of WYLL values, which show the loss of working years of life, showed Bulgaria to have incurred the highest such loss within the set of examined countries (Figure 2D-E; note that the high total WYLL value for Iceland is possibly an artifact of the small population of the country). In contrast, in countries such as Italy, France and Spain, only $18 \%-19 \%$ of excess deaths are under 75 years of age. In Italy and Spain, 34\% - 35\% of the excess deaths are of people older than 90. In France, $46 \%$ of excess deaths are of people older than 90. Remarkably, in Greece, one of the least affected countries in the EU (having a low EMR and P-score), $55 \%$ of all excess deaths are of people above 90 and $20 \%$ are people under 80 .

For Bulgaria, we find an average PYLL value of $13.46 \pm$ 0.11 in total, $12.56 \pm 0.03$ for males, and $13.68 \pm 0.24$ per female (Figure 2). Excluding outliers (note that average PYLL values based on excess mortality are very high in countries such as Iceland, Luxembourg due to stochasticity associated with the very low number of excess deaths), these values are generally higher than what is seen in Western Europe. The only three countries with an average PYLL greater than 13 are Bulgaria, Poland, and Romania, compared to values as low as in the 10 to 11 years range for countries such as Denmark, Switzerland and Sweden (Supplementary Table 17). Despite males exhibiting higher mortality due to COVID-19, the average PYLL based on excess deaths in Bulgaria is higher for females (it is also higher for females in several other European countries; Supplementary Figure 3).

Using official COVID-attributed deaths, for Bulgaria we obtain an average of 12.37 years lost for males and 14.01 years lost for females. Based on the official COVID-19 mortality data for Czechia (the other country for which exact data about the age of the diseased is available) we obtain 9.78 and 9.35 for males and females, respectively. In both cases, the estimates we obtain for the average PYLLs from excess mortality and official COVID-19 deaths data are in agreement (note, however, that there are substantial differences between Bulgaria and Czechia in other aspects - for example, the average age of officially registered COVID-19 deaths for women is 71 years in Bulgaria compared to a life expectancy of 78.4 years, while in Czechia, the average age of the female COVID-19 deaths is 80.81 , which is very close to the 82.1 life expectancy for women in that country).

These observations suggest that the impact of the pandemic in hard hit in late 2020 countries in Eastern Europe was not only large in absolute terms but also heavily affected younger demographics than in Western Europe.

\section{Demographic-specific mortality patterns in Bulgaria}

By the official statistics of the Ministry of Health $18 \mid 19$ the average age of a deceased male and female from COVID19 are 69 and 71, respectively. The leading comorbidity is cardiovascular disease $(55 \%)$, followed by diabetes $(17 \%)$, pulmonary disease $(12 \%)$, obesity $(3 \%)$, and $30 \%$ are listed with no known comorbidity. An overwhelming majority of 
94.5\% of all 7576 COVID-19 deaths occurred in the hospitals with working age deaths comprising $28 \%$ of all COVID19 deaths. For the working age group females on average died at age 55.9 and males at age 55.7 with $45 \%$ of the deceased having a cardiovascular disease.

Data on excess mortality for people under 65 reveals a slightly different picture. The working age group excess deaths are $18.3 \%$ of all excess deaths with an average age of the deceased $55.65 \pm 0.07$ for men and $57.57 \pm 0.28$ for women. The reason for the higher average age for women is that our data does not reveal excess deaths in women under 40 , whereas in the official statistics $5 \%$ of the casualties are of ages between 10 and 39 .

Next, we examine mortality in Bulgaria within the working age population in detail. Due to the well-documented age-related skew of COVID fatalities, we focused on two subgroups of working age individuals - those in the 30-39 and those in the 40-64 age ranges.

We find no elevated mortality in females in the 30-39 age group, while mortality is elevated in males of the same age bracket, with $\mathrm{P}$-scores of -0.39 and 9.37 , respectively (Figure $4 \mathrm{~A}-\mathrm{C}$ ).

In contrast, we find highly elevated excess mortality in both males and females in the 40-64 age group, in which Bulgaria ranks highest in the EU (Figure 4D-F), with Pscores of 17.7 and 20.6 for males and females, respectively. The difference between males and females is remarkable, as, unlike the typical situation, elsewhere in the world in this group in Bulgaria excess mortality measured by P-scores is lower for males than for females. A similar reversal of the usual sex-specific mortality pattern is only also observed in Spain within the EU. We discuss the possible explanation for these observations in subsequent sections.

\section{Regional disparities in COVID pandemic-related mortality in Bulgaria}

Following from the observation of considerable disparities between different European regions, we then analyzed regional differences in pandemic impacts within Bulgaria (Figure 5). As a reminder, the overall statistics for Bulgaria are an EMR of $0.25 \%, \mathrm{P}$-score of $19.5 \%$, CFR of $3.7 \%$, an EMR/PFR ratio of 2.3, and a percentage of population tested positive of $2.9 \%$.

The first major such disparity we observe is that between the four most populated provinces and the rest of the country. The excess deaths in these four major regions - Sofia (city), Plovdiv, Varna and Burgas - account for just $34 \%$ of all excess deaths even though $\geq 50 \%$ of the Bulgarian population lives there. Moverover, Sofia (city), Varna and Burgas have the lowest EMR of all provinces (Figure 5A) and P-scores of up to 20\% (Figure 5B). The provinces of Sofia (city) and Burgas also show the two lowest CFR values (Figure $5 \mathrm{~F}$ ).

In contrast, the more peripheral regions are among the most heavily affected. For example, the regions of Vidin and Silistra exhibit some of the highest EMRs -0.37 and 0.40 , respectively. Vidin also has the second highest CFR (8\%). The relatively low P-score of $19 \%$ in Vidin is likely a result of already very high pre-pandemic mortality in the region (the region has one of the fastest aging populations in the EU and the death rate there is 22 per 1000 people per year, whereas the death rate for Bulgaria is 15 deaths per 1000 people per year). In Silistra, the EMR/PFR ratio is 3.00, the second highest in the country and the P-score is $28 \%$. In Kardzhali, the EMR/PFR ratio is 4.00, the highest in the country, and the $\mathrm{P}$-score is $24 \%$. With a $\mathrm{P}$-score of $31 \%$ and EMR of 0.42, Smolyan is the hardest hit region in the country. It also has a CFR of $8.9 \%$, which is the highest among all provinces.

These regions also tend to show a lower percentage of the population that has tested positive, despite exhibiting the highest excess mortality (Figure 5E), often high CFRs (Figure 5F), and high EMR/PFR ratios (Figure 5G).

We also find curious disparities in regional patterns of male- and female-specific excess mortality (Figure 5C-D; Supplementary Tables 18 19). The highest male excess mortality was observed in Pazardzhik, Gabrovo, Sofia (region) and Smolyan, while the highest female excess mortality is seen in Blagoevgrad, Silistra, Pazardzhik and Targovishte.

Remarkably, only $30 \%$ of all excess deaths in the working age group occurred in Sofia (city), Plovdiv, Varna and Burgas. For women in the working age group only $27 \%$ of the deaths occurred in those regions. A regional analysis reveals that the regions that with the highest $\mathrm{P}$-scores in this demographic category are Blagoevgrad, Silistra, Pazardzhik, Targovishte, Kardzhali, Kyustendil and Dobrich ranging from $52 \% \pm 6 \%$ to $36 \% \pm 7 \%$ (Figure $5 \mathrm{C}$ ). Women in the age group $65-69$, which includes working women in retirement age, were also heavily affected with an overall P-score of $23.7 \%$ and exceptionally high regional $\mathrm{P}$-scores in the provinces of Sliven - $76 \% \pm 10 \%$, Kardzhali - $46 \% \pm 8 \%$ Blagoevgrad $-45 \% \pm 7 \%$, Pazadzhik $-43 \% \pm 6 \%$, and Smolyan $-42 \% \pm 11 \%$ and (Supplementary Figure 5 Supplementary Tables 20 21). We discuss the possible explanations for these observations in the Discussion section.

\section{The trajectory of the pandemic in Bulgaria and the effectiveness of implemented pandemic control measures}

Finally, we mapped the trajectory of the pandemic in Bulgaria onto the timeline of imposition of social distancing measures and independent measures of actual changes in societal mobility to understand the relationship between those factors and its development (Figure 6).

The first period of the COVID-19 pandemic in Bulgaria, from March to the end of September, was marked by a slight elevation of the new confirmed cases in the summer, peaking at 242 cases per day towards the end of July. The excess mortality for this period is around 300 people and the official COVID-19 death toll amounts to 820 people, with a 
medRxiv preprint doi: https://doi.org/10.1101/2021.04.06.21254958; this version posted April 10, 2021. The copyright holder for this preprint (which was not certified by peer review) is the author/funder, who has granted medRxiv a license to display the preprint in perpetuity.

It is made available under a CC-BY-NC-ND 4.0 International license .
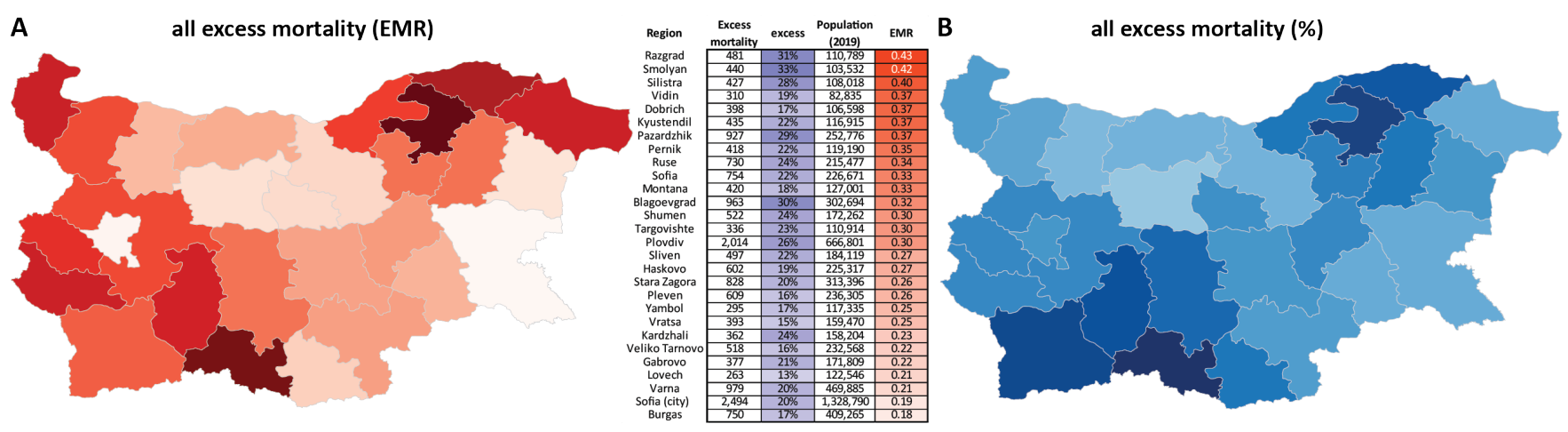

C

females ages 40-64 excess mortality (\%)
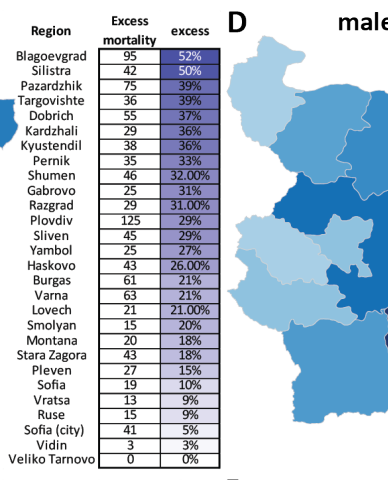

males ages 40-64 excess mortality (\%)

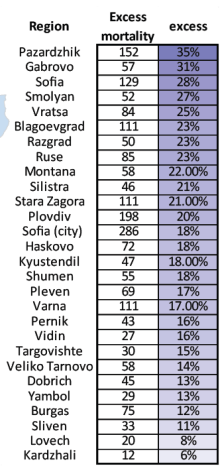

E percentage of population tested positive (\%)

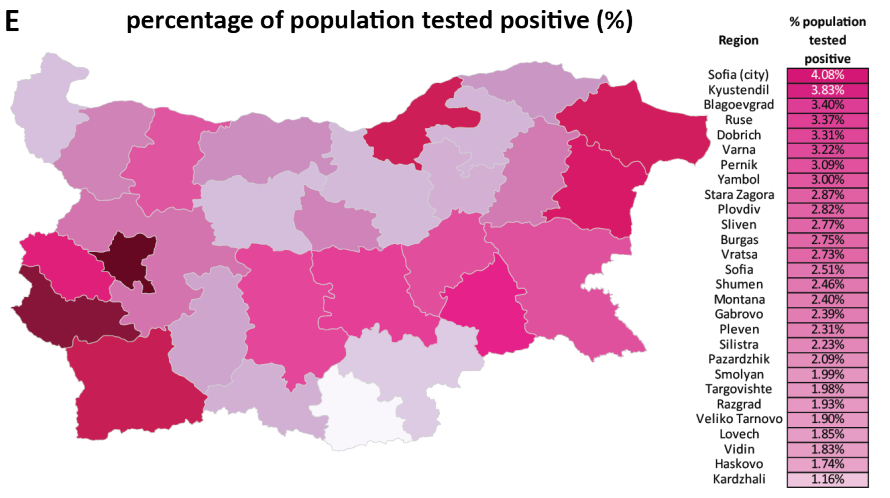

F

CFR (\%)

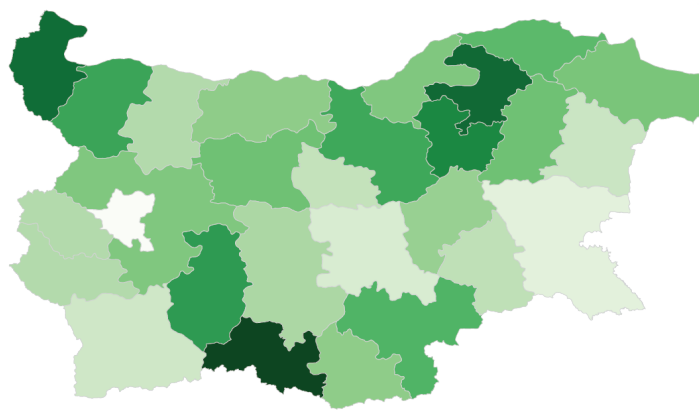

G
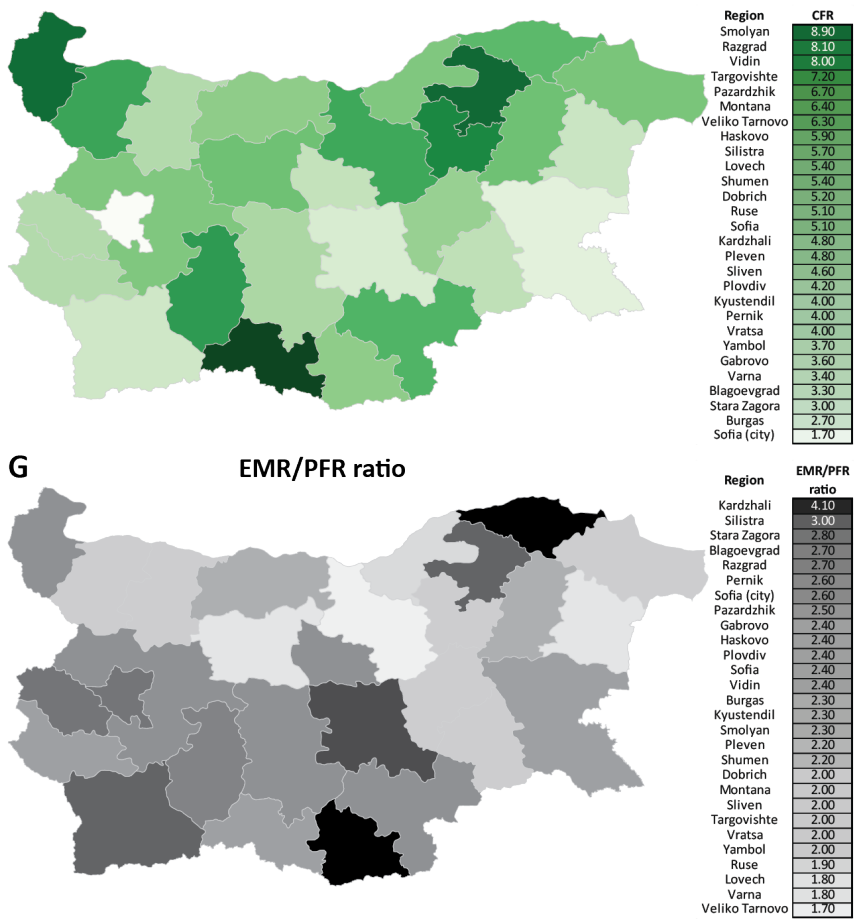

Figure 5: Regional disparities in the impacts of the COVID-19 pandemic in Bulgaria. (A) Overall excess mortality in Bulgarian regions (EMR units); (B) Overall excess mortality in Bulgarian regions (P-score); (C) Excess mortality in working age (40-64) females in Bulgarian regions (P-score); (D) Excess mortality in working age (40-64) males in Bulgarian regions (P-score); (E) Percentage of the population who have tested positive for SARS-CoV-2 in Bulgarian regions; (F) CFR values for Bulgarian regions; $(\mathrm{G})$ Ratio between excess deaths (EMR) and official COVID-19-attributed deaths (PFR). 
A
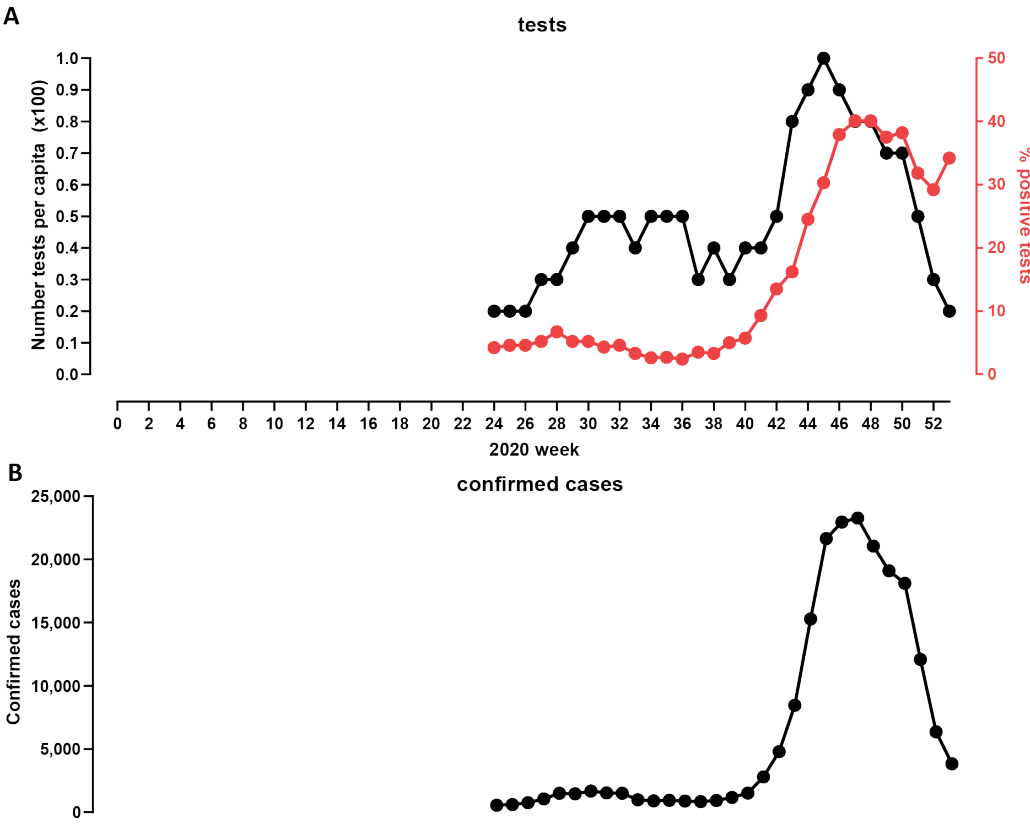

C
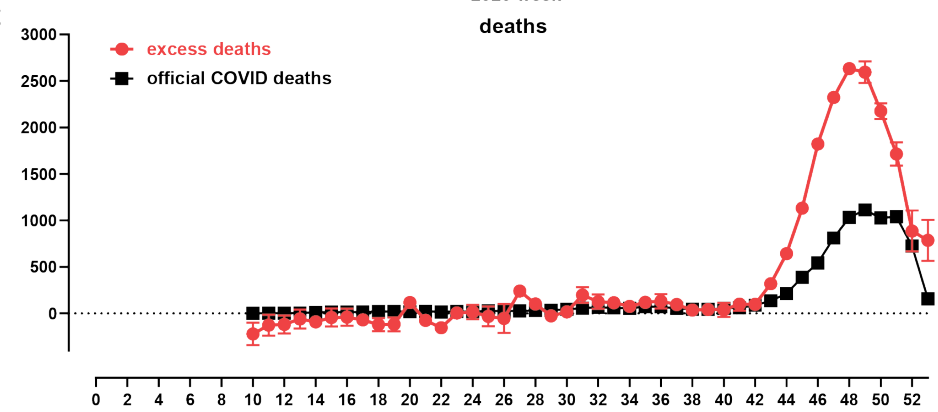

2020 week

D

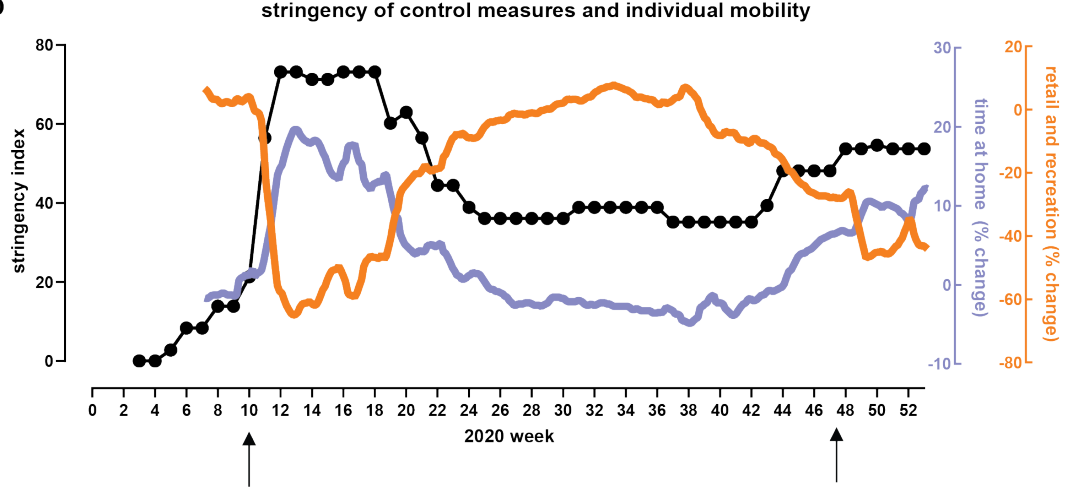

Figure 6: Development of the COVID pandemic in Bulgaria over 2020 and the effectives of measures implemented in order to control it. (A) Number of tests conduced and test positivity percentage over the second half of $2020^{a}$ (B) Officially registered COVID cases. Note that rapid antigen tests were only included in statistics starting from December 22nd 2020. (C) Officially registered weekly COVID deaths and overall weekly excess mortality over the course of 2020. (D) Social mobility changes and the timing of imposition of restrictions. Arrows indicate the time of imposition of "lockdown" measures. "Time Home" refers to the change of the number of visitors to residential areas relative to the period before the pandemic. "Time Retail and Recreation" refers to the change of the number of visitors to places of retail and recreation relative to the period before the pandemic. This includes restaurants, cafes, shopping centers, theme parks, museums, movie theatres, libraries.

${ }^{a}$ Official daily testing data was only made available from 06 Jun 2020 - Open Data Portal (https://data.egov.bg/data/resourceView/ e59f95dd-afde-43af-83c8-ea2916badd19) daily death rate of up to 10 deaths until the middle of October.

Rapid growth in the number of new confirmed cases started around the end of September. Then an explosion of cases occurred in late October, November and the first half of December (Figure 6B). The peak in the 7-day moving average of the number of confirmed cases occurred on November 19th.

Official COVID-19 deaths peaked on December 6th with a 7 -day moving average of 140 , or $\sim 18 \mathrm{DPM} /$ day; excess deaths started decreasing around the same time (Figure 6C). Excess deaths began diverging from official statistics with the start of the Fall surge, in the middle of October, and peaked at $~ 54 \mathrm{DPM} /$ day in the week ending on November 27th. This corresponds to a $112.3 \%$ increase in relative age-standardised mortality rates (rASMRs) according to the ONS ${ }^{35}$; a higher number in Europe in 2020 was observed only in Spain for the week ending on April 3rd at at $142.9 \%$.

One of the obvious candidate explanations for the dis- 
A

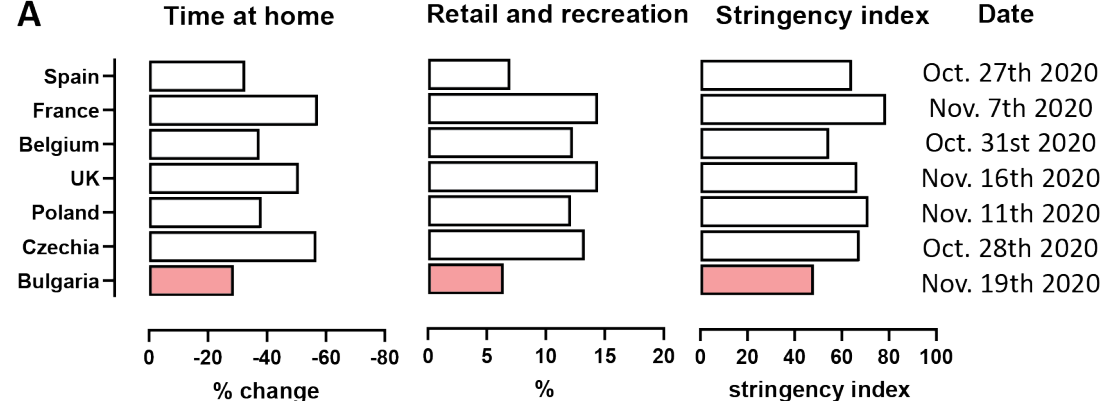

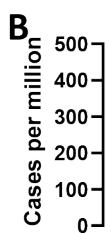

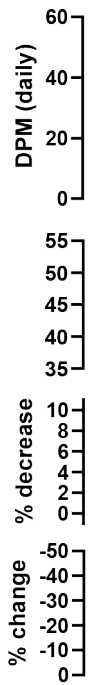

cases

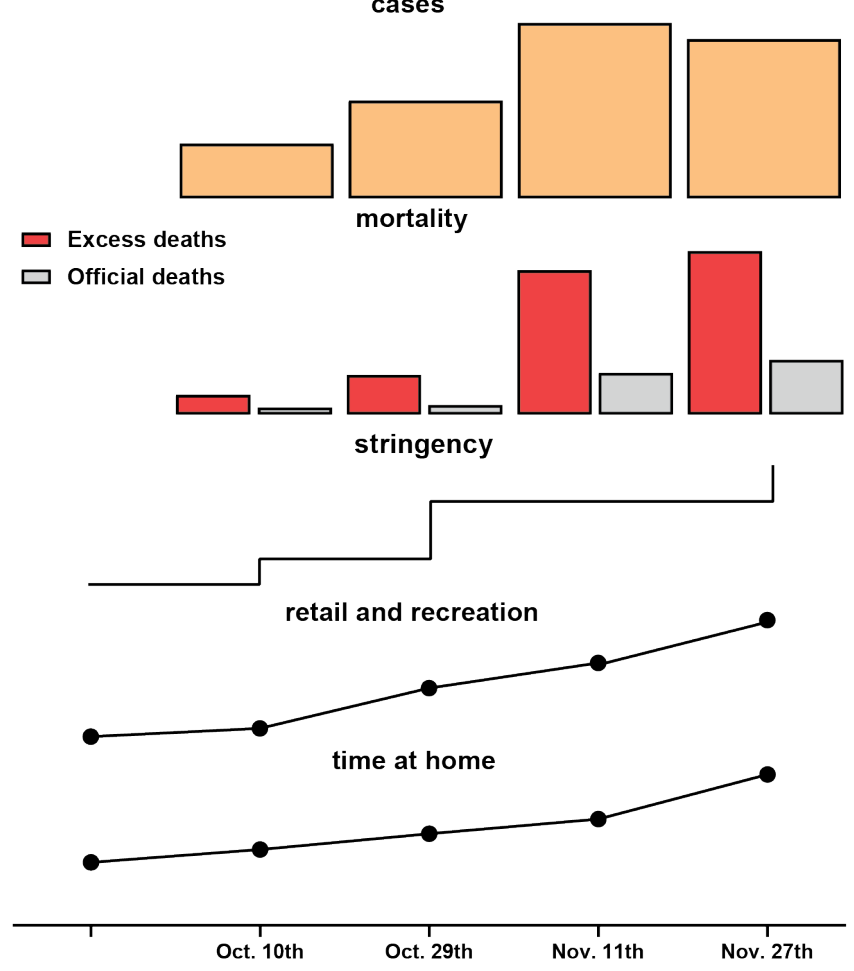

Figure 7: Mobility metrics, stringency of restrictions and mortality and cases at the peak of the late2020 wave in Bulgaria (A) Google Mobility Data and Stringency Index at the peak of the fall wave in Bulgaria and other EU countries. "Time Home" refers to the change of the number of visitors to residential areas relative to the period before the pandemic. "Time Retail and Recreation" refers to the change of the number of visitors to places of retail and recreation relative to the period before the pandemic. This includes restaurants, cafes, shopping centers, theme parks, museums, movie theatres, libraries. (B) Timeline of imposition of social distancing measures and of reductions in mobility in Bulgaria around the peak of the late-2020 wave. The peak occurred around November 11th 2020, as demonstrated by mortality data, which at any given moment reflects the dynamic of new cases in Bulgaria approximately 2.5 weeks prior to that moment. crepancy between official and excess deaths is insufficient testing 36 .

Indeed, that appears to be the case for Bulgaria. Test positivity rates peaked $\sim 40 \%$ in late November. However, a curious pattern is observed in the number of tests recorded in official statistics, which actually began decreasing while the positivity was still increasing in the month of November (Figure 6A). An explanation for this pattern is that the results of rapid antigen tests were not included in official statistics until late December, and a considerable portion of testing shifted from PCR to antigen tests as the Fall wave developed. This likely accounts for at least some of the discrepancy between recorded and excess deaths.

We then examined the factors responsible for the Fall surge eventually receding using the stringency index and mobility metrics (see Methods), changes in which have been shown before to be predictive of the trajectory of COVID epidemics $37+40$.

The stringency index was at 35.19 from mid September until October 29th (Figures 6D and 7B), when the Bulgar- ian government imposed some new restrictions (high schools and universities moved to remote learning; nightclubs, pubs and bars were closed), which is reflected by an increase in the stringency index to 48.15. No further substantial epidemiological measures were introduced until after the peak of the fall wave - on November 27th, restaurants, bars, malls, schools and gyms were closed. However, the stringency index, though now increased to $53.7 \%$, remained considerably below the levels of restrictions imposed in other European countries (Figure 7A), as no stay-at-home orders or curfews were imposed, non-essential stores and hairdressing salons remained open, and gatherings of up to 15 people were permitted.

As the peak of restrictions occurred around the time of the peak of excess mortality and thus after the peak of infections, it is likely that restrictions were not the main cause for the eventual decline in cases. Indeed, changes in people's behavior as reflected in social mobility measures were observed much earlier than the imposition of restrictions, likely due to fear of becoming infected spreading among 
the population, a pattern previously noted elsewhere in the world 41 . Our data supports this: $40 \%$ of the total increase from October 1st to November 27th of the time spent at home occurred in the period November 3rd to November 27 th when no new substantial measures were introduced (see 7B).

The 7-day running average Google mobility data measured on November 19th shows a total decrease of $-29 \%$ percent of time spent in retail and recreation and a $6.43 \%$ increase in time spent at home compared to the baseline (Figures 6D and 7B). However, as with the stringency index, these values are still the lowest among analyzed European countries (Figure 7B), which is likely a contributing factor to the very high excess mortality resulting from the pandemic.

Finally, we examine hospitalization trends in Bulgaria and several other European countries. We find that at their peak on December 12th, hospitalizations in Bulgaria reached a level of $0.1 \%$ of the population, which is one of the highest hospitalization rates up to date (it has since been exceed by Hungary and by Bulgaria itself during the subsequent March surge; Figure 8).

\section{Discussion}

In this survey, we analyze the impact of the COVID-19 pandemic in 2020 in Bulgaria and the broader Eastern European context. After a relatively low level of COVID-19 cases and deaths prior to that, in the concentrated span of less than three months in October, November, and December 2020, Bulgaria recorded the largest (per capita) number of excess deaths among the examined countries. Similar, though somewhat lower, large excess mortality increases were observed in most other countries in Eastern Europe. However, official COVID-19-attributed deaths account for only less than half of the excess deaths.

This discrepancy is likely caused by a combination of multiple factors - COVID-19 cases leading to death that were not reported as such in official statistics, COVID19 cases resulting in death some time after recovery due to longer-term complications from the disease, and deaths from other causes that increased as a result to the inability of the healthcare system to treat them due to it being overwhelmed by COVID-19 patients. As the disparity between excess deaths and official COVID-19 mortality is very large in the case of Bulgaria - excess deaths amount to $\sim 0.25 \%$ of the population while official COVID-19 are at $\sim 0.11 \%$, i.e. a $\sim 0.14 \%$ difference - and excess mortality is highly temporally concentrated in a short time span of about ten weeks (i.e. the contribution of the latter two factors is unlikely to have been so large in such a brief period), it is most likely that the bulk of excess deaths were caused directly by COVID-19.

Why they were not recorded as such is also probably due to a multitude of factors. Testing in Bulgaria has been greatly insufficient throughout the pandemic and even more so during the late-2020 surge and the lowest among the examined countries (Supplementary Figure 7 in addition to that, the decision to not include rapid antigen tests in public statistics certainly has contributed to the underreporting. Most reported deaths occurred in hospitals, and many of those who could not be hospitalized due to healthcare systems being overwhelmed and died at home were not recorded as having died of COVID. Whether additional social and socioeconomic factors could have contributed, as has been suggested to be the case elsewhere in the world ${ }^{42}$, is a subject for future investigations, as is the question of whether the reasons for underreporting are uniform across the more general Eastern European region. Lack of testing on its own in turn has probably contributed to the epidemic growing out of control and leading to such a number of excess deaths.

Another contributing factor to the high mortality rate in Eastern Europe is probably the very high prevalence of cardiovascular diseases in the region ${ }^{43}$. In Bulgaria over half of the COVID-19 officially reported fatalities are listed with cardiovascular disease as a comorbidity.

Bulgaria also exhibits the most highly elevated workingage excess mortality, and it is also an outlier in terms of working-age excess mortality among females. We also observe significant regional disparities within the different regions in the country in total and in working age sexspecific excess mortality. A possible explanation for the latter is the development of outbreaks at workplaces where mostly women work - for example, garment, textile and shoe factories, which in Bulgaria almost exclusively employee women and which are major sectors of the economy in provinces such as Blagoevgrad, Kardzhali, Smolyan, Sliven, and Kyustendil 44 . Indeed, there were numerous reports about outbreaks in such settings. Analogous causality might be behind regional disparities in working age malespecific excess mortality (Figure 5D). A list of reports about outbreaks in these regions can be found in our GitHub repository, which includes reports about outbreaks in battery, automotive parts, power transmission, sanitary ceramics, and other factories.

Of note, Spain is another European country with a notable substantial number of working-age female excess deaths. The likely cause in that case is the overrepresentation of middle-aged women among home care workers, who were identified as essential workers early on in the pandemic and were thus affected by it to a greater extent 455 .

Regional disparities in overall excess mortality, in particular the clear dichotomy emerging between the major population centers, in which generally better outcomes are observed, and the more heavily affected peripheral regions, also warrant further investigation. COVID-19 is still often considered a disease that impacts highly populated big cities the most, where disease spread is thought to be facilitated by density; this is due to many of the most notable initial outbreaks affecting well-connected in terms of international travel large metropolitan areas. However, as the 
peak COVID hospitalizations

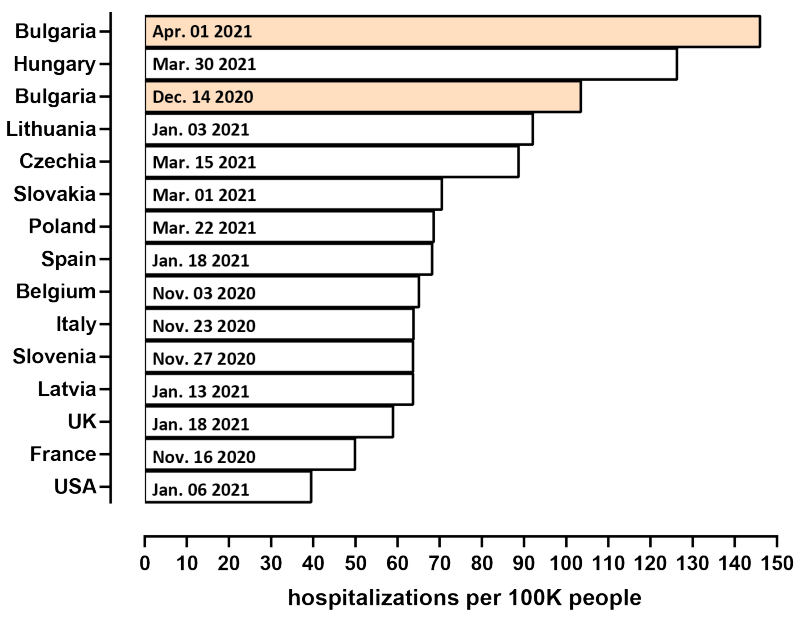

Figure 8: Peak hospitalizations in Bulgaria and other countries.

pandemic has spread throughout the countries that have not controlled it, it may be the case that previously established regional disparities in healthcare infrastructure are becoming a key factor determining differential outcomes between generally better resourced major cities on one hand, and the less equipped to test, track and treat COVID-19 patients countryside areas. There is evidence that such causation is at play in Bulgaria - many of the heavily affected regions have fewer ICU beds, fewer doctors, and fewer specialists in the most relevant to the treatment of COVID-19 specialties than the capital and a few other major cities (Supplementary Figure 6). For example, Vidin and Silistra have fewer than average hospital beds, Kardzhali has the lowest number of doctors, general practitioners and pulmonologists and the second to last number of ICU beds per capita in the country, and Smolyan has the lowest number of ICU beds (just 9 in total for the whole region) and a generally low number of doctors.

In addition, in some of these regions (e.g. Smolyan, the most heavily impacted in the country) there are purely geographic factors that may have complicated the timely treatment of patients due to the logistic challenges of transporting patients to the regional center (which is where the only ICU units are located) from remote small towns through mountainous terrain while the core city's health infrastructure is itself under immense stress (as shown in Figure 8 , Bulgaria recorded record hospitalization levels during the peaks of the pandemic). Whether similar regional patterns of pandemic-related excess mortality are observed in other areas of Europe will be informative and instructive for minimizing the impact of subsequent COVID-19 waves.

It should also be noted that healthcare disparities possibly play a role on a broader-level 46 48, as Eastern Europe's healthcare systems as a whole are well-documented to be suffering from an outflow of skilled medical labor due to large numbers of doctors and nurses emigrating to Western
Europe in recent years 49 .

However, the main factor behind the very high levels of excess mortality is still most likely the late imposition of restrictions on social mobility and lax governmental efforts at controlling the spread of SARS-CoV-2, as our analysis shows. In Bulgaria these were adopted long after exponential growth in cases had commenced and was clearly going to overwhelm hospital resources, little testing was carried out and insufficient efforts were made to ensure the isolation of infected individuals, and even when restrictions were imposed, they were generally the most lax in Europe; furthermore, the late-2020 epidemic appears to have begun to trend downward due to changes in individual behavior, the onset of which actually preceded the imposition of restrictions by the government. The high levels of excess mortality are probably a natural consequence of following these policies.

\section{Notes}

\section{Competing Interests}

The authors declare no competing interests.

\section{References}

1. Wang C, Horby PW, Hayden FG, Gao GF. 2020. A novel coronavirus outbreak of global health concern. Lancet 395(10223):470-473.

2. Zhou P, Yang XL, Wang XG, Hu B, Zhang L, Zhang W, Si HR, Zhu Y, Li B, Huang CL, Chen HD, Chen J, Luo Y, Guo H, Jiang RD, Liu MQ, Chen Y, Shen XR, Wang X, Zheng XS, Zhao K, Chen QJ, Deng F, Liu LL, Yan B, Zhan FX, Wang YY, Xiao GF, Shi ZL. 2020. A pneumonia outbreak associated 
with a new coronavirus of probable bat origin. Nature $\mathbf{5 7 9}(7798): 270-273$.

3. Huang C, Wang Y, Li X, Ren L, Zhao J, Hu Y, Zhang L, Fan G, Xu J, Gu X, Cheng Z, Yu T, Xia J, Wei Y, Wu W, Xie X, Yin W, Li H, Liu M, Xiao Y, Gao H, Guo L, Xie J, Wang G, Jiang R, Gao Z, Jin Q, Wang J, Cao B. 2020. Clinical features of patients infected with 2019 novel coronavirus in Wuhan, China. Lancet 395(10223):497-506.

4. Li Y, Wang X, Nair H. 2020. Global Seasonality of Human Seasonal Coronaviruses: A Clue for Postpandemic Circulating Season of Severe Acute Respiratory Syndrome Coronavirus 2? J Infect Dis 222(7):10901097.

5. Smit AJ, Fitchett JM, Engelbrecht FA, Scholes RJ, Dzhivhuho G, Sweijd NA. 2020. Winter Is Coming: A Southern Hemisphere Perspective of the Environmental Drivers of SARS-CoV-2 and the Potential Seasonality of COVID-19. Int $J$ Environ Res Public Health 17(16):5634.

6. Karlinsky A, Kobak D. 2021. The World Mortality Dataset: Tracking excess mortality across countries during the COVID-19 pandemic medRxiv 2021.01.27.21250604.

7. Bustos Sierra N, Bossuyt N, Braeye T, Leroy M, Moyersoen I, Peeters I, Scohy A, Van der Heyden J, Van Oyen H, Renard F. 2020. All-cause mortality supports the COVID-19 mortality in Belgium and comparison with major fatal events of the last century. Arch Public Health 78(1):117.

8. Kontopantelis E, Mamas MA, Deanfield J, Asaria M, Doran T. 2020. Excess mortality in England and Wales during the first wave of the COVID-19 pandemic. $J$ Epidemiol Community Health jech-2020-214764.

9. Fouillet A, Pontais I, Caserio-Schönemann C. 2020. Excess all-cause mortality during the first wave of the COVID-19 epidemic in France, March to May 2020. Euro Surveill 25(34):2001485.

10. Morfeld P, Timmermann B, GroßJV, DeMatteis S, Campagna M, Lewis P, Cocco P, Erren TC. 2020. COVID-19: Spatial resolution of excess mortality in Germany and Italy. J Infect S0163-4453(20)306782.

11. Eurostat. Deaths by week, sex, 5-year age group, https://ec.europa.eu/eurostat/databrowser/ view/demo_r_mwk_05/default/table?lang=en

12. Eurostat. Deaths by week, sex, 5-year age group and NUTS-3 region, https://ec.europa.eu/eurostat/ databrowser/view/demo_r_mweek3/default/ table?lang=en.

13. Eurostat. Population on 1 January by age group and sex region, https://ec.europa.eu/eurostat/ databrowser/view/demo_pjangroup/default/ table?lang=en.

14. UNdata Data Service. Population by age, sex and urban/rural residence, http://data.un.org/Data. aspx?d=POP\&f=tableCode\%3A22.

15. Bulgarian National Statistical Institute. Mortality and life expectancy by sex and place of residence, https://www.nsi.bg/en/content/6643/ mortality-and-life-expectancy-sex-and-place -residence.

16. Czech Statistical Office. Life Tables for the Czech Republic, Cohesion Regions, and Regions2018-2019, https://www.czso.cz/csu/czso/ life-tables-for-the-czech-republic-cohesion -regions-and-regions-2018-2019

17. World Health Organization. Expectation of life at age $X$ (Mortality and global health estimates, https://apps . who.int/gho/data/node.imr.LIFE_ 0000000035 ?lang=en

18. Bulgarian Ministry of Health. https://www.mh. government.bg/en/

19. Statistical information of the Ministry of Health. Open Data Porta https://data.egov.bg/covid-19? section $=8 \&$ subsection $=16 \&$ item $=36$.

20. Onemocnení Aktuálne od MZCR. COVID-19: Overview of deaths according to reports from regional hygienic stations https://onemocneni-aktualne. mzcr.cz/api/v2/covid-19

21. Our World In Data. Excess mortality during the Coronavirus pandemic (COVID-19) https: //ourworldindata.org/excess-mortality-covid\# how-is-excess-mortality-measured

22. Our World In Data. Total COVID-19 tests per 1,000 people, Our World in Data https://ourworldindata.org/grapher/ full-list-cumulative-total-tests-per-thousan $d$ ? time $=2020-03-01 \ldots 2020-12-31$

23. Preedy V, Watson R (Eds.). 2010. Handbook of Disease Burdens and Quality of Life Measures. Springer.

24. Martinez R, Soliz P, Caixeta R, Ordunez P. 2019. Reflection on modern methods: years of life lost due to premature mortality - a versatile and comprehensive measure for monitoring non-communicable disease mortality. Int $J$ Epidemiol.

25. Google COVID-19 Community Mobility Reports https://www.google.com/covid19/mobility/.

26. Oxford Blavatnik School of Government. Covid19 Government Response Tracker https://www. google.com/covid19/mobility/.

27. Hale T, Angrist N, Goldszmidt R, Kira B, Petherick A, Phillips T, Webster S, Cameron-Blake E, Hallas L, Majumdar S, Tatlow H. 2021. A global panel database of pandemic policies (Oxford COVID19 Government Response Tracker). Nat Hum Behav doi: 10.1038/s41562-021-01079.

28. Eurostat. Population change - crude rates of total change, natural change and net migration plus adjustment. https://ec.europa.eu/eurostat/ 
medRxiv preprint doi: https://doi.org/10.1101/2021.04.06.21254958; this version posted April 10, 2021. The copyright holder for this preprint (which was not certified by peer review) is the author/funder, who has granted medRxiv a license to display the preprint in perpetuity. It is made available under a CC-BY-NC-ND 4.0 International license .

databrowser/view/tps00019/default/table? lang=en.

29. Eurostat. Population change - Demographic balance and crude rates at national level https://ec.europa.eu/eurostat/databrowser/ view/demo_gind/default/table?lang=en.

30. Finnish Center for Pensions. Retirement Ages. https: //www.etk.fi/en/work-and-pensions-abroad/ international-comparisons/retirement-ages/

31. Eurostat. Individuals using mobile devices to access the internet on the move. https: //ec.europa.eu/eurostat/databrowser/view/ tin00083/default/table?lang=en

32. Bhopal SS, Bhopal R. 2020. Sex differential in COVID-19 mortality varies markedly by age. Lancet 396(10250):532-533.

33. Aburto JM, Schöley J, Zhang L, Kashnitsky I, Rahal C, Missov TI, Mills MC, Dowd JB, Kashyap R. 2021. Recent Gains in Life Expectancy Reversed by the COVID-19 Pandemic. medRxiv 2021.03.02.21252772.

34. Pifarré I, Arolas H, Acosta E, López-Casasnovas G, Lo A, Nicodemo C, Riffe T, Myrskylä M. 2021. Years of life lost to COVID-19 in 81 countries. Sci Rep 11(1):3504.

35. Office for National Statistics. 2021. Comparisons of all-cause mortality between European countries and regions: 2020. https://www. ons.gov.uk/peoplepopulationandcommunity/ birthsdeathsandmarriages/deaths/articles/ comparisonsofallcausemortalitybetweeneuropean countriesandregions/2020.

36. Liang LL, Tseng CH, Ho HJ, Wu CY. 2020. Covid19 mortality is negatively associated with test number and government effectiveness. Sci Rep 10(1):12567.

37. Wang Y, Liu Y, Struthers J, Lian M. 2021. Spatiotemporal Characteristics of the COVID-19 Epidemic in the United States. Clin Infect Dis 72(4):643-651

38. Gao S, Rao J, Kang Y, Liang Y, Kruse J, Dopfer D, Sethi AK, Mandujano Reyes JF, Yandell BS, Patz JA. 2020. Association of Mobile Phone Location Data Indications of Travel and Stay-at-Home Mandates With COVID-19 Infection Rates in the US. JAMA Netw Open 3(9):e2020485

39. Candido DS, Claro IM, de Jesus JG, Souza WM, Moreira FRR, Dellicour S, Mellan TA, du Plessis L, Pereira RHM, Sales FCS, Manuli ER, Thézé J, Almeida L, Menezes MT, Voloch CM, Fumagalli MJ, Coletti TM, da Silva CAM, Ramundo MS, Amorim MR, Hoeltgebaum HH, Mishra S, Gill MS, Carvalho LM, Buss LF, Prete CA Jr, Ashworth J, Nakaya HI, Peixoto PS, Brady OJ, Nicholls SM, Tanuri A, Rossi ÁD, Braga
CKV, Gerber AL, de C Guimarães AP, Gaburo N Jr, Alencar CS, Ferreira ACS, Lima CX, Levi JE, Granato C, Ferreira GM, Francisco RS Jr, Granja F, Garcia MT, Moretti ML, Perroud MW Jr, Castiñeiras TMPP, Lazari CS, Hill SC, de Souza Santos AA, Simeoni CL, Forato J, Sposito AC, Schreiber AZ, Santos MNN, de Sá CZ, Souza RP, Resende-Moreira LC, Teixeira MM, Hubner J, Leme PAF, Moreira RG, Nogueira ML; Brazil-UK Centre for Arbovirus Discovery, Diagnosis, Genomics and Epidemiology (CADDE) Genomic Network, Ferguson NM, Costa SF, Proenca-Modena JL, Vasconcelos ATR, Bhatt S, Lemey P, Wu CH, Rambaut A, Loman NJ, Aguiar RS, Pybus OG, Sabino EC, Faria NR. 2020. Evolution and epidemic spread of SARS-CoV-2 in Brazil. Science 369(6508):1255-1260

40. Islam N, Sharp SJ, Chowell G, Shabnam S, Kawachi I, Lacey B, Massaro JM, D’Agostino RB Sr, White M. 2020. Physical distancing interventions and incidence of coronavirus disease 2019: natural experiment in 149 countries. BMJ 370:m2743.

41. Goolsbee A, Syversonab C. 2021. Fear, lockdown, and diversion: Comparing drivers of pandemic economic decline. Journal of Public Economics, 193 (104311).

42. Stokes AC, Lundberg DJ, Elo IT, Hempstead K, Bor J, Preston SH. 2020. Assessing the Impact of the Covid19 Pandemic on US Mortality: A County-Level Analysis. medRxiv 2020.08.31.20184036

43. Eurostat. Cardiovascular Statistics. https://ec. europa.eu/eurostat/statistics-explained/ index.php/Cardiovascular_diseases_ statistics\#Deaths_from_cardiovascular_ diseases

44. Bulgarian Ministry of Economy. Economic map of Bulgaria.

45. Spanish Health Ministry, Carlos III Health Institute (ISCIII). Fourth round of the National SARS-COV-2 antibody seroprevalence Study, December 15th, 2020. https://www.lamoncloa.gob. es/serviciosdeprensa/notasprensa/sanidad14/ Documents/2020/151220_informe_definitivo_ cuarta_ronda_enecovid.pdf

46. "Central Europe, Spared in the Spring, Suffers as Virus Surges," New York Times, Oct. 14th 2020.

47. "Bulgaria's health system on brink of collapse from coronavirus crisis," Politico, Dec. 3rd, 2020.

48. "'It's Like the Second World War.' Covid-19 Is Tearing Into the Parts of Europe That Lack Doctors", Wall Street Journal, Nov. 27th, 2020.

49. Adovor E, Czaika M, Docquier F, Moullan Y. 2021. Medical brain drain: How many, where and why? J Health Econ 76:102409 
medRxiv preprint doi: https://doi.org/10.1101/2021.04.06.21254958; this version posted April 10, 2021. The copyright holder for this preprint (which was not certified by peer review) is the author/funder, who has granted medRxiv a license to display the preprint in perpetuity.

It is made available under a CC-BY-NC-ND 4.0 International license .

\section{Supplementary Materials}

\section{Supplementary Figures}
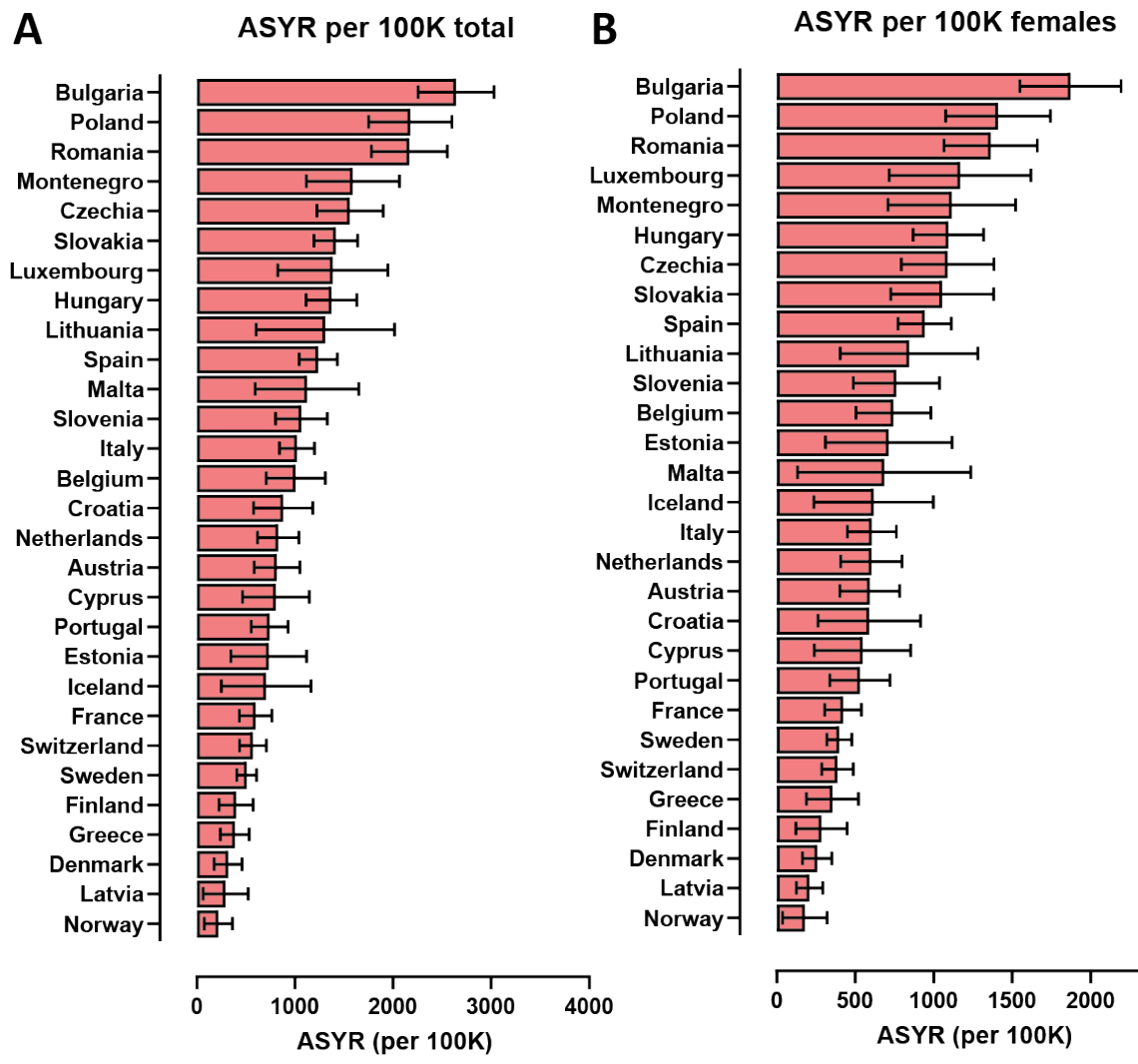

C

$$
\begin{array}{r}
\text { Bulgaria- } \\
\text { Poland-- } \\
\text { Romania- } \\
\text { Montenegro-- } \\
\text { Czechia- } \\
\text { Slovakia- } \\
\text { Lithuania- } \\
\text { Luxembourg- } \\
\text { Hungary- } \\
\text { Malta- } \\
\text { Spain- } \\
\text { Italy- } \\
\text { Slovenia- } \\
\text { Belgium- } \\
\text { Croatia- } \\
\text { Cyprus- } \\
\text { Austria- } \\
\text { Netherlands- } \\
\text { Iceland- } \\
\text { Portugal- } \\
\text { Estonia- } \\
\text { Switzerland- } \\
\text { France- } \\
\text { Sweden- } \\
\text { Finland- } \\
\text { Latvia- } \\
\text { Greece- } \\
\text { Denmark- } \\
\text { Norway- }
\end{array}
$$
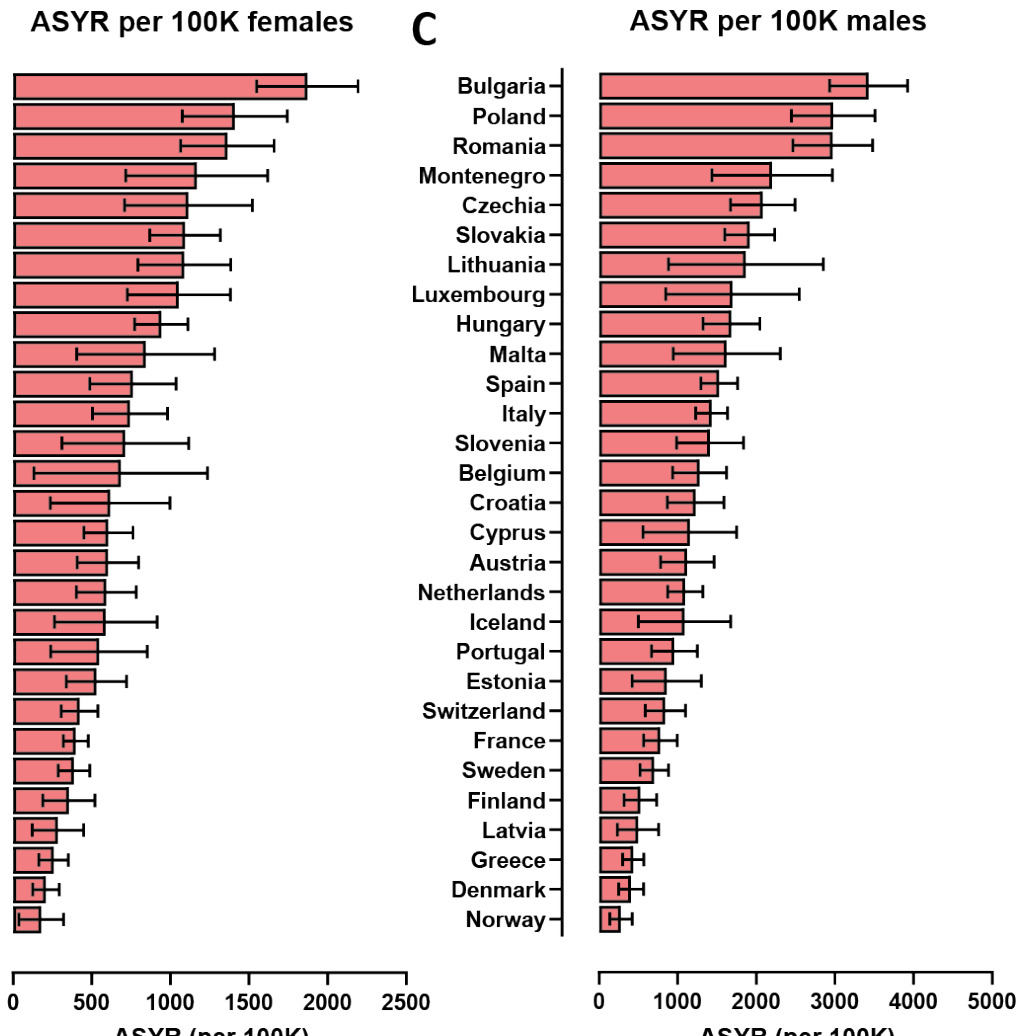

Supplementary Figure 1: Excess mortality-based ASYR values for European countries in 2020. Shown are the total (per 100K people) values. (A) ASYR values for the whole population; (B) ASYR values for females; (C) ASYR values for males. 
medRxiv preprint doi: https://doi.org/10.1101/2021.04.06.21254958; this version posted April 10, 2021. The copyright holder for this preprint (which was not certified by peer review) is the author/funder, who has granted medRxiv a license to display the preprint in perpetuity. It is made available under a CC-BY-NC-ND 4.0 International license .

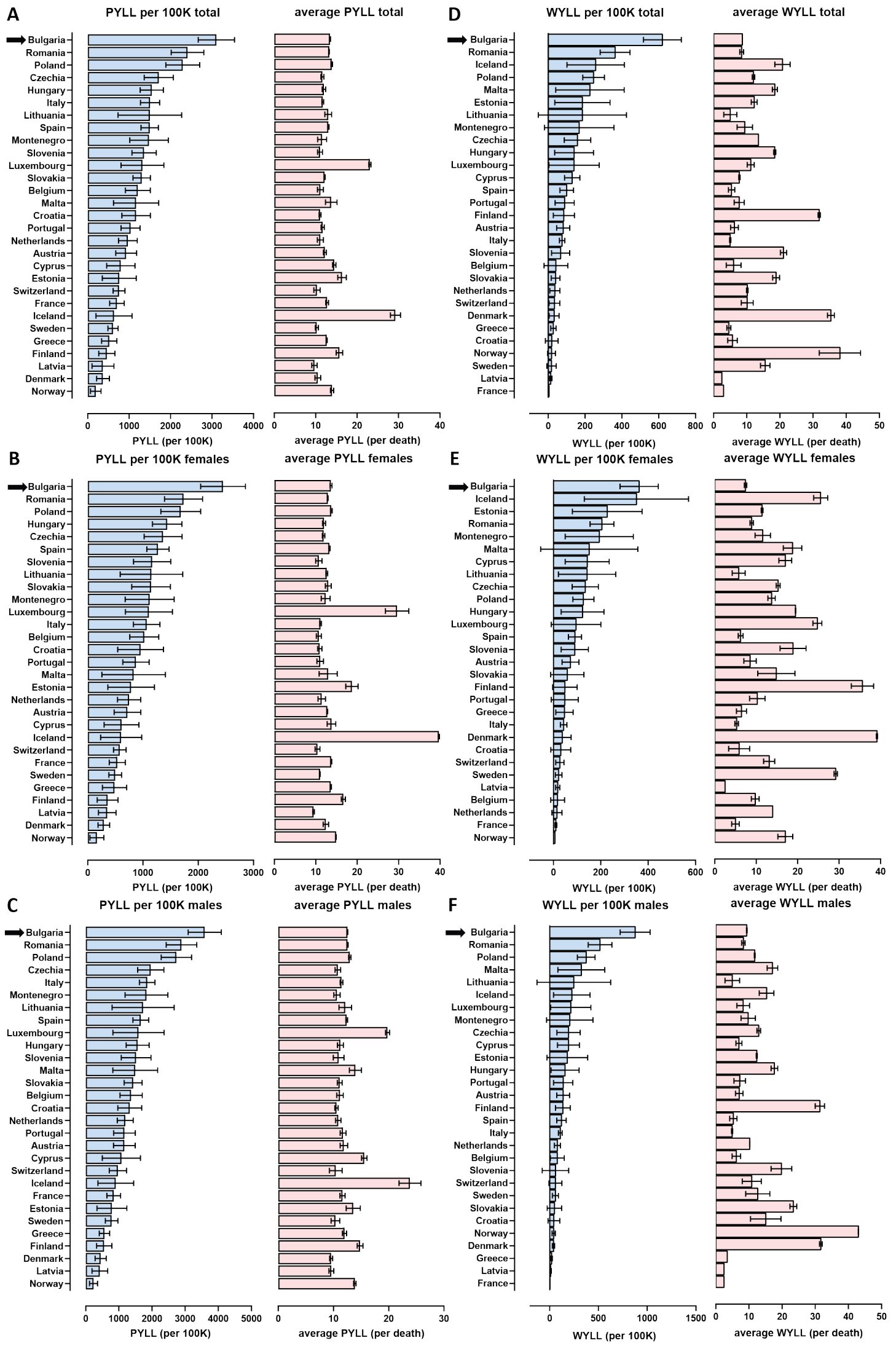

Supplementary Figure 2: Excess mortality-based PYLLs and WYLL values for EU countries in 2020. Shown are the total (per 100K people) and average (per death) values. (A) PYLL values for the whole population; (B) PYLL values for females; (C) PYLL values for males; (D) WYLL values for the whole population; (E) WYLL values for females; (F) WYLL values for males. 


\section{average PYLL males vs. females}

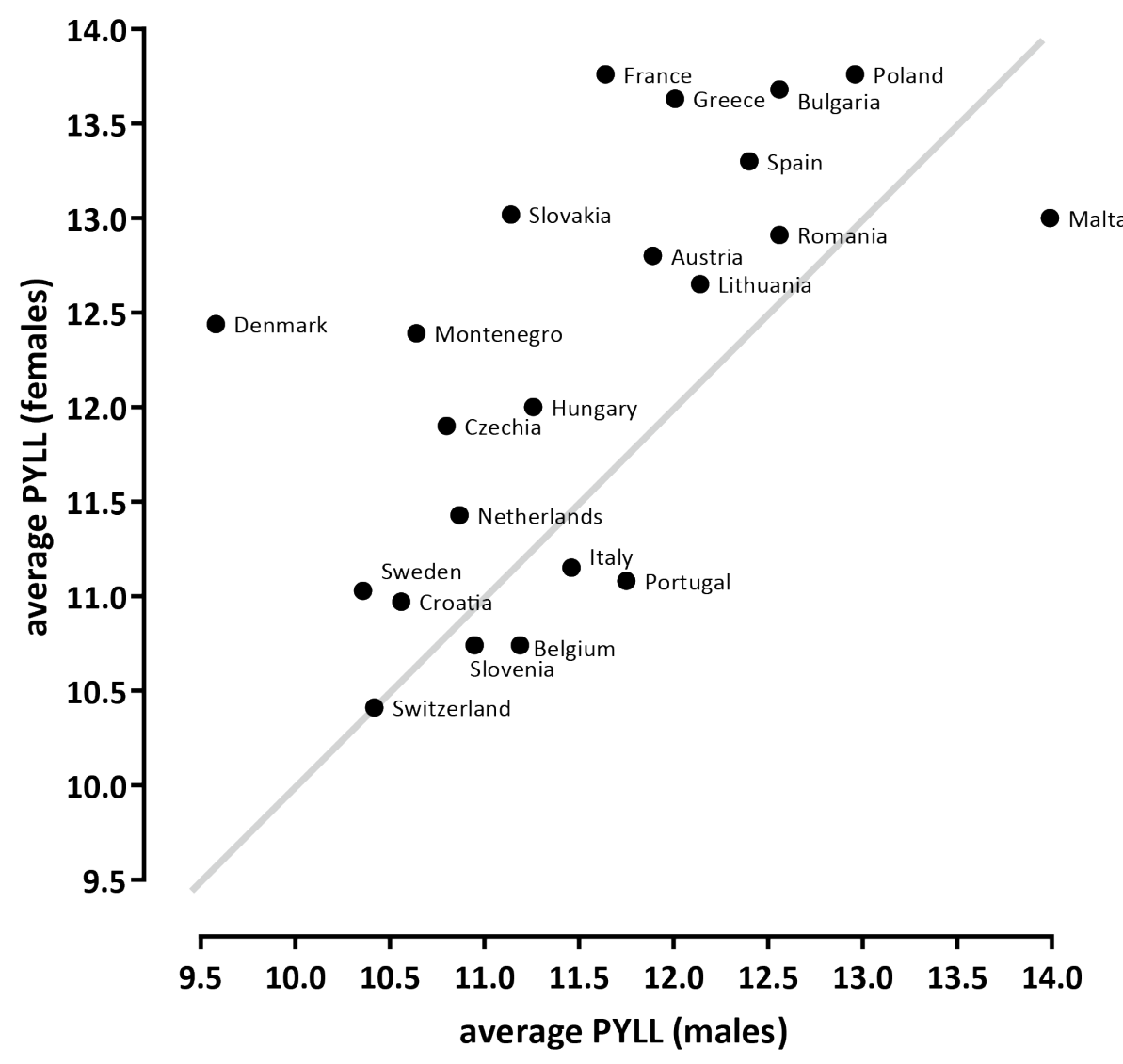

Supplementary Figure 3: Comparison between male- and female-specific average PYLL values in European countries. Shown are the average PYLL values per excess death.
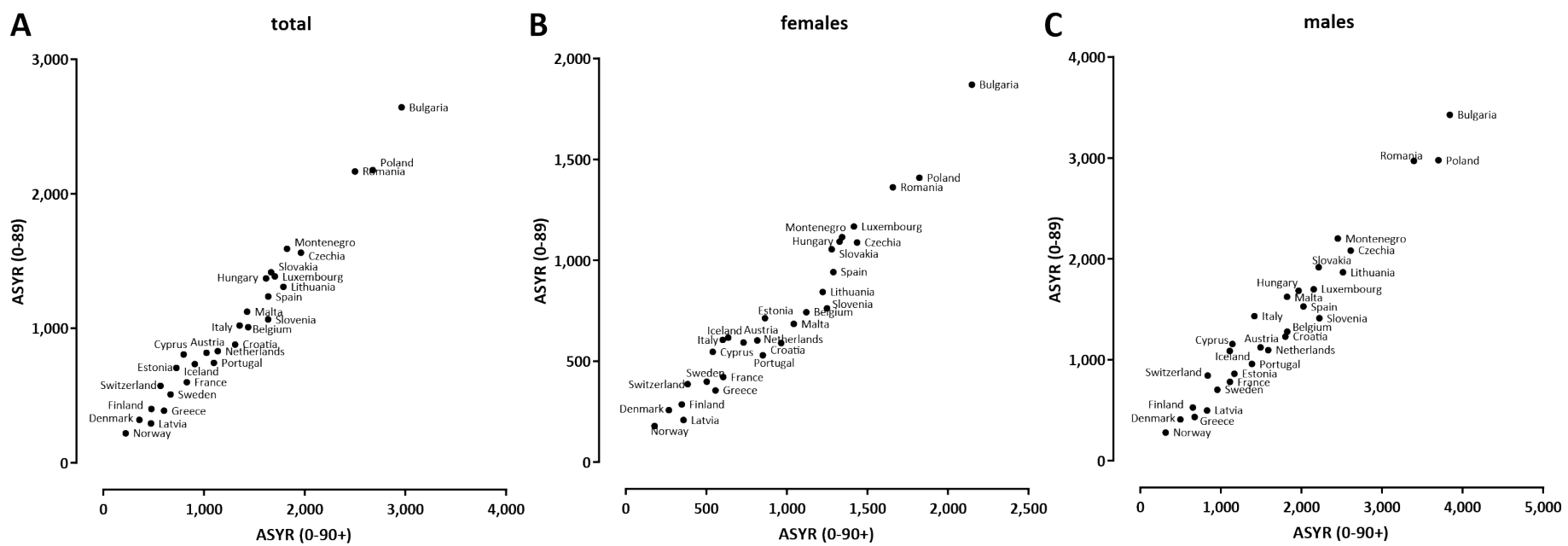

Supplementary Figure 4: ASYR values computed over the 0-89 age range and ASYR values computed over the whole population (with 90+ year-olds included) are consistent. (A) ASYR total; (B) ASYR females; (C) ASYR males. 
medRxiv preprint doi: https://doi.org/10.1101/2021.04.06.21254958; this version posted April 10, 2021. The copyright holder for this preprint (which was not certified by peer review) is the author/funder, who has granted medRxiv a license to display the preprint in perpetuity.

It is made available under a CC-BY-NC-ND 4.0 International license .
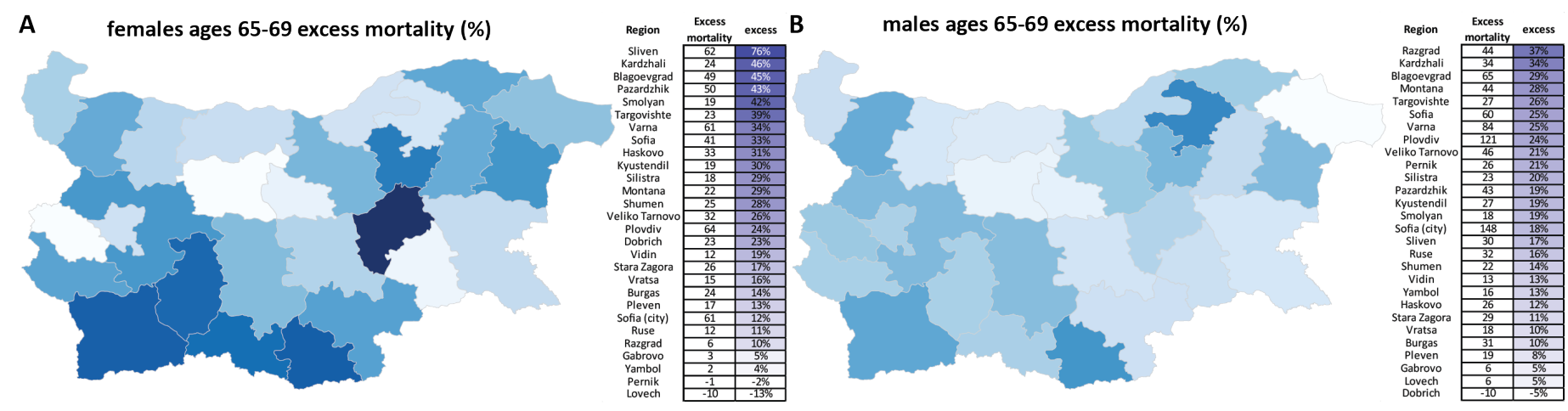

Supplementary Figure 5: Excess mortality in the 65-69 age range in Bulgarian regions. (A) females, P-scores; (B) males, P-scores. 
medRxiv preprint doi: https://doi.org/10.1101/2021.04.06.21254958; this version posted April 10, 2021. The copyright holder for this preprint (which was not certified by peer review) is the author/funder, who has granted medRxiv a license to display the preprint in perpetuity.

It is made available under a CC-BY-NC-ND 4.0 International license .

A
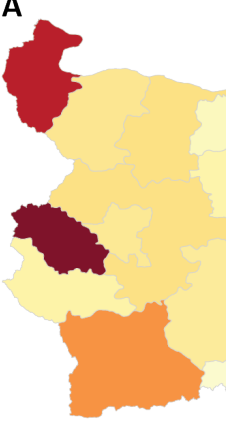

C

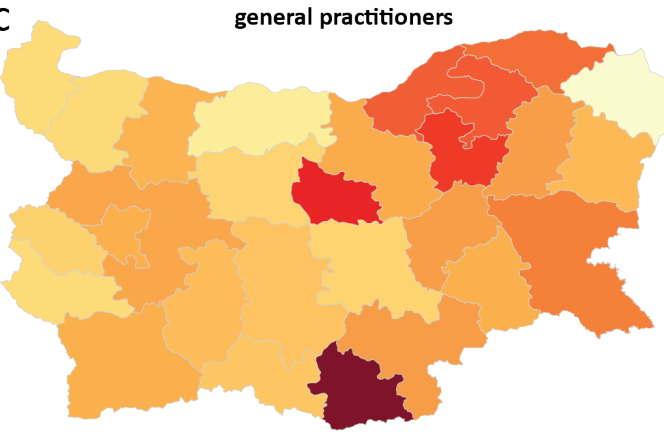

E

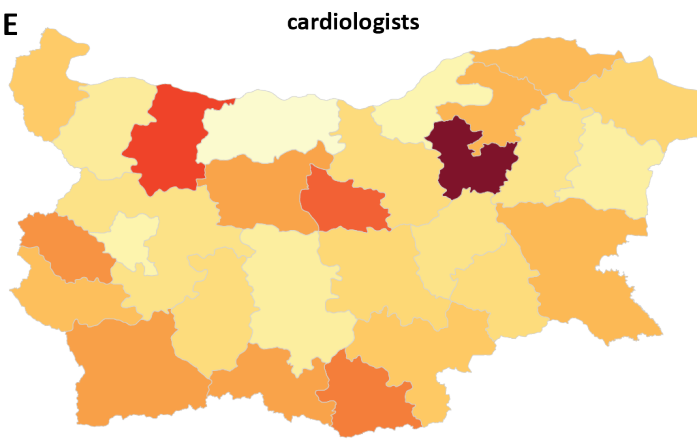

F hospital beds

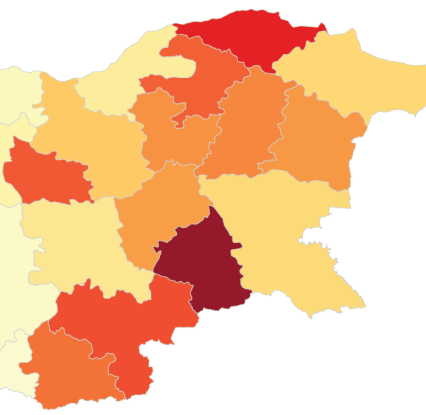

fection disease doctors

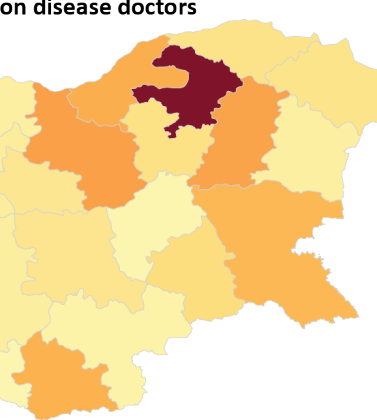

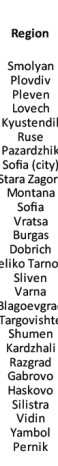

people per
hospital

ICU beds

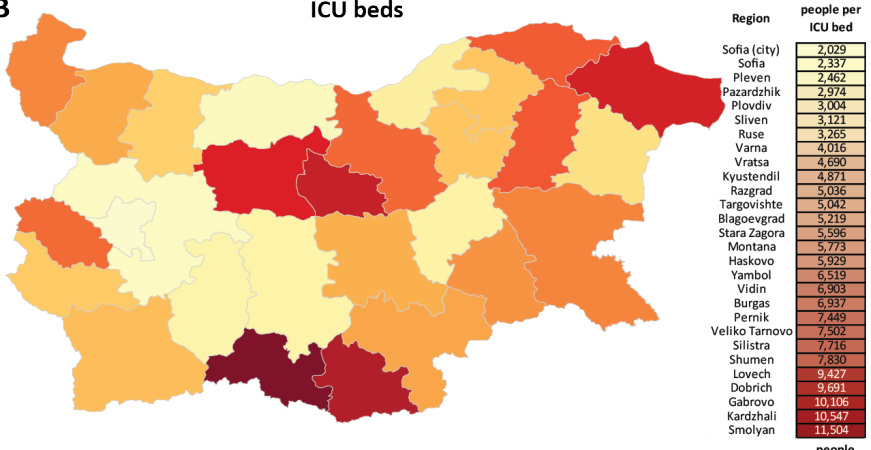

Region $\underset{\substack{\text { poople } \\ \text { per }}}{\text { D }}$

D all doctors
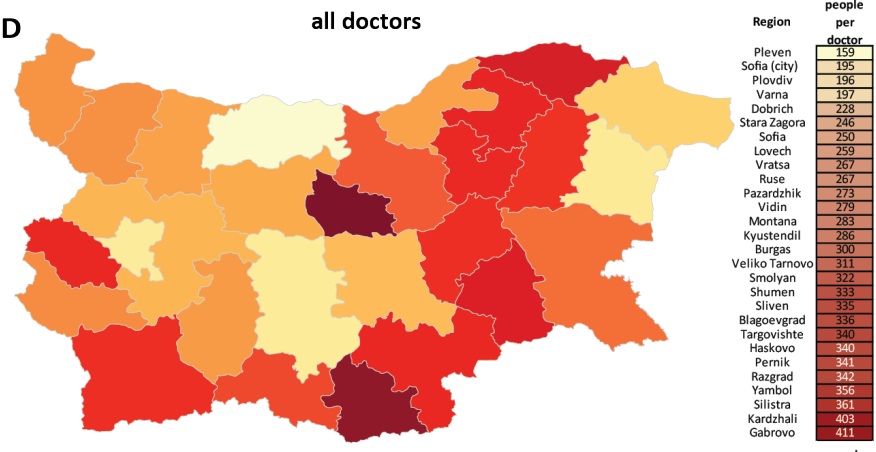

$F$

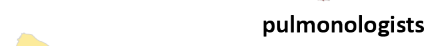

Region $\begin{gathered}\text { people } \\ \text { per }\end{gathered}$
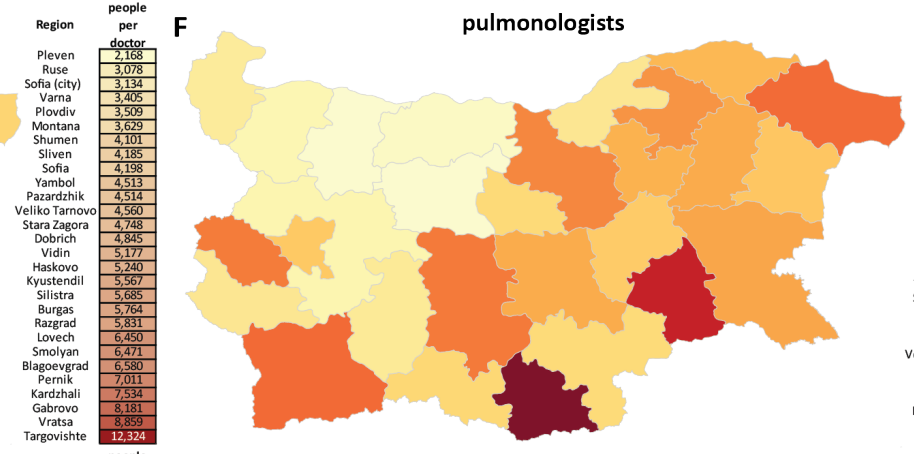

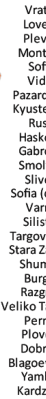
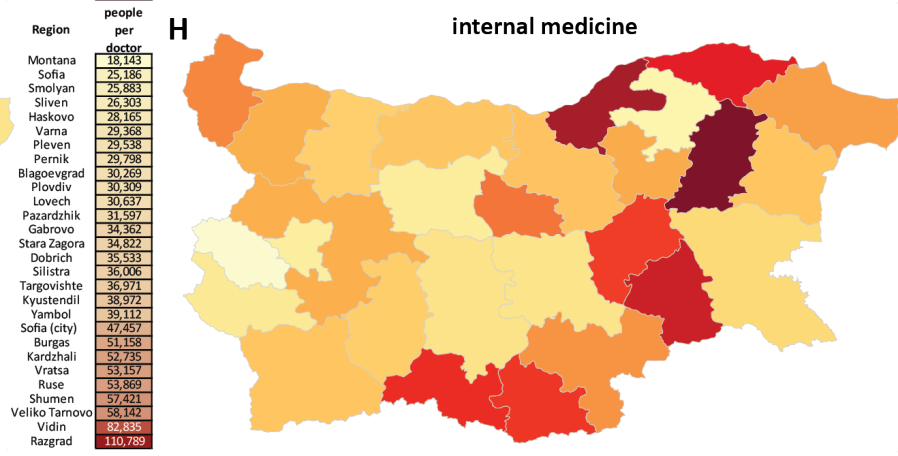

H

internal medicine

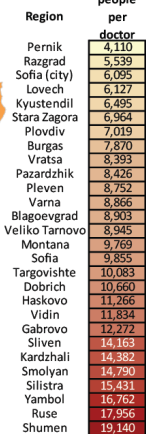

Supplementary Figure 6: Availability of medical resources in Bulgarian regions. (A) Overall hospital beds (in units of people per bed); (B) ICU beds; (C) Total doctors; (D) General practitioners; (E) Cadiologists; (F) Pulmonologists; (G) Infection disease specialists; $(\mathrm{H})$ Internal medicine specialists. Data from the Bulgarian National Statistical Institute (https://www.nsi.bg/bg) 
medRxiv preprint doi: https://doi.org/10.1101/2021.04.06.21254958; this version posted April 10, 2021. The copyright holder for this preprint (which was not certified by peer review) is the author/funder, who has granted medRxiv a license to display the preprint in perpetuity.

It is made available under a CC-BY-NC-ND 4.0 International license .

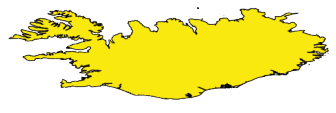

\begin{tabular}{|c|c|}
\hline Austria & 426.02 \\
\hline Belgium & 600.93 \\
\hline Bulgaria & 165.44 \\
\hline Croatia & 248.24 \\
\hline Denmark & 1819.67 \\
\hline Estonia & 481.25 \\
\hline Finland & 452.21 \\
\hline Greece & 324.52 \\
\hline Hungary & 230.53 \\
\hline Iceland & 707.46 \\
\hline Italy & 439.92 \\
\hline Latvia & 464.96 \\
\hline Lithuania & 603.13 \\
\hline Luxembourg & 2638.55 \\
\hline Malta & 1171.92 \\
\hline Netherlands & 302.27 \\
\hline Norway & 520.37 \\
\hline Poland & 183.41 \\
\hline Portugal & 557.22 \\
\hline Romania & 248.26 \\
\hline Slovakia & 594.67 \\
\hline Slovenia & 326.37 \\
\hline Spain & 485.27 \\
\hline Switzerland & 380.00 \\
\hline
\end{tabular}
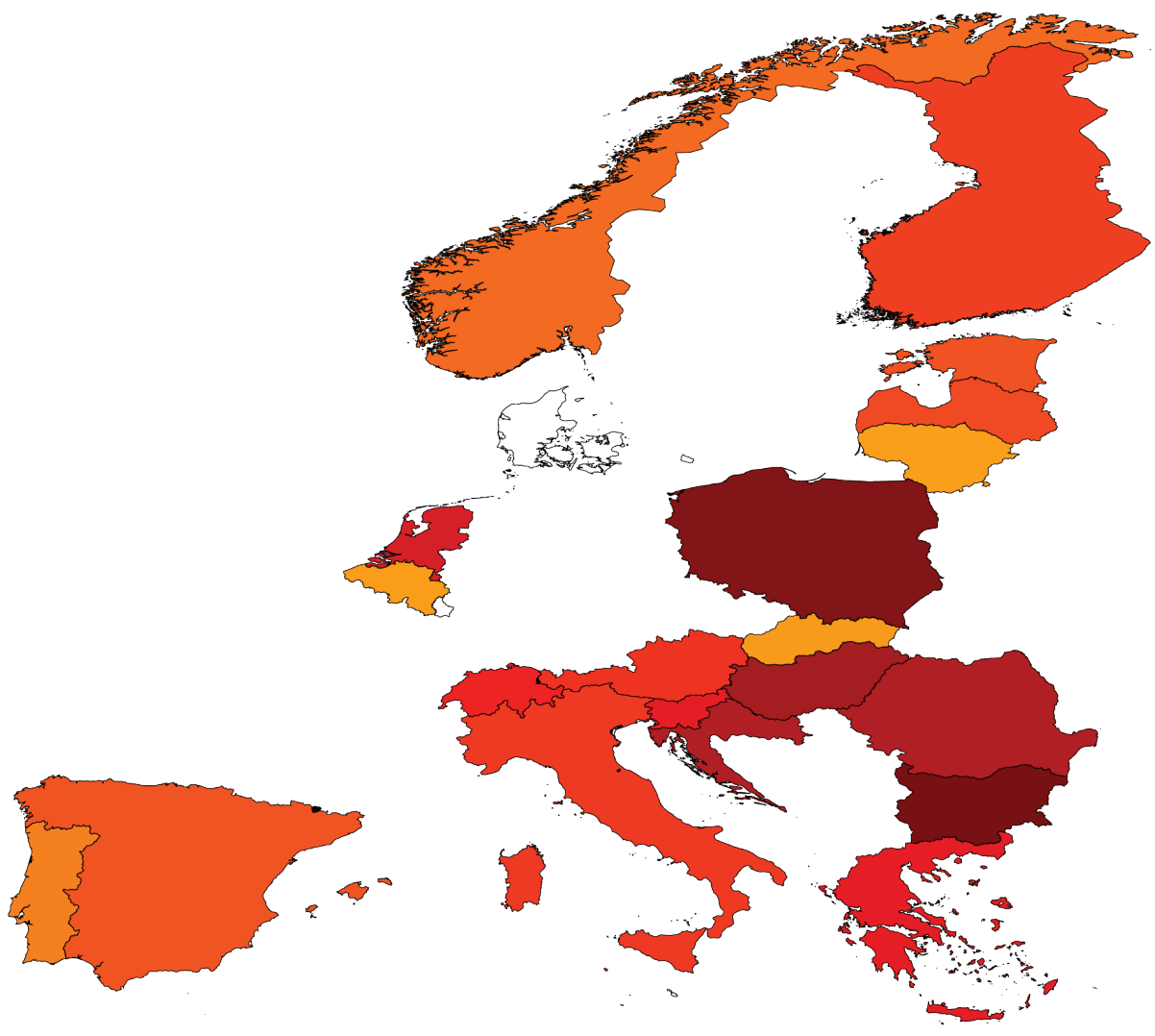

Supplementary Figure 7: COVID testing in European countries. Shown is the number of tests per 1,000 population for the period up to December 31st 2020. Data from https://ourworldindata.org/coronavirus 
medRxiv preprint doi: https://doi.org/10.1101/2021.04.06.21254958; this version posted April 10, 2021. The copyright holder for this preprint (which was not certified by peer review) is the author/funder, who has granted medRxiv a license to display the preprint in perpetuity.

It is made available under a CC-BY-NC-ND 4.0 International license .

\section{Supplementary Tables}




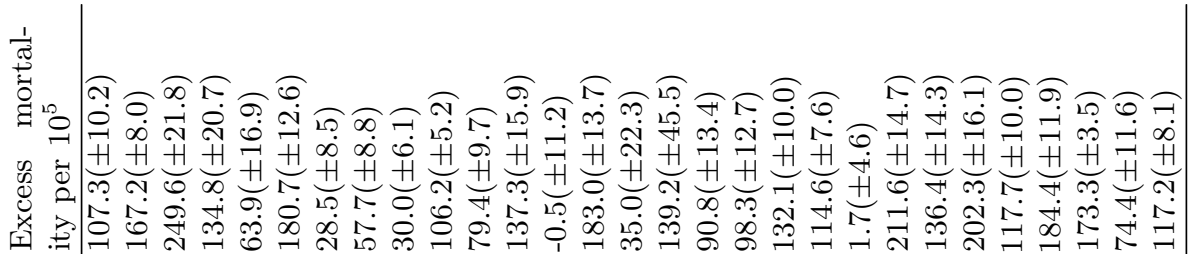

要

菅

م.

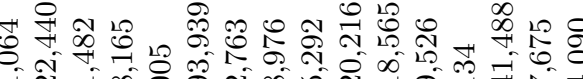

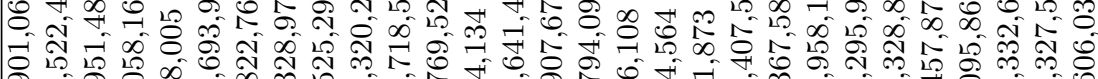

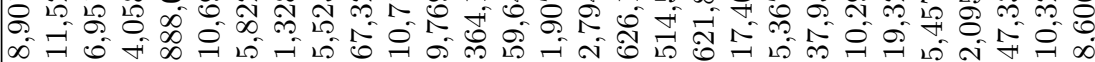

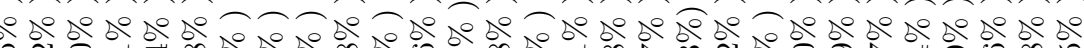

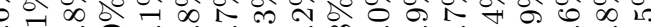

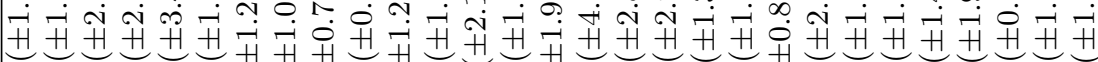

F

ص

$$
\text { 票 }
$$

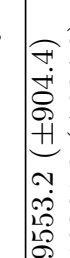

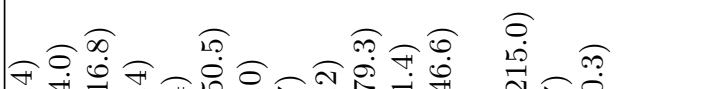

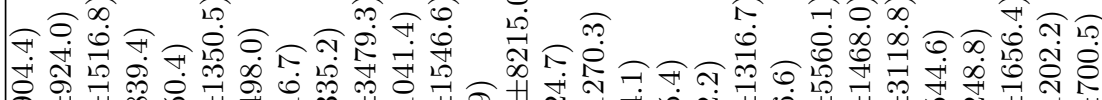

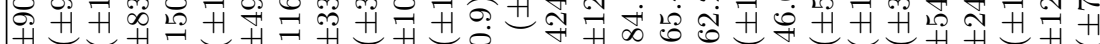
H N 方

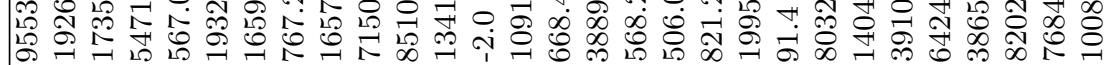

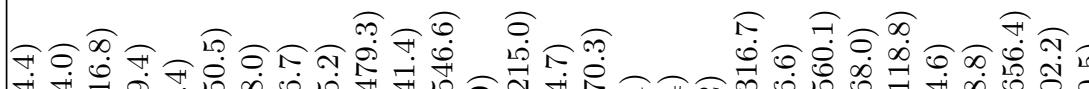

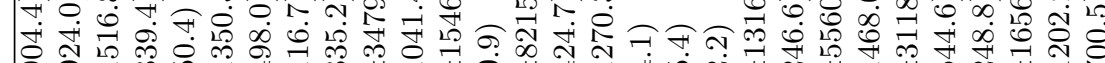

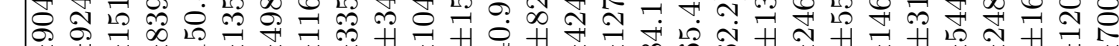

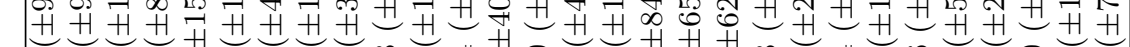

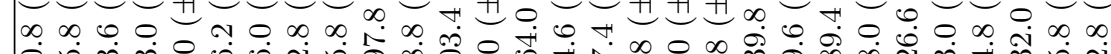
R

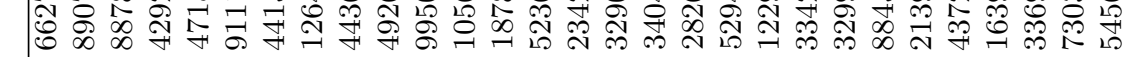

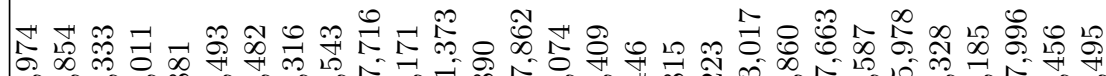
至

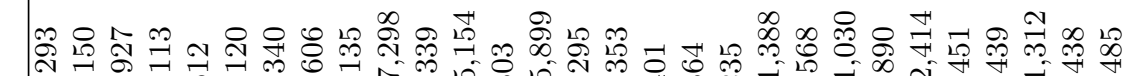

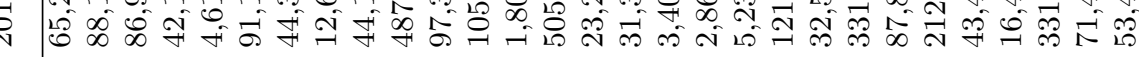

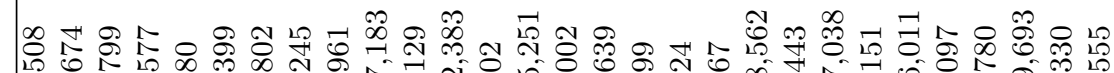

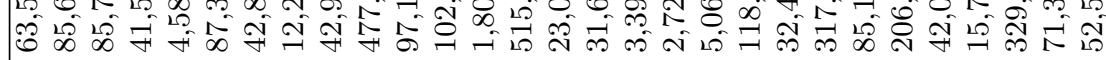

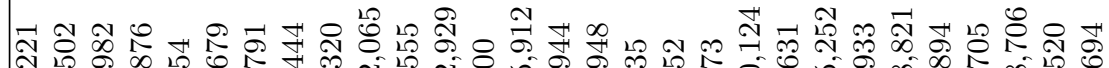
等

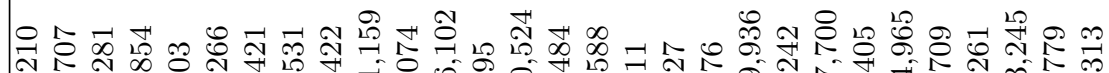

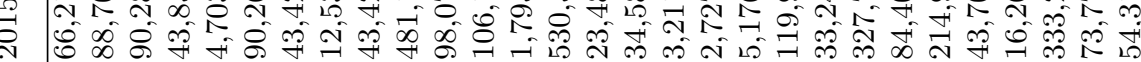

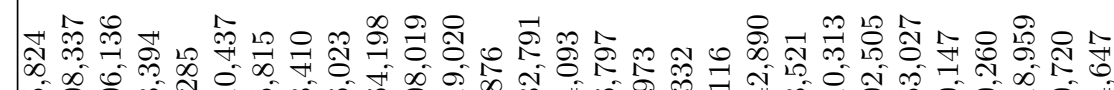
is 00 \%

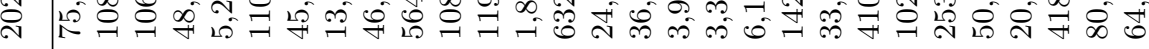

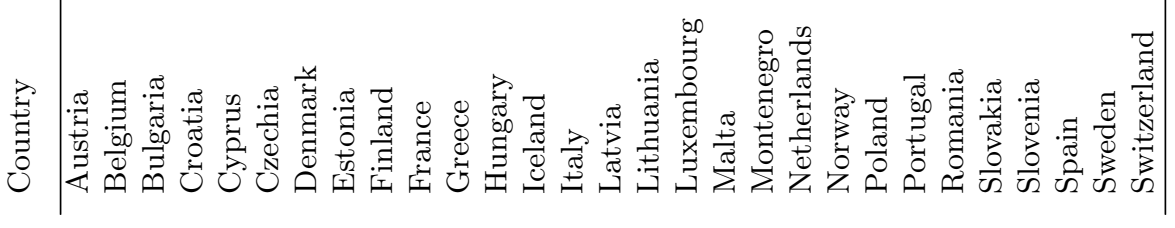




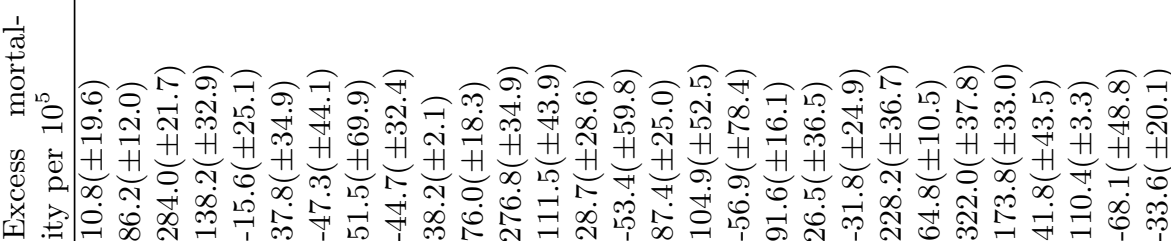

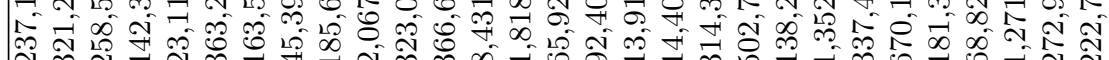

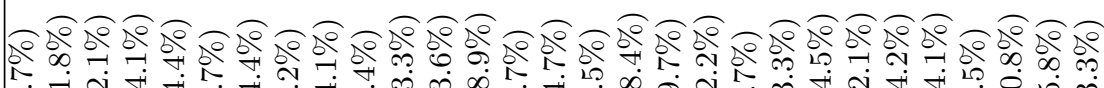

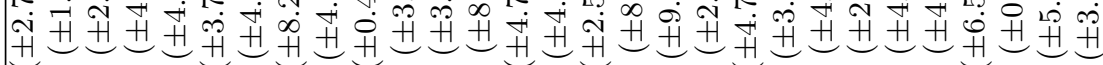
道 L

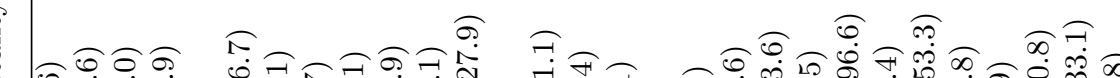

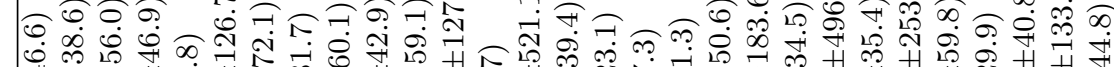

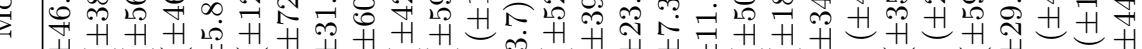

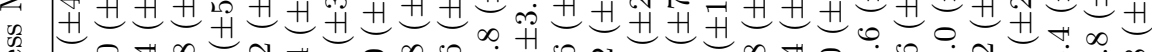

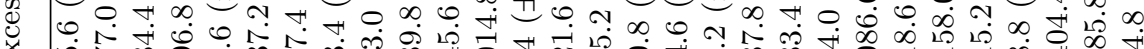

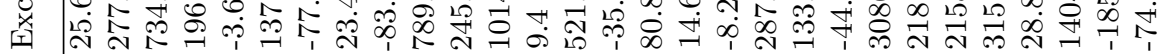

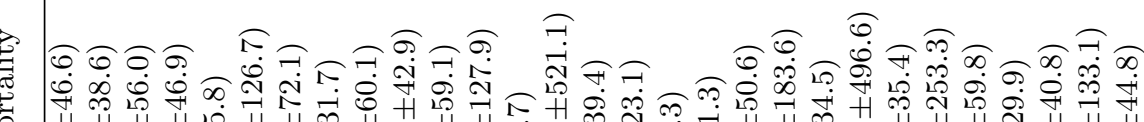

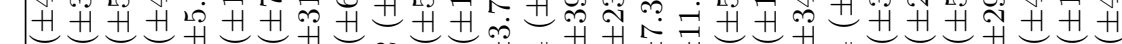
$F_{0} 0.0 \quad N$ O ஷ் 之

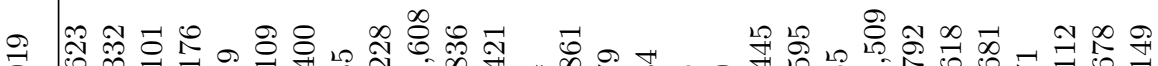
党

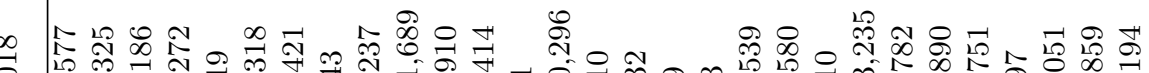
穴

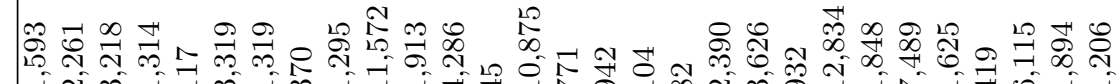

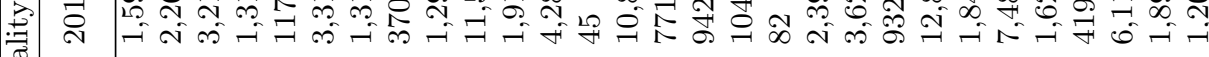
苟

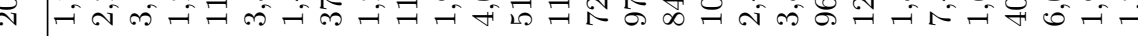
n

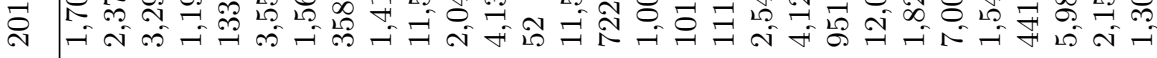

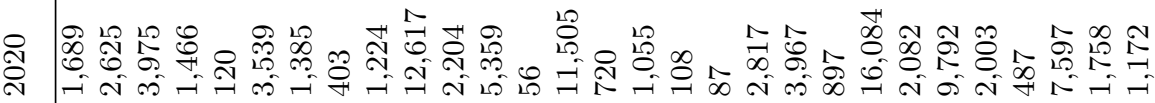

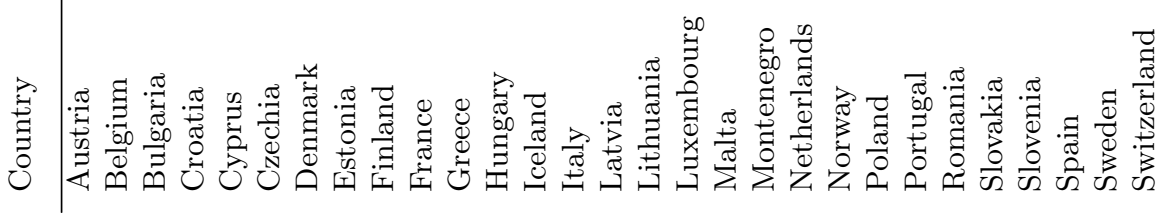




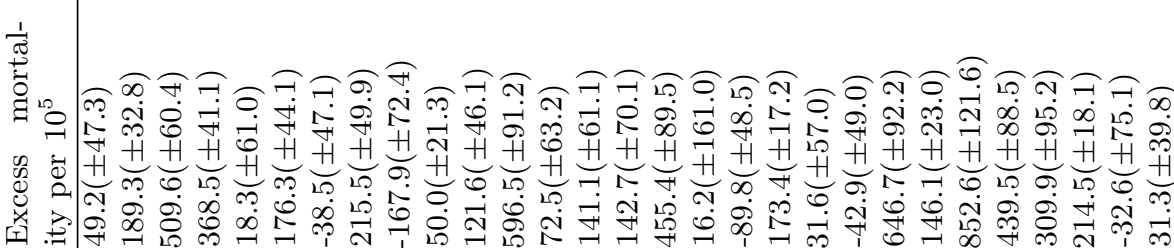

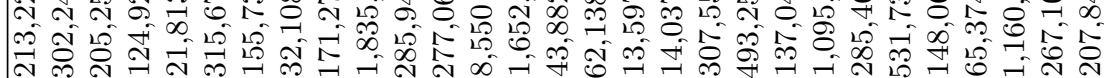

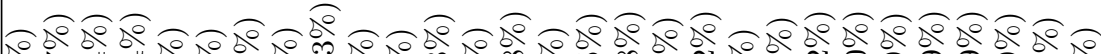
is r. 7 H

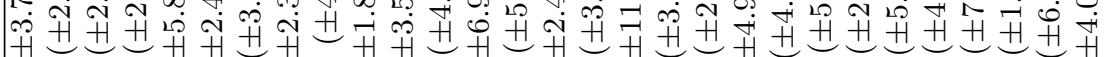

Ho 인

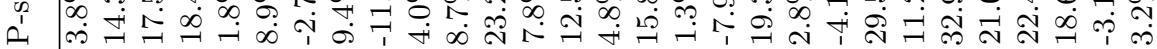

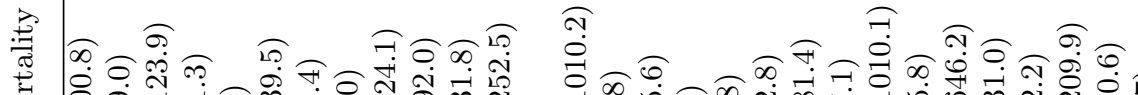

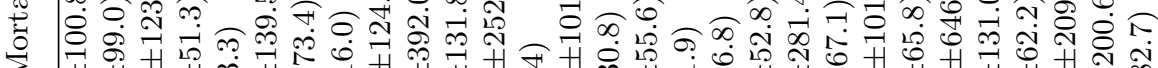

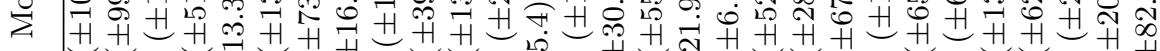
O 0 N

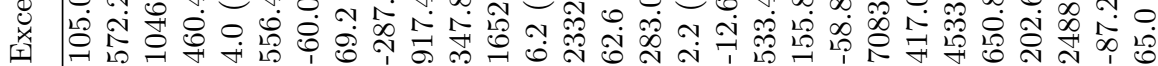

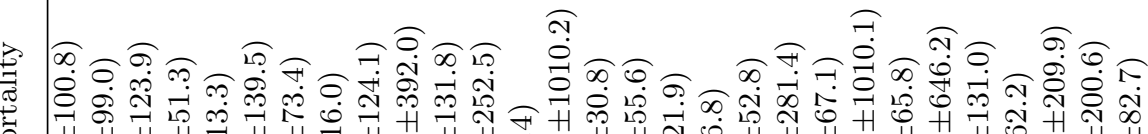

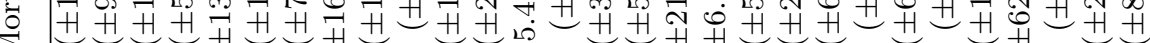

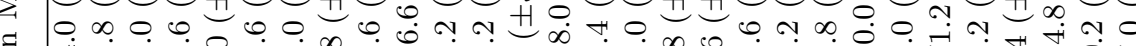

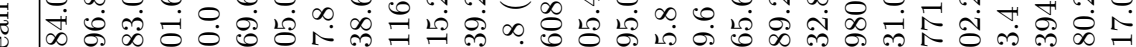
茫 N

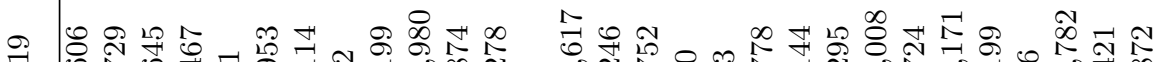

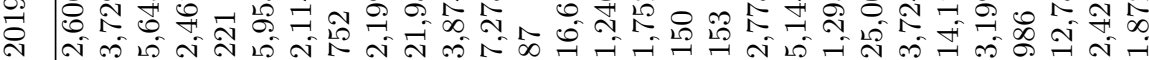
잉요 薄

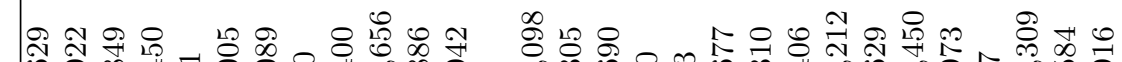

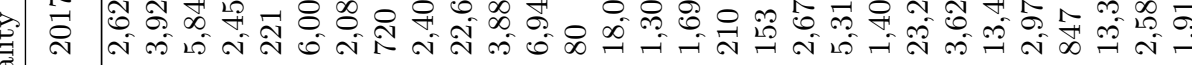

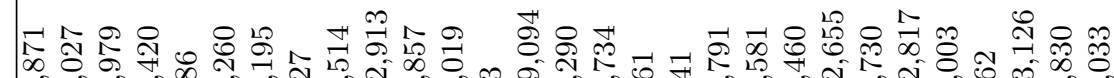

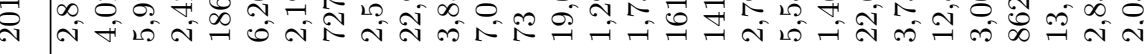

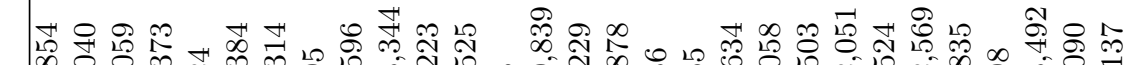

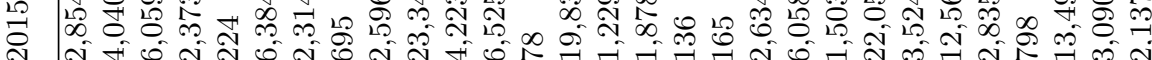

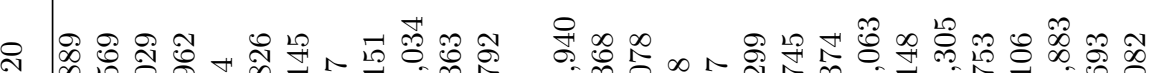

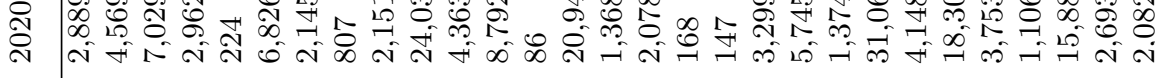

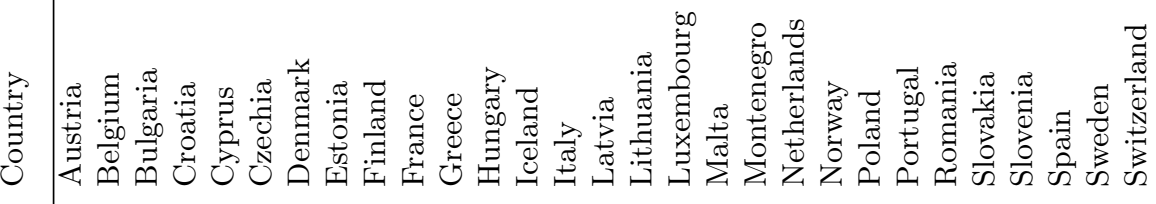


medRxiv preprint doi: https://doi.org/10.1101/2021.04.06.21254958; this version posted April 10, 2021. The copyright holder for this preprint (which was not certified by peer review) is the author/funder, who has granted medRxiv a license to display the preprint in perpetuity.

It is made available under a CC-BY-NC-ND 4.0 International license .

Supplementary Table 4: ASYR values for European countries for the year 2020, for ages 0-89.

\begin{tabular}{|c|c|c|c|c|c|}
\hline \multicolumn{2}{|c|}{ ASYR total } & \multicolumn{2}{|c|}{ ASYR males } & \multicolumn{2}{|c|}{ ASYR females } \\
\hline country & ASYR & country & ASYR & country & ASYR \\
\hline Bulgaria & $2642.71 \pm 387.64$ & Bulgaria & $3429.04 \pm 494.95$ & Bulgaria & $1870.95 \pm 322.65$ \\
\hline Poland & $2176.02 \pm 425.24$ & Poland & $2979.2 \pm 531.98$ & Poland & $1409.38 \pm 333.52$ \\
\hline Romania & $2166.23 \pm 386.11$ & Romania & $2971.23 \pm 506.87$ & Romania & $1362.30 \pm 297.74$ \\
\hline Montenegro & $1591.07 \pm 474.47$ & Montenegro & $2201.28 \pm 765.93$ & Luxembourg & $1167.63 \pm 450.58$ \\
\hline Czechia & $1561.77 \pm 338.36$ & Czechia & $2083.52 \pm 411.74$ & Montenegro & $1114.90 \pm 406.12$ \\
\hline Slovakia & $1416.99 \pm 222.16$ & Slovakia & $1916.80 \pm 316.7$ & Hungary & $1093.03 \pm 224.89$ \\
\hline Luxembourg & $1385.34 \pm 561.60$ & Lithuania & $1867.11 \pm 984.67$ & Czechia & $1088.59 \pm 294.64$ \\
\hline Hungary & $1371.86 \pm 257.82$ & Luxembourg & $1698.68 \pm 848.55$ & Slovakia & $1054.24 \pm 327.81$ \\
\hline Lithuania & $1308.71 \pm 705.12$ & Hungary & $1684.16 \pm 360.10$ & Spain & $942.20 \pm 169.04$ \\
\hline Spain & $1237.10 \pm 195.03$ & Malta & $1624.29 \pm 680.96$ & Lithuania & $842.8 \pm 438.91$ \\
\hline Malta & $1122.81 \pm 528.47$ & Spain & $1528.26 \pm 232.74$ & Slovenia & $761.89 \pm 274.98$ \\
\hline Slovenia & $1065.83 \pm 262.79$ & Italy & $1431.94 \pm 203.13$ & Belgium & $743.09 \pm 237.88$ \\
\hline Italy & $1020.91 \pm 177.37$ & Slovenia & $1412.31 \pm 423.85$ & Estonia & $713.18 \pm 403.65$ \\
\hline Belgium & $1008.50 \pm 301.28$ & Belgium & $1278.93 \pm 342.72$ & Malta & $684.67 \pm 551.42$ \\
\hline Croatia & $879.37 \pm 301.07$ & Croatia & $1229.67 \pm 361.12$ & Iceland & $616.88 \pm 380.42$ \\
\hline Netherlands & $830.38 \pm 210.23$ & Cyprus & $1155.62 \pm 595.19$ & Italy & $605.74 \pm 155.89$ \\
\hline Austria & $818.23 \pm 233.29$ & Austria & $1123.27 \pm 340.89$ & Netherlands & $603.04 \pm 195.17$ \\
\hline Cyprus & $806.27 \pm 339.84$ & Netherlands & $1095.74 \pm 222.74$ & Austria & $592.24 \pm 189.30$ \\
\hline Portugal & $742.72 \pm 187.97$ & Iceland & $1087.99 \pm 587.39$ & Croatia & $589.37 \pm 326.44$ \\
\hline Estonia & $733.79 \pm 384.83$ & Portugal & $959.40 \pm 291.99$ & Cyprus & $546.61 \pm 306.67$ \\
\hline Iceland & $705.81 \pm 457.04$ & Estonia & $861.08 \pm 440.19$ & Portugal & $529.72 \pm 192.09$ \\
\hline France & $599.00 \pm 165.45$ & Switzerland & $842.88 \pm 255.68$ & France & $422.21 \pm 117.61$ \\
\hline Switzerland & $572.07 \pm 136.63$ & France & $780.58 \pm 213.49$ & Sweden & $398.40 \pm 79.04$ \\
\hline Sweden & $508.34 \pm 100.43$ & Sweden & $702.98 \pm 179.45$ & Switzerland & $386.31 \pm 100.48$ \\
\hline Finland & $400.07 \pm 172.88$ & Finland & $526.50 \pm 207.13$ & Greece & $355.06 \pm 165.77$ \\
\hline Greece & $387.31 \pm 147.26$ & Latvia & $496.83 \pm 261.61$ & Finland & $285.37 \pm 162.98$ \\
\hline Denmark & $319.15 \pm 141.77$ & Greece & $433.70 \pm 135.00$ & Denmark & $257.42 \pm 92.80$ \\
\hline Latvia & $292.95 \pm 229.64$ & Denmark & $408.03 \pm 160.00$ & Latvia & $208.70 \pm 84.34$ \\
\hline Norway & $219.82 \pm 142.17$ & Norway & $279.00 \pm 142.00$ & Norway & $179.47 \pm 141.82$ \\
\hline
\end{tabular}


medRxiv preprint doi: https://doi.org/10.1101/2021.04.06.21254958; this version posted April 10, 2021. The copyright holder for this preprint (which was not certified by peer review) is the author/funder, who has granted medRxiv a license to display the preprint in perpetuity.

It is made available under a CC-BY-NC-ND 4.0 International license .

Supplementary Table 5: ASYR values for European countries for the year 2020, for ages 0 to $90+$.

\begin{tabular}{|c|c|c|c|c|c|}
\hline \multicolumn{2}{|c|}{ ASYR total } & \multicolumn{2}{|c|}{ ASYR males } & \multicolumn{2}{|c|}{ ASYR females } \\
\hline country & ASYR & country & ASYR & country & ASYR \\
\hline Bulgaria & $2963.08 \pm 423.25$ & Bulgaria & $3842.60 \pm 529.63$ & Bulgaria & $2147.98 \pm 362.37$ \\
\hline Poland & $2676.11 \pm 479.93$ & Poland & $3700.81 \pm 597.50$ & Poland & $1823.31 \pm 387.70$ \\
\hline Romania & $2501.03 \pm 430.02$ & Romania & $3396.66 \pm 546.60$ & Romania & $1658.84 \pm 344.88$ \\
\hline Czechia & $1963.81 \pm 389.01$ & Czechia & $2612.61 \pm 476.53$ & Czechia & $1435.77 \pm 346.58$ \\
\hline Montenegro & $1825.12 \pm 530.49$ & Lithuania & $2517.08 \pm 1058.43$ & Luxembourg & $1416.52 \pm 505.13$ \\
\hline Lithuania & $1789.84 \pm 758.74$ & Montenegro & $2451.80 \pm 866.94$ & Montenegro & $1342.87 \pm 487.51$ \\
\hline Luxembourg & $1704.25 \pm 628.43$ & Slovenia & $2223.7 \pm 534.70$ & Hungary & $1326.87 \pm 255.44$ \\
\hline Slovakia & $1666.51 \pm 250.84$ & Slovakia & $2213.56 \pm 344.59$ & Spain & $1288.61 \pm 190.40$ \\
\hline Spain & $1638.01 \pm 220.31$ & Luxembourg & $2152.29 \pm 961.87$ & Slovakia & $1277.82 \pm 358.38$ \\
\hline Slovenia & $1635.98 \pm 320.95$ & Spain & $2026.51 \pm 275.46$ & Slovenia & $1249.83 \pm 328.03$ \\
\hline Hungary & $1616.83 \pm 282.59$ & Hungary & $1966.58 \pm 380.22$ & Lithuania & $1222.45 \pm 495.15$ \\
\hline Belgium & $1438.89 \pm 330.31$ & Belgium & $1822.65 \pm 392.28$ & Belgium & $1120.08 \pm 268.13$ \\
\hline Malta & $1427.67 \pm 577.51$ & Malta & $1820.27 \pm 747.73$ & Malta & $1043.07 \pm 606.69$ \\
\hline Italy & $1354.28 \pm 204.22$ & Croatia & $1800.53 \pm 448.09$ & Croatia & $965.27 \pm 368.26$ \\
\hline Croatia & $1309.57 \pm 352.60$ & Netherlands & $1587.07 \pm 291.09$ & Estonia & $863.81 \pm 443.5$ \\
\hline Netherlands & $1136.98 \pm 238.97$ & Austria & $1492.68 \pm 402.59$ & Portugal & $850.83 \pm 238.20$ \\
\hline Portugal & $1098.04 \pm 245.12$ & Italy & $1415.77 \pm 200.74$ & Netherlands & $816.38 \pm 210.52$ \\
\hline Austria & $1024.27 \pm 276.29$ & Portugal & $1384.46 \pm 374.22$ & Austria & $730.49 \pm 231.15$ \\
\hline Estonia & $909.88 \pm 451.22$ & Estonia & $1168.07 \pm 571.62$ & Iceland & $635.56 \pm 436.84$ \\
\hline France & $829.05 \pm 192.34$ & Cyprus & $1142.61 \pm 587.28$ & France & $605.05 \pm 145.93$ \\
\hline Cyprus & $796.80 \pm 335.12$ & France & $1112.10 \pm 247.55$ & Italy & $601.71 \pm 154.81$ \\
\hline Iceland & $725.93 \pm 507.83$ & Iceland & $1109.31 \pm 639.07$ & Greece & $557.5 \pm 228.32$ \\
\hline Sweden & $667.81 \pm 126.16$ & Sweden & $955.58 \pm 203.81$ & Cyprus & $539.87 \pm 303.08$ \\
\hline Greece & $604.26 \pm 207.60$ & Switzerland & $837.75 \pm 252.29$ & Sweden & $503.02 \pm 110.52$ \\
\hline Switzerland & $567.55 \pm 134.87$ & Latvia & $826.88 \pm 373.38$ & Switzerland & $384.27 \pm 99.47$ \\
\hline Finland & $476.93 \pm 198.87$ & Greece & $674.05 \pm 198.07$ & Latvia & $357.84 \pm 152.71$ \\
\hline Latvia & $474.65 \pm 301.96$ & Finland & $651.73 \pm 265.71$ & Finland & $346.96 \pm 182.45$ \\
\hline Denmark & $358.89 \pm 151.64$ & Denmark & $496.97 \pm 181.88$ & Denmark & $267.38 \pm 99.06$ \\
\hline Norway & $221.17 \pm 146.99$ & Norway & $314.10 \pm 161.51$ & Norway & $177.81 \pm 140.37$ \\
\hline
\end{tabular}


medRxiv preprint doi: https://doi.org/10.1101/2021.04.06.21254958; this version posted April 10, 2021. The copyright holder for this preprint (which was not certified by peer review) is the author/funder, who has granted medRxiv a license to display the preprint in perpetuity.

It is made available under a CC-BY-NC-ND 4.0 International license .

Supplementary Table 6: Average PYLL values for European countries for the year 2020.

\begin{tabular}{|c|c|c|c|c|c|}
\hline \multicolumn{2}{|c|}{ PYLL total } & \multicolumn{2}{|c|}{ PYLL males } & \multicolumn{2}{|c|}{ PYLL females } \\
\hline country & PYLL & country & PYLL & country & PYLL \\
\hline Iceland & $29.25 \pm 1.22$ & Iceland & $23.86 \pm 1.99$ & Iceland & $39.71 \pm 0.13$ \\
\hline Luxembourg & $23.08 \pm 0.26$ & Luxembourg & $19.79 \pm 0.37$ & Luxembourg & $29.63 \pm 2.83$ \\
\hline Estonia & $16.37 \pm 1.03$ & Cyprus & $15.58 \pm 0.49$ & Estonia & $18.73 \pm 1.48$ \\
\hline Finland & $15.73 \pm 0.77$ & Finland & $14.82 \pm 0.51$ & Finland & $16.65 \pm 0.48$ \\
\hline Cyprus & $14.48 \pm 0.41$ & Malta & $13.99 \pm 1.09$ & Norway & $14.92 \pm 0.02$ \\
\hline Norway & $13.95 \pm 0.39$ & Norway & $13.88 \pm 0.22$ & Cyprus & $13.79 \pm 1.04$ \\
\hline Poland & $13.87 \pm 0.18$ & Estonia & $13.58 \pm 1.28$ & France & $13.76 \pm 0.1$ \\
\hline Malta & $13.76 \pm 1.4$ & Poland & $12.96 \pm 0.21$ & Poland & $13.76 \pm 0.19$ \\
\hline Bulgaria & $13.46 \pm 0.11$ & Romania & $12.56 \pm 0.11$ & Bulgaria & $13.68 \pm 0.24$ \\
\hline Romania & $13.29 \pm 0.01$ & Bulgaria & $12.56 \pm 0.03$ & Greece & $13.63 \pm 0.14$ \\
\hline Spain & $13.08 \pm 0.16$ & Spain & $12.4 \pm 0.15$ & Spain & $13.3 \pm 0.14$ \\
\hline Lithuania & $13.04 \pm 0.82$ & Lithuania & $12.14 \pm 1.14$ & Slovakia & $13.02 \pm 0.7$ \\
\hline France & $12.77 \pm 0.33$ & Greece & $12.01 \pm 0.38$ & Malta & $13 \pm 2.19$ \\
\hline Greece & $12.68 \pm 0.1$ & Austria & $11.89 \pm 0.68$ & Romania & $12.91 \pm 0.05$ \\
\hline Austria & $12.21 \pm 0.35$ & Portugal & $11.75 \pm 0.53$ & Austria & $12.8 \pm 0.07$ \\
\hline Slovakia & $12.17 \pm 0.12$ & France & $11.64 \pm 0.46$ & Lithuania & $12.65 \pm 0.21$ \\
\hline Hungary & $11.99 \pm 0.43$ & Italy & $11.46 \pm 0.25$ & Denmark & $12.44 \pm 0.66$ \\
\hline Italy & $11.72 \pm 0.21$ & Hungary & $11.26 \pm 0.54$ & Montenegro & $12.39 \pm 1.07$ \\
\hline Portugal & $11.69 \pm 0.38$ & Belgium & $11.19 \pm 0.59$ & Hungary & $12 \pm 0.37$ \\
\hline Czechia & $11.62 \pm 0.37$ & Slovakia & $11.14 \pm 0.43$ & Czechia & $11.9 \pm 0.3$ \\
\hline Montenegro & $11.57 \pm 1.08$ & Slovenia & $10.95 \pm 0.97$ & Netherlands & $11.43 \pm 0.9$ \\
\hline Belgium & $11.15 \pm 0.72$ & Netherlands & $10.87 \pm 0.49$ & Italy & $11.15 \pm 0.22$ \\
\hline Netherlands & $11.14 \pm 0.73$ & Czechia & $10.8 \pm 0.5$ & Portugal & $11.08 \pm 0.79$ \\
\hline Croatia & $11.06 \pm 0.23$ & Montenegro & $10.64 \pm 0.58$ & Sweden & $11.03 \pm 0.02$ \\
\hline Slovenia & $11.05 \pm 0.6$ & Croatia & $10.56 \pm 0.3$ & Croatia & $10.97 \pm 0.52$ \\
\hline Denmark & $10.52 \pm 0.68$ & Switzerland & $10.42 \pm 1.15$ & Belgium & $10.74 \pm 0.6$ \\
\hline Switzerland & $10.32 \pm 0.77$ & Sweden & $10.36 \pm 0.78$ & Slovenia & $10.74 \pm 0.77$ \\
\hline Sweden & $10.29 \pm 0.37$ & Latvia & $9.63 \pm 0.44$ & Switzerland & $10.41 \pm 0.59$ \\
\hline Latvia & $9.71 \pm 0.66$ & Denmark & $9.58 \pm 0.27$ & Latvia & $9.47 \pm 0.18$ \\
\hline
\end{tabular}


medRxiv preprint doi: https://doi.org/10.1101/2021.04.06.21254958; this version posted April 10, 2021. The copyright holder for this preprint (which was not certified by peer review) is the author/funder, who has granted medRxiv a license to display the preprint in perpetuity.

It is made available under a CC-BY-NC-ND 4.0 International license .

Supplementary Table 7: Average WYLL values for European countries for the year 2020.

\begin{tabular}{|c|c|c|c|c|c|}
\hline \multicolumn{2}{|c|}{ WYLL total } & \multicolumn{2}{|c|}{ WYLL males } & \multicolumn{2}{|c|}{ WYLL females } \\
\hline country & WYLL & country & WYLL & country & WYLL \\
\hline Norway & $38.11 \pm 6.23$ & Norway & $43.02 \pm 0.02$ & Denmark & $39.15 \pm 0.13$ \\
\hline Denmark & $35.38 \pm 1.03$ & Denmark & $31.69 \pm 0.41$ & Finland & $35.65 \pm 2.69$ \\
\hline Finland & $31.87 \pm 0.33$ & Finland & $31.39 \pm 1.39$ & Sweden & $29.18 \pm 0.4$ \\
\hline Slovenia & $21.09 \pm 0.92$ & Slovakia & $23.4 \pm 1.04$ & Iceland & $25.56 \pm 1.69$ \\
\hline Iceland & $20.78 \pm 2.31$ & Slovenia & $19.81 \pm 3.12$ & Luxembourg & $24.77 \pm 1.09$ \\
\hline Slovakia & $18.84 \pm 1.04$ & Hungary & $17.68 \pm 1.01$ & Hungary & $19.5 \pm 0.06$ \\
\hline Malta & $18.47 \pm 0.75$ & Malta & $17.08 \pm 1.6$ & Slovenia & $18.89 \pm 3.14$ \\
\hline Hungary & $18.43 \pm 0.31$ & Iceland & $15.32 \pm 2.22$ & Malta & $18.77 \pm 2.23$ \\
\hline Sweden & $15.57 \pm 1.43$ & Croatia & $15.07 \pm 4.6$ & Norway & $17.03 \pm 1.79$ \\
\hline Czechia & $13.54 \pm 0$ & Czechia & $12.96 \pm 0.56$ & Cyprus & $17.03 \pm 1.54$ \\
\hline Estonia & $12.25 \pm 0.9$ & Sweden & $12.66 \pm 3.65$ & Czechia & $15.3 \pm 0.47$ \\
\hline Poland & $12.04 \pm 0.37$ & Estonia & $12.37 \pm 0.17$ & Slovakia & $14.86 \pm 4.48$ \\
\hline Luxembourg & $11.21 \pm 1.06$ & Poland & $11.74 \pm 0.1$ & Netherlands & $14.01 \pm 0.47$ \\
\hline Netherlands & $10.17 \pm 0.24$ & Switzerland & $10.86 \pm 2.88$ & Poland & $13.72 \pm 0.89$ \\
\hline Switzerland & $10.13 \pm 1.81$ & Netherlands & $10.26 \pm 0.02$ & Switzerland & $13.14 \pm 1.34$ \\
\hline Montenegro & $9.4 \pm 2.33$ & Montenegro & $9.77 \pm 2.16$ & Montenegro & $11.59 \pm 1.85$ \\
\hline Bulgaria & $8.68 \pm 0$ & Bulgaria & $9.35 \pm 0.07$ & Estonia & $11.42 \pm 0.22$ \\
\hline Romania & $8.47 \pm 0.58$ & Romania & $8.32 \pm 0.52$ & Portugal & $10.27 \pm 1.86$ \\
\hline Cyprus & $7.78 \pm 0.21$ & Luxembourg & $8.27 \pm 1.91$ & Belgium & $9.77 \pm 0.95$ \\
\hline Portugal & $7.73 \pm 1.52$ & Portugal & $7.22 \pm 1.75$ & Romania & $8.91 \pm 0.42$ \\
\hline Austria & $6.28 \pm 1.16$ & Austria & $7.09 \pm 1.13$ & Austria & $8.52 \pm 1.49$ \\
\hline Belgium & $6.03 \pm 2.23$ & Cyprus & $6.98 \pm 0.92$ & Bulgaria & $7.43 \pm 0.28$ \\
\hline Croatia & $5.69 \pm 1.44$ & Belgium & $6.2 \pm 1.28$ & Greece & $6.46 \pm 1.22$ \\
\hline Spain & $5.42 \pm 0.96$ & Spain & $5.3 \pm 1.1$ & Spain & $6.25 \pm 0.6$ \\
\hline Lithuania & $5.03 \pm 1.97$ & Lithuania & $4.97 \pm 2.19$ & Croatia & $5.89 \pm 2.53$ \\
\hline Italy & $5 \pm 0.18$ & Italy & $4.93 \pm 0.16$ & Lithuania & $5.78 \pm 1.57$ \\
\hline Greece & $4.61 \pm 0.6$ & Greece & $3.46 \pm 0.32$ & Italy & $5.29 \pm 0.42$ \\
\hline France & $3.04 \pm 0.67$ & France & $2.5 \pm 0$ & France & $5 \pm 0.91$ \\
\hline Latvia & $2.5 \pm 0$ & Latvia & $2.5 \pm 0$ & Latvia & $2.5 \pm 0$ \\
\hline
\end{tabular}




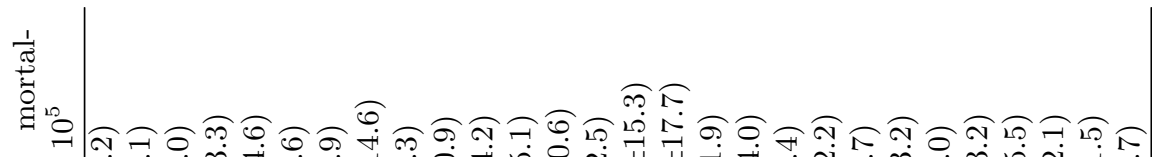

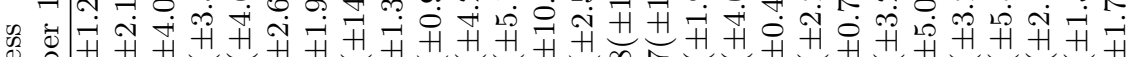

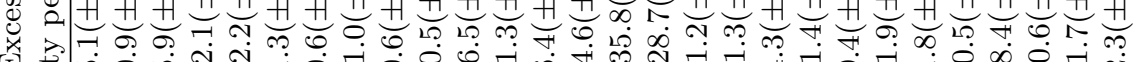
幽

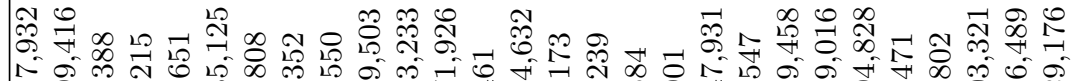

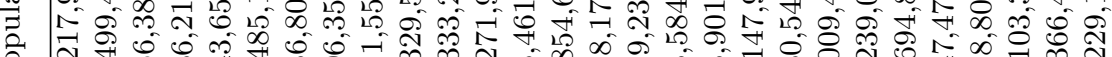
Oิ ন

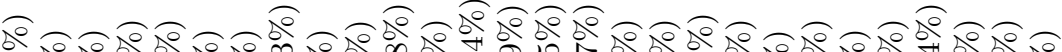

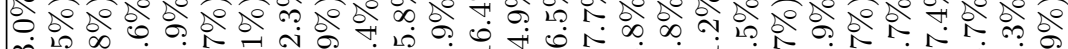

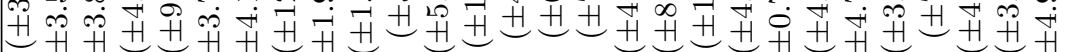
年

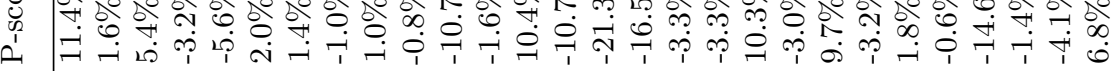

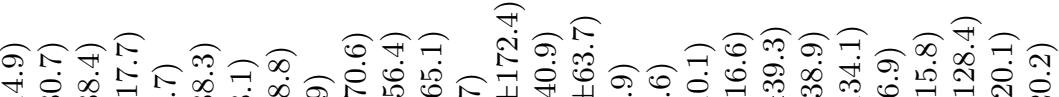

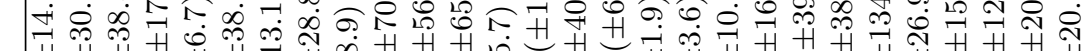

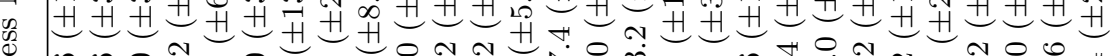
¿

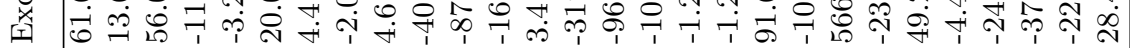

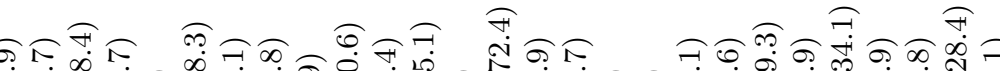

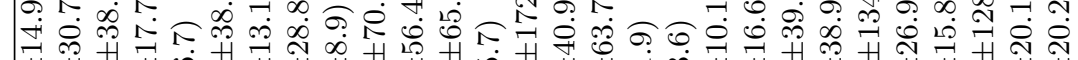

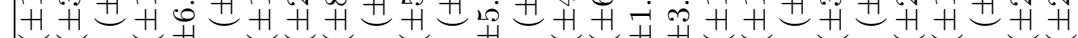

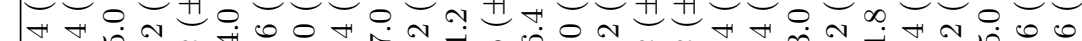

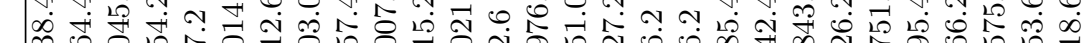
倍

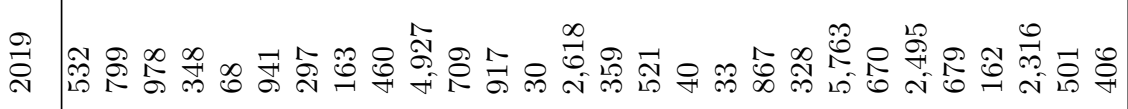

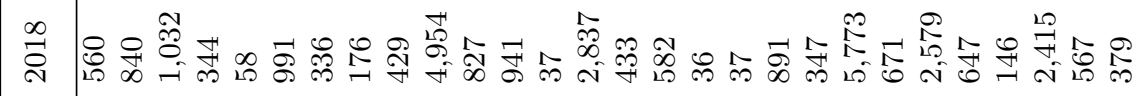

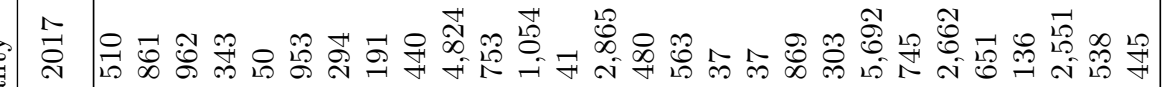

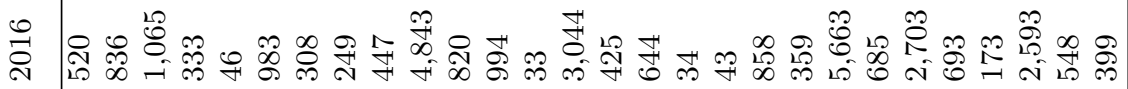

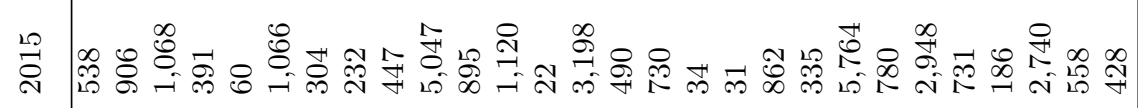

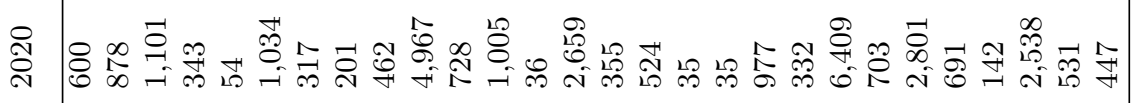

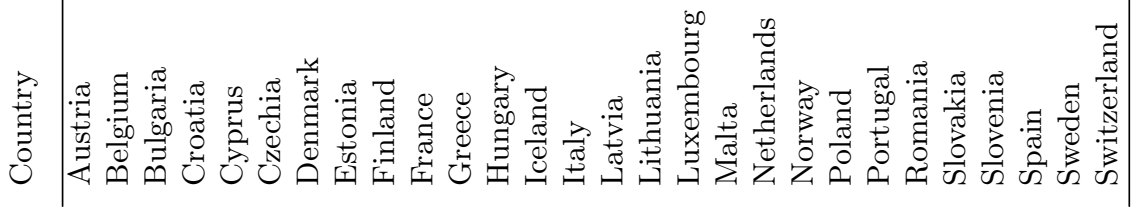


要

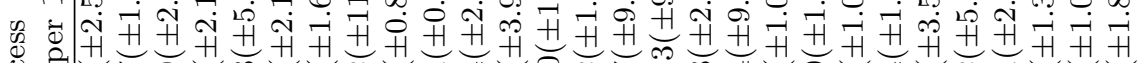

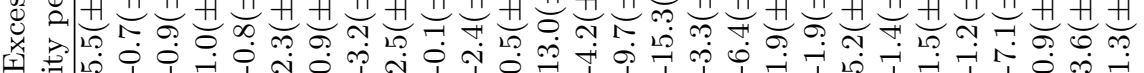

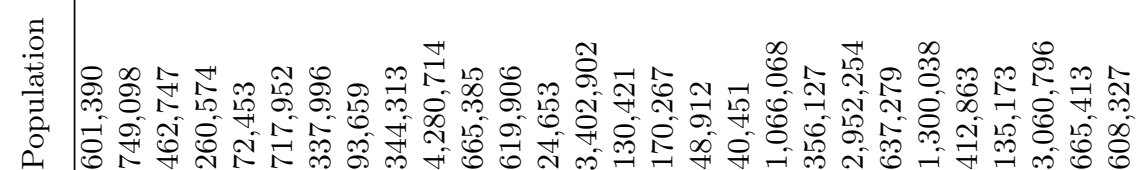

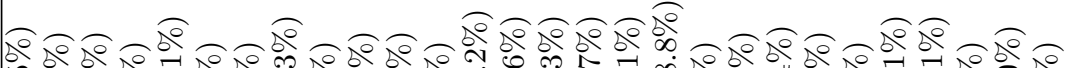
1.

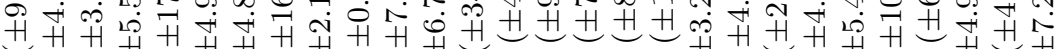
-

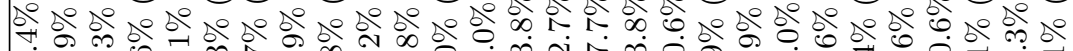

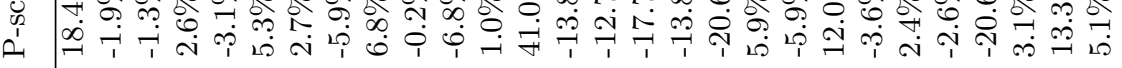

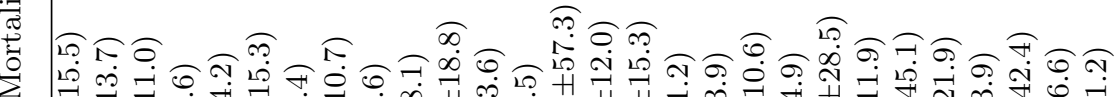

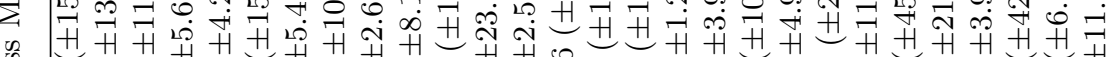

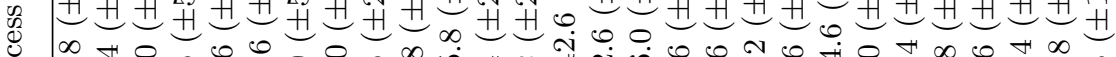

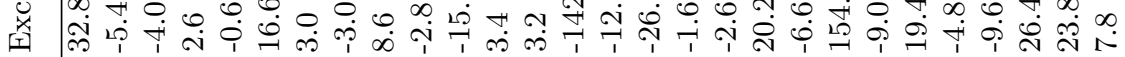

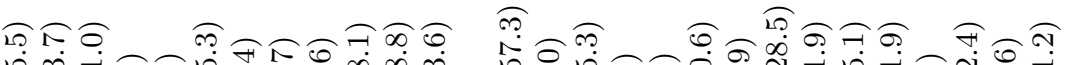

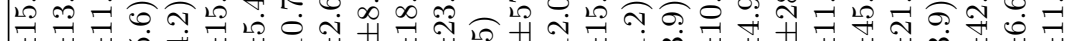

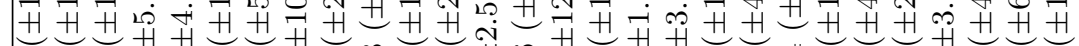

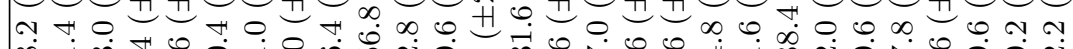

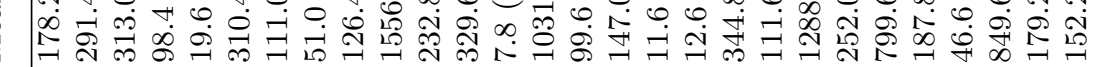

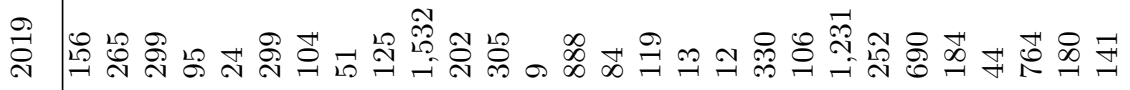

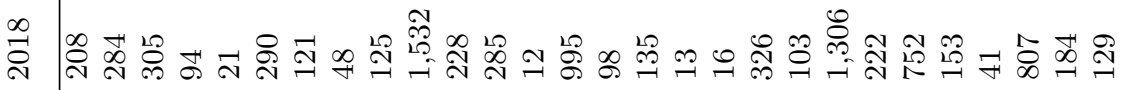
공

串 品 독 궁

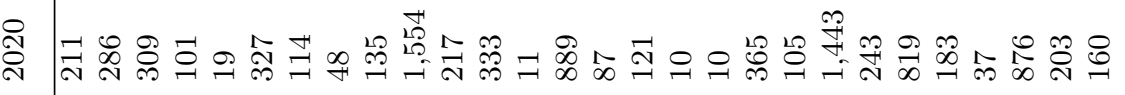

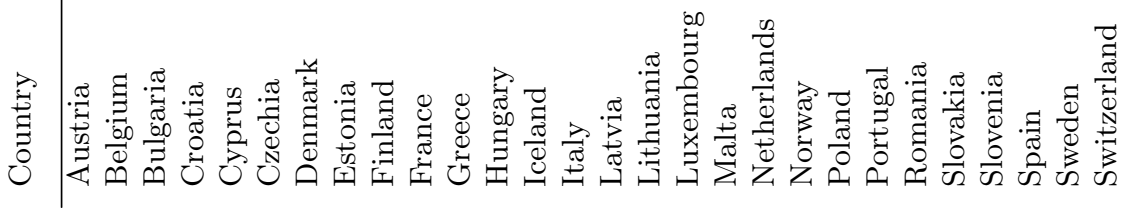




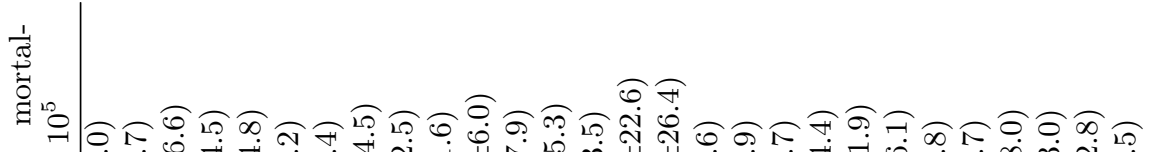

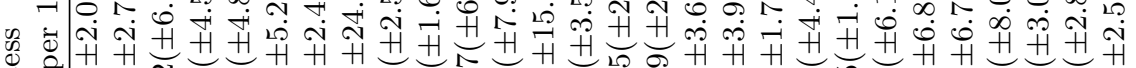

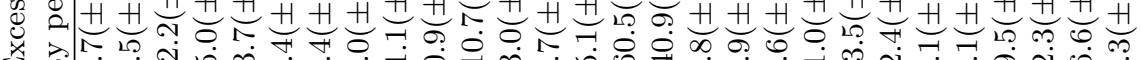

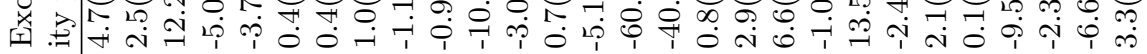

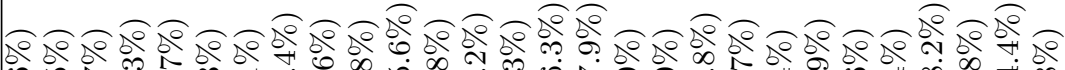

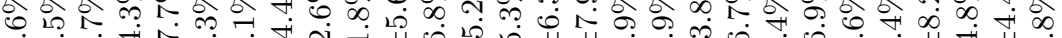

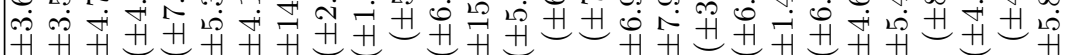
Het

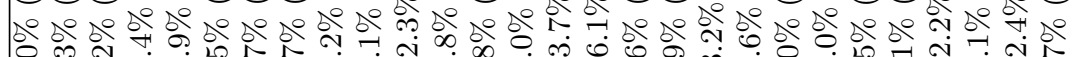
南

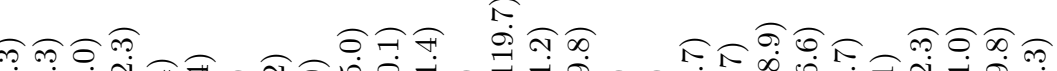
元

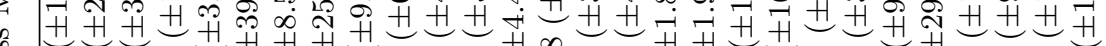
$\begin{array}{lllll}\infty & 0 & 0 & \infty & 0\end{array}$

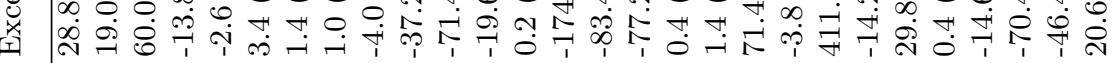

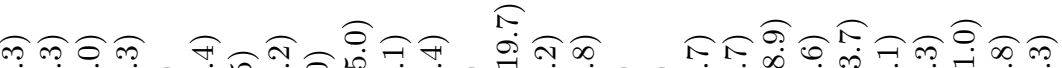
ป

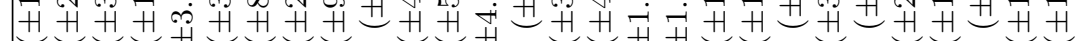

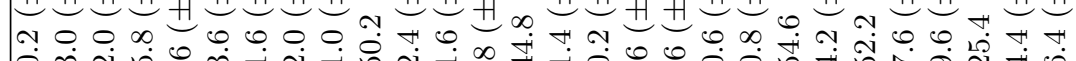
焉

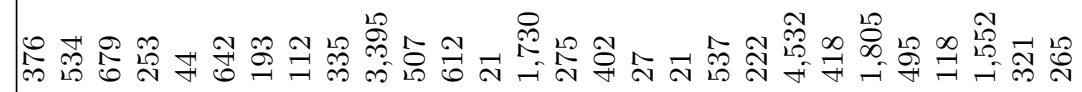

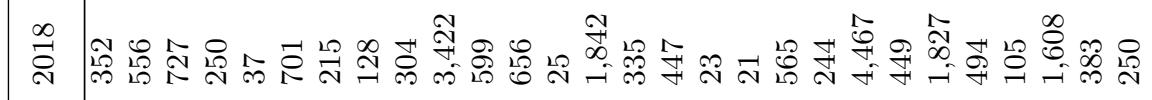

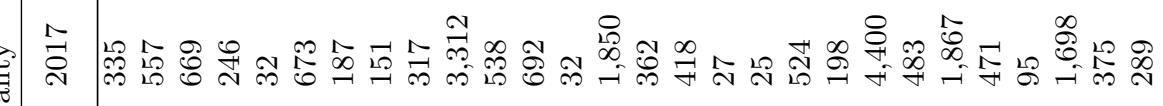

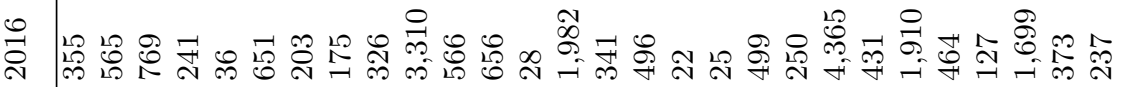
番

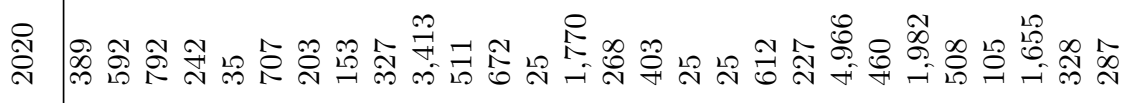

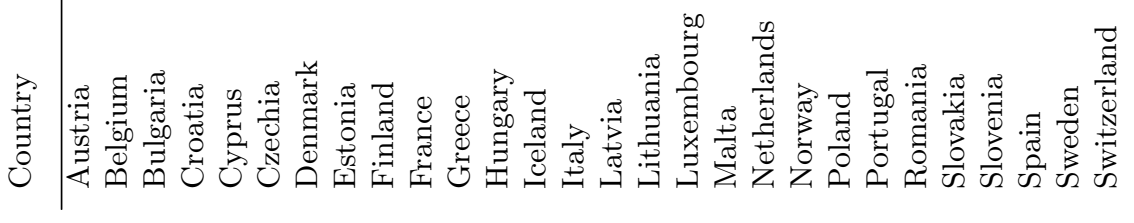


荡

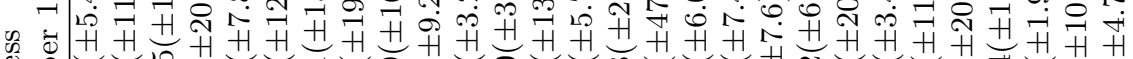
过

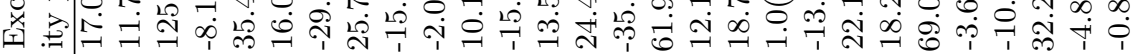

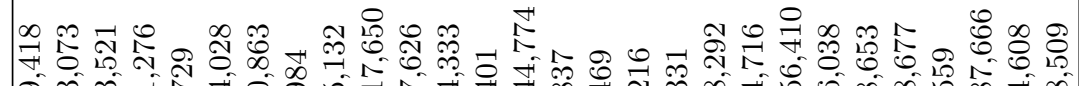

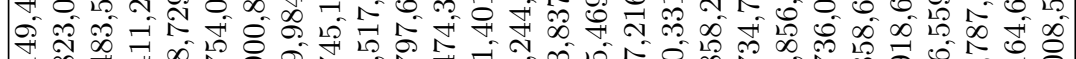

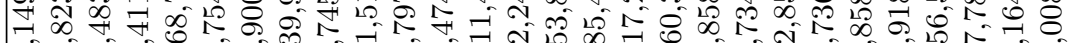

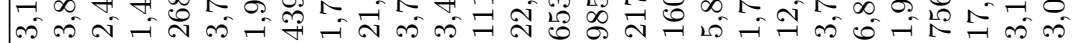

S可

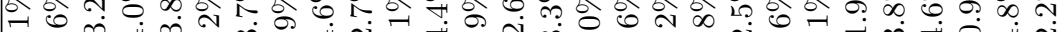

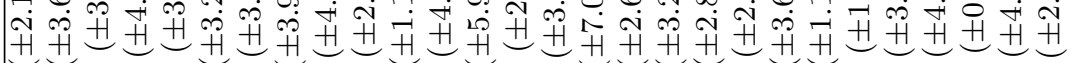
(4)

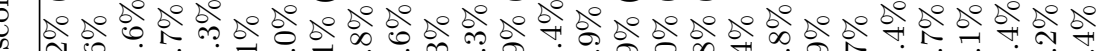

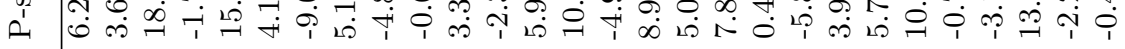

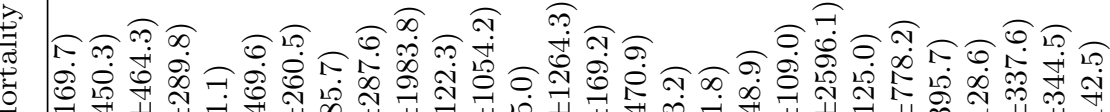

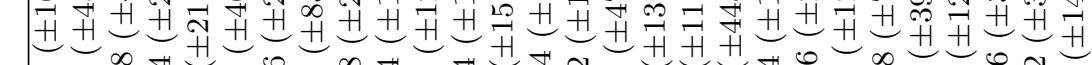

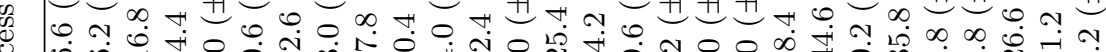

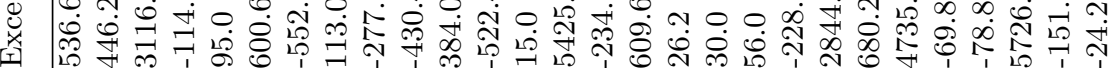

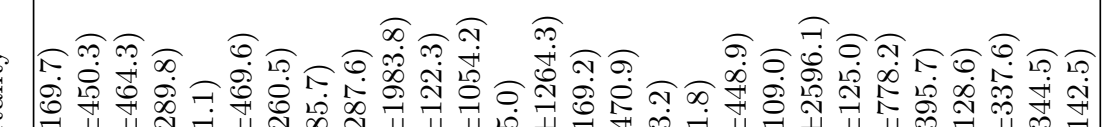
西

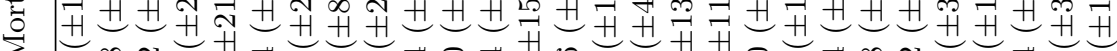

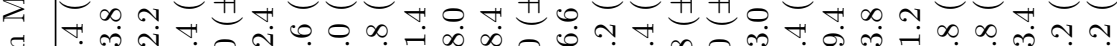
శ $\infty$

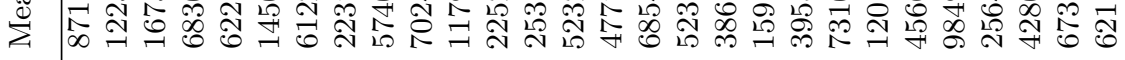

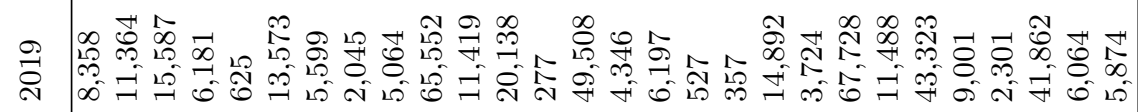

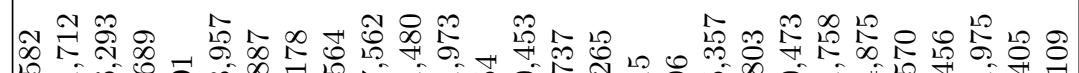

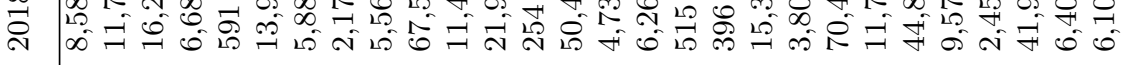

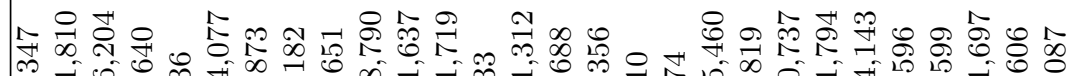

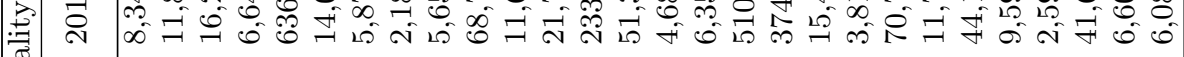

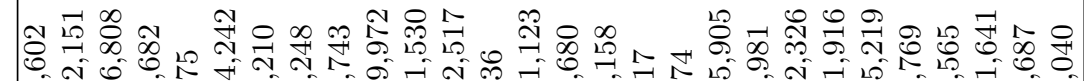

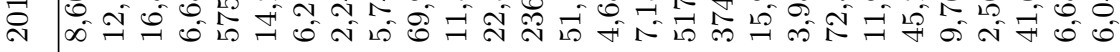

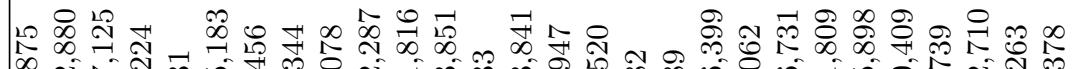

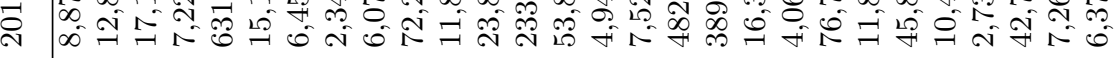
它

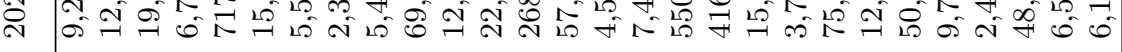

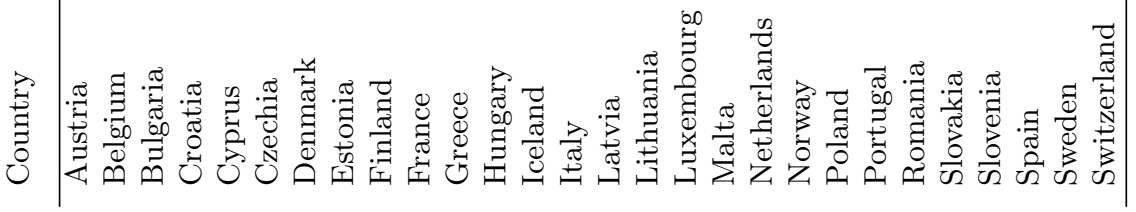




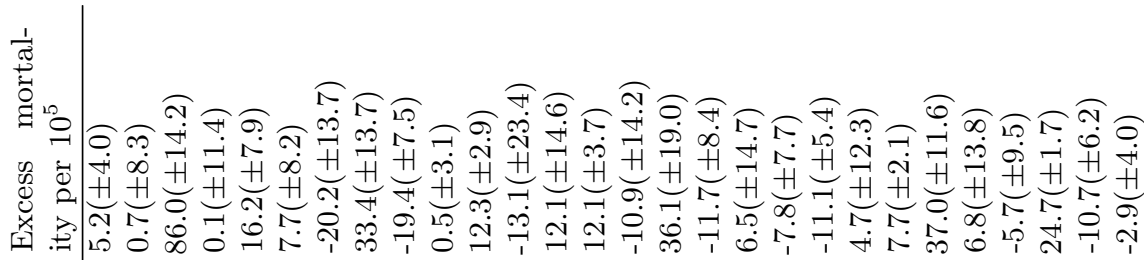

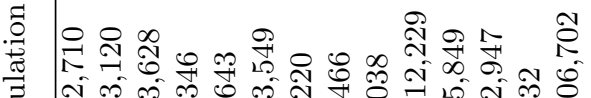

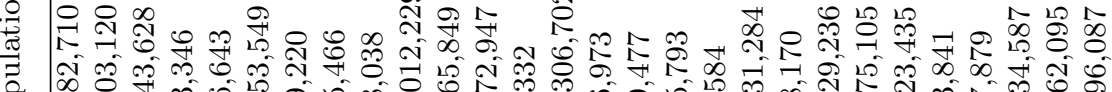
\%

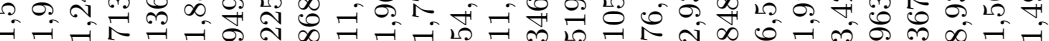

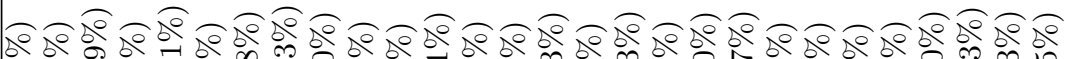
m

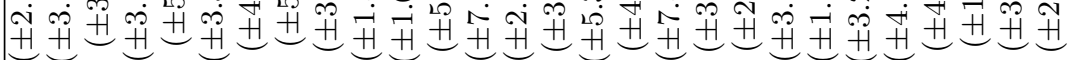

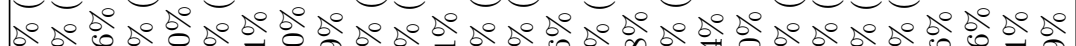
㨁 L

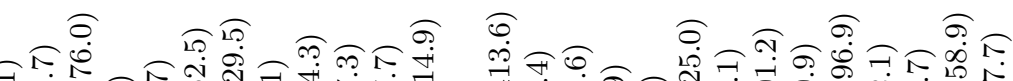

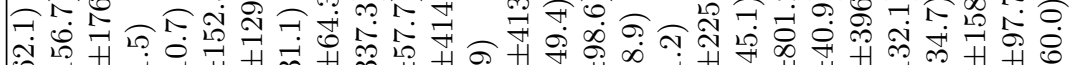

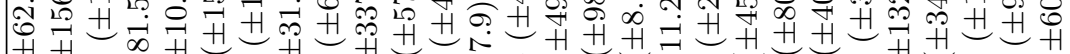

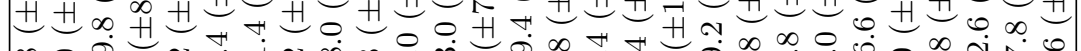

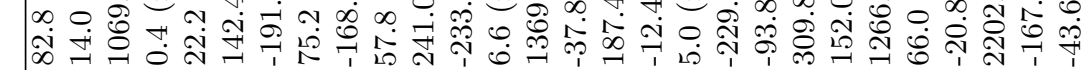

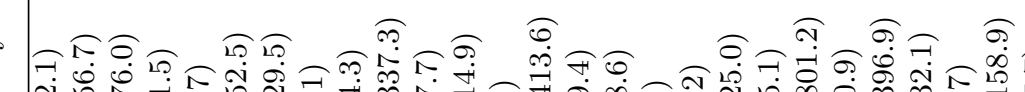
ก่

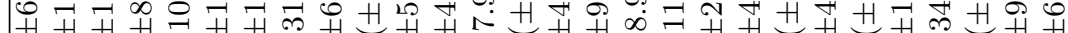

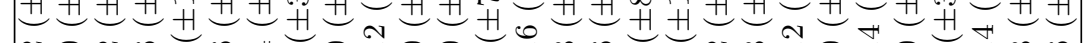

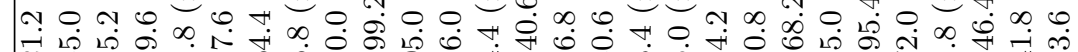

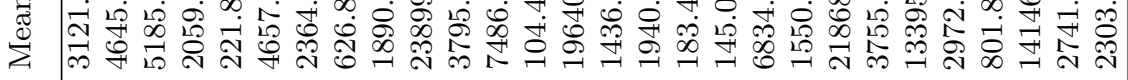

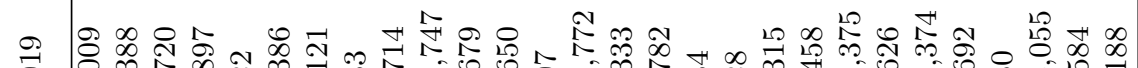

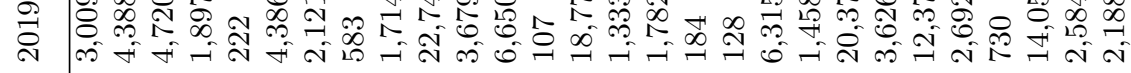

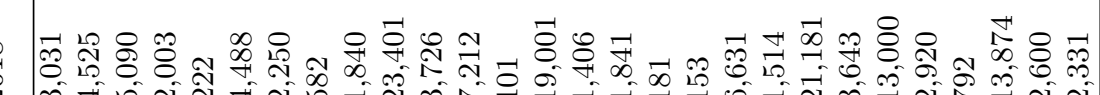
ลิ

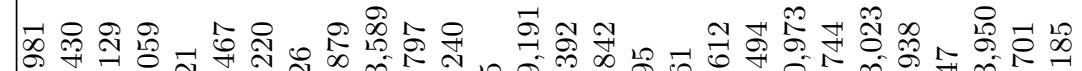
矛

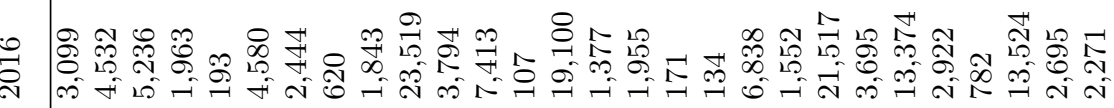

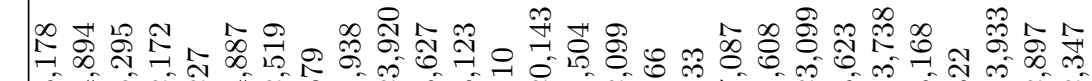

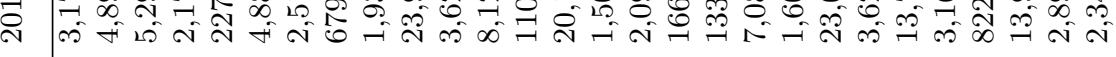

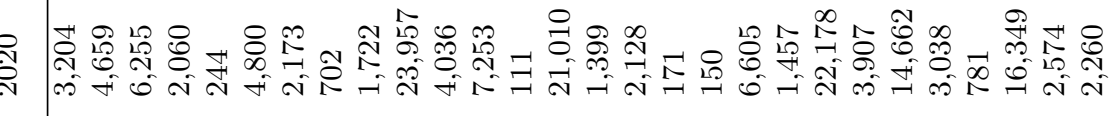

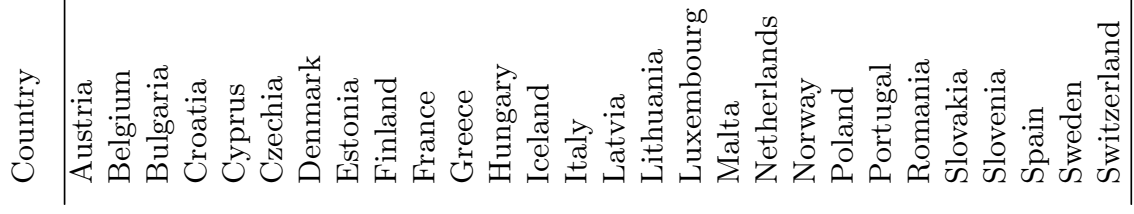




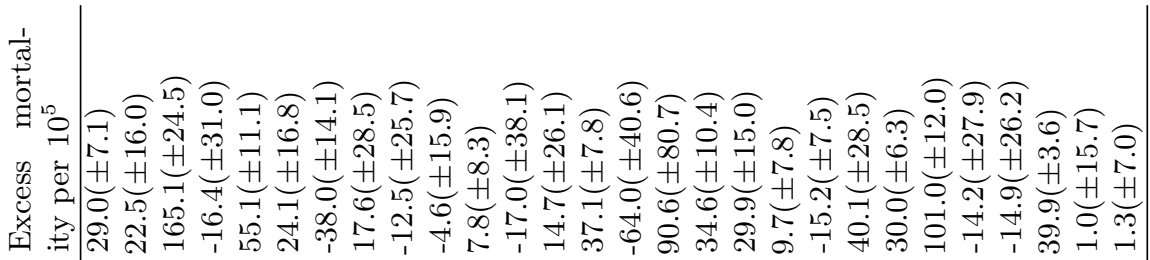

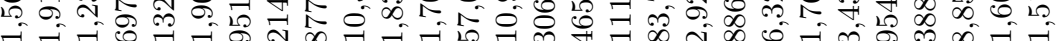

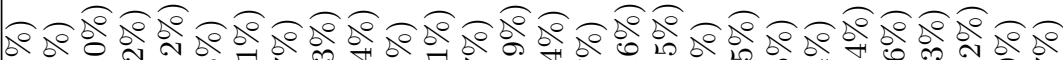
-

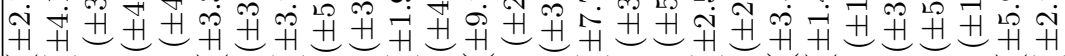

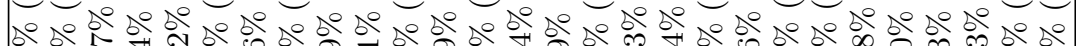

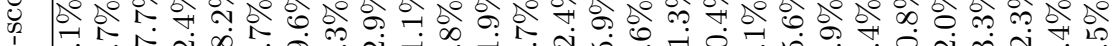

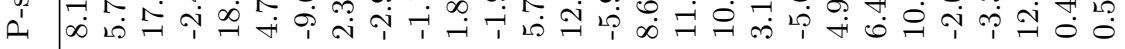

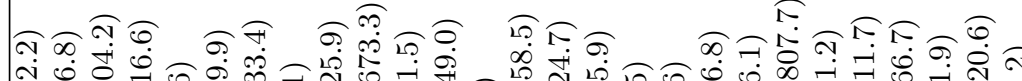

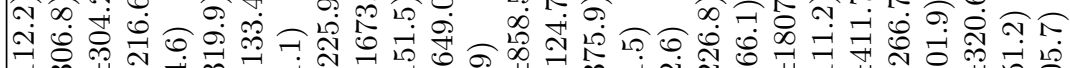

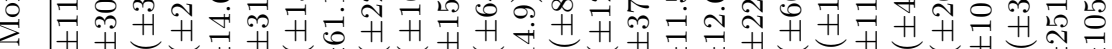

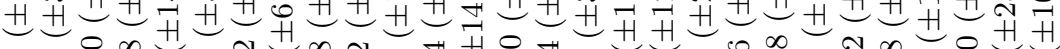

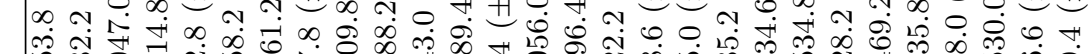

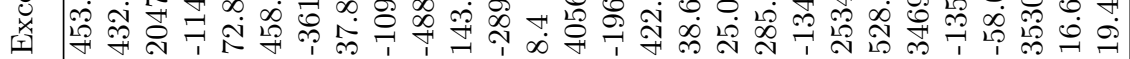

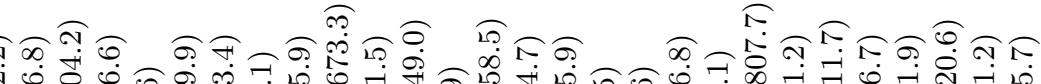

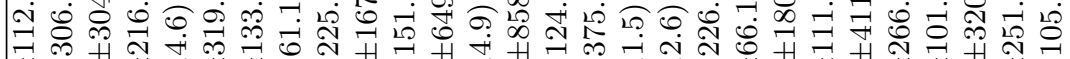

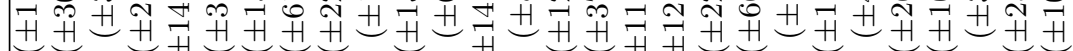

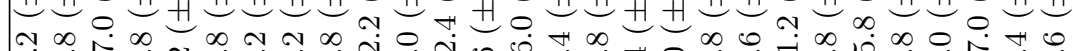

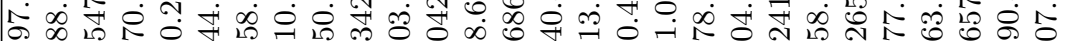

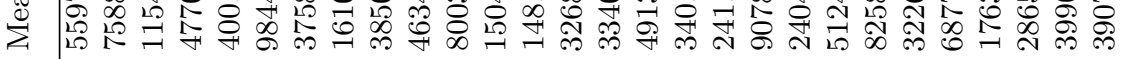

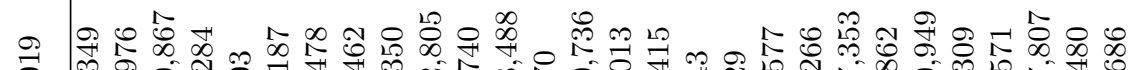

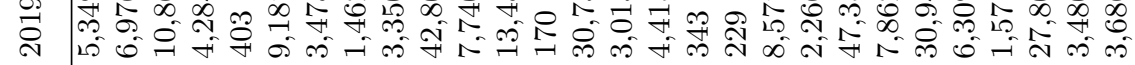

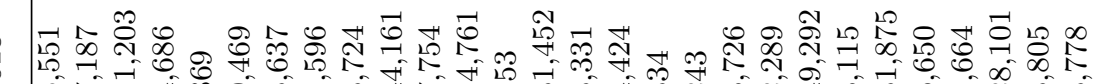
穴

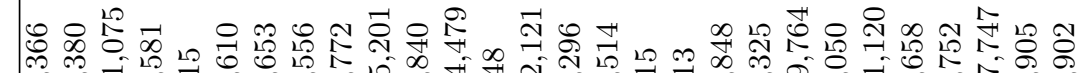

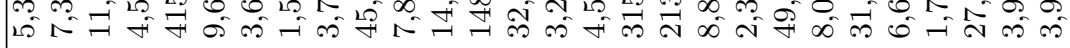

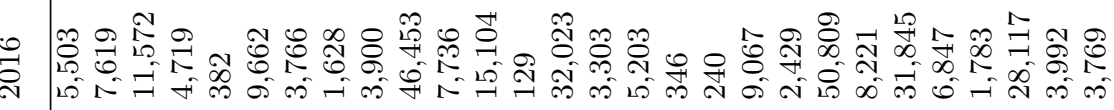

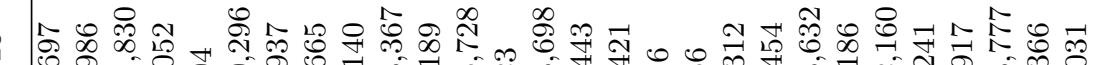

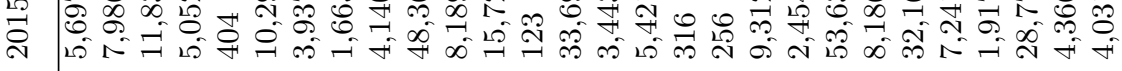

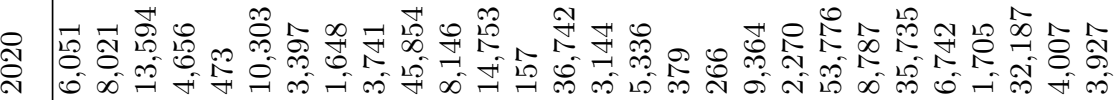

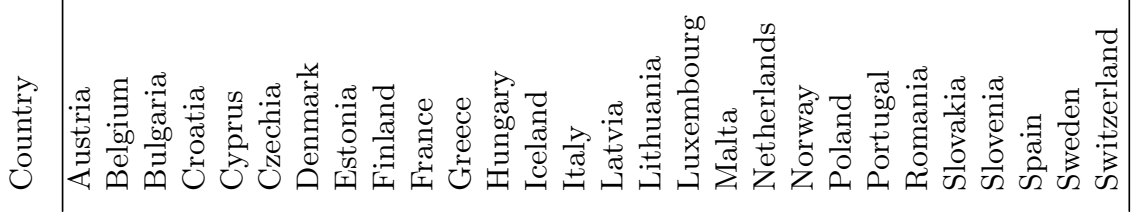




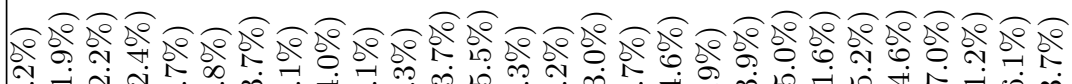

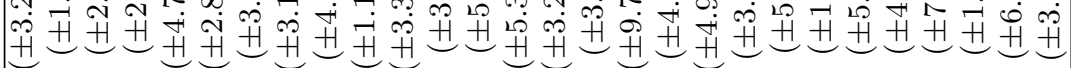
50 50 50 U

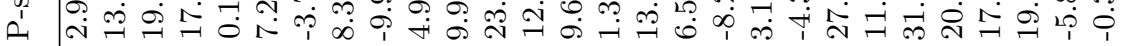

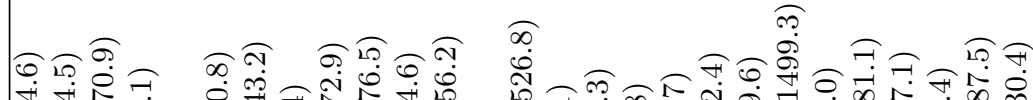

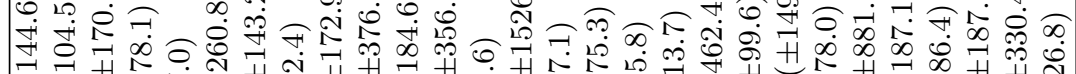

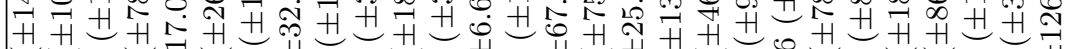

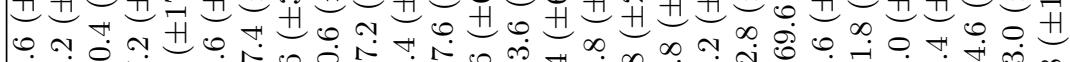

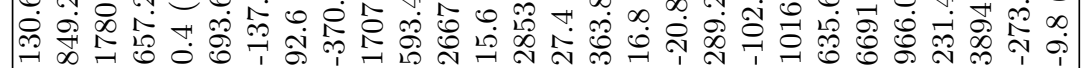

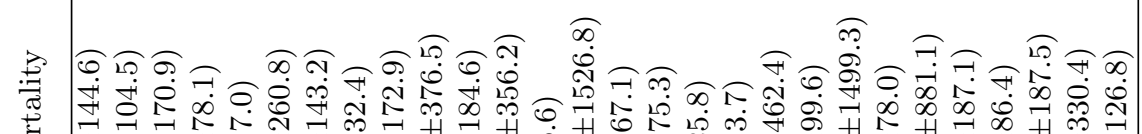

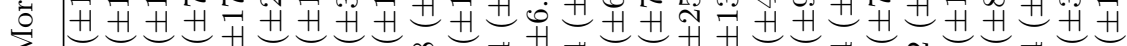

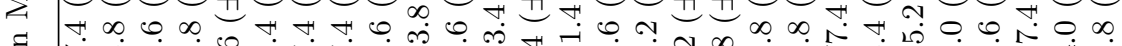

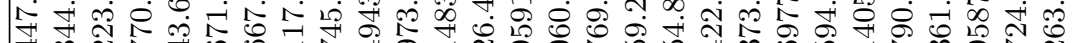

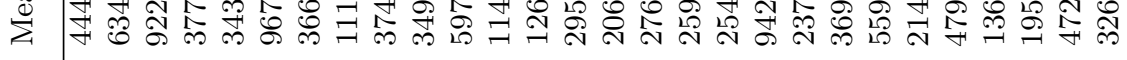

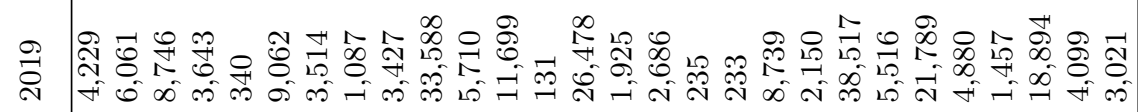

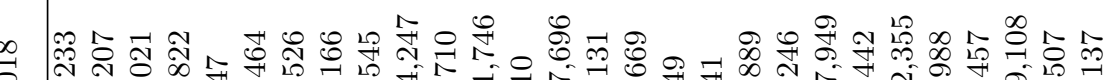

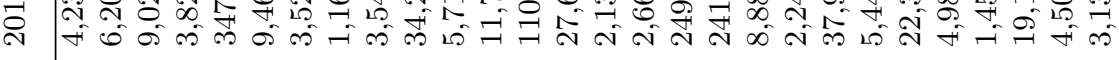

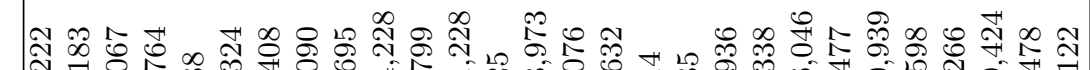

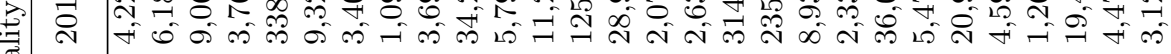

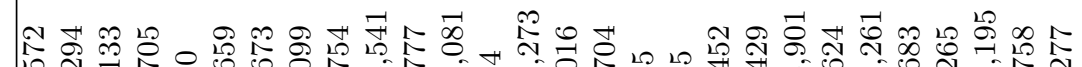
穴

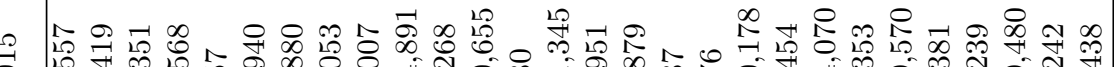
त

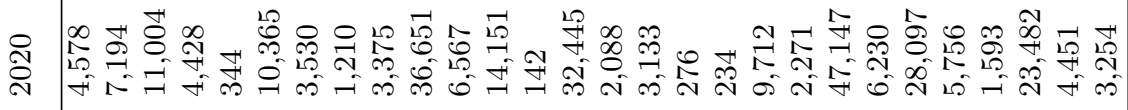

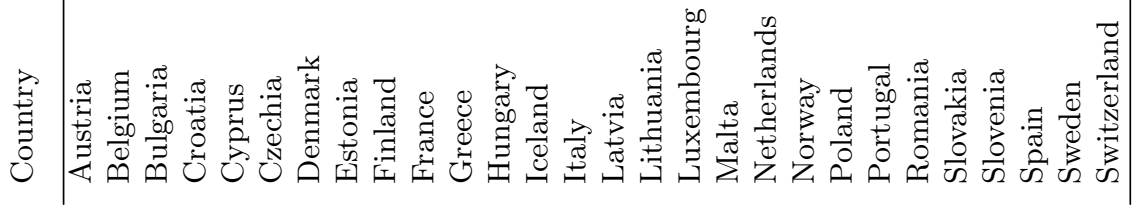




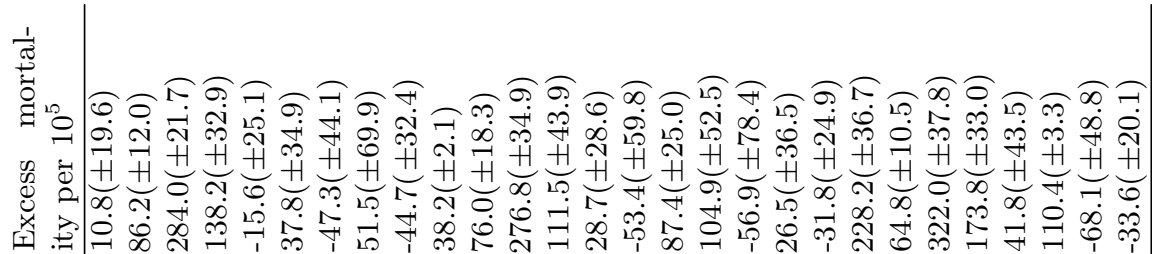

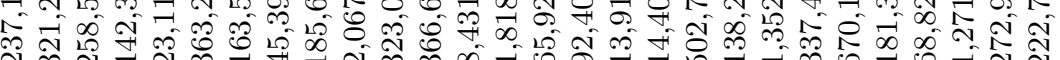

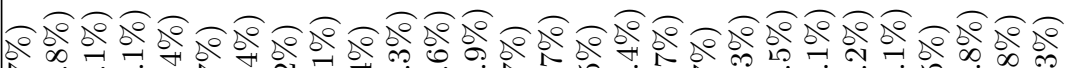
人,

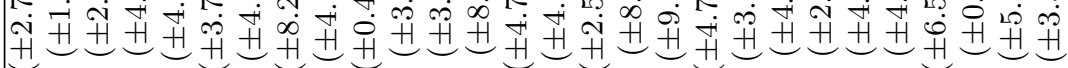

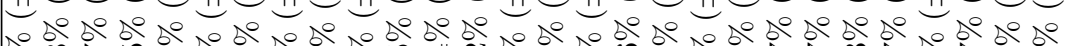

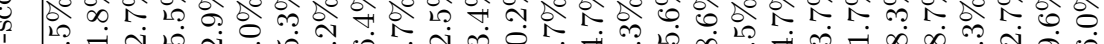

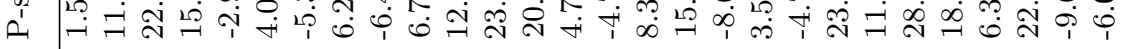

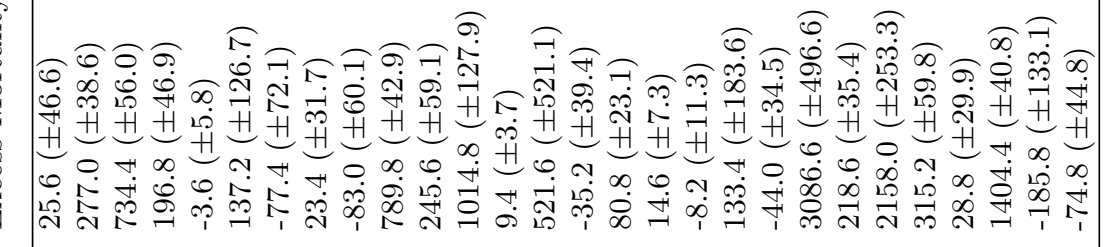

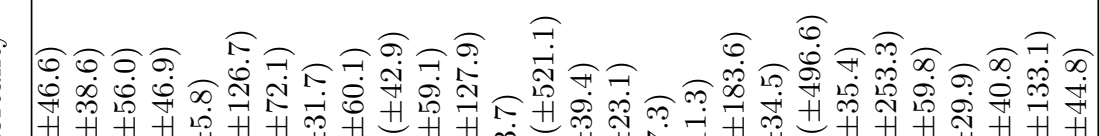

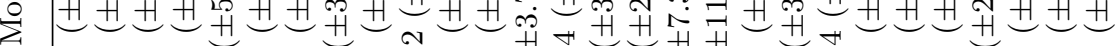

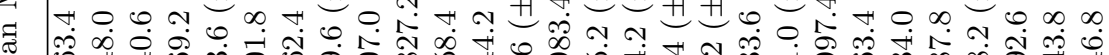
శ్

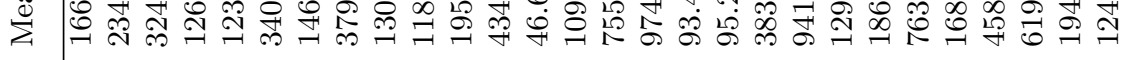

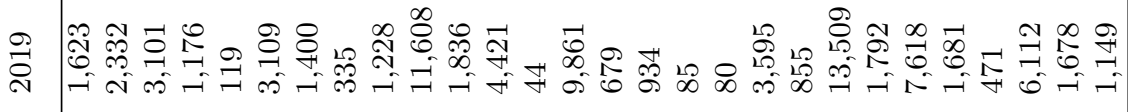

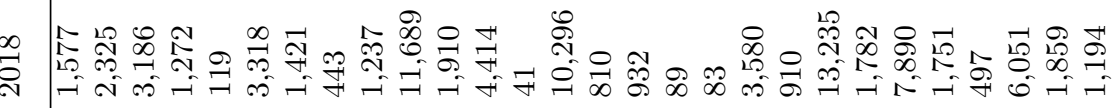

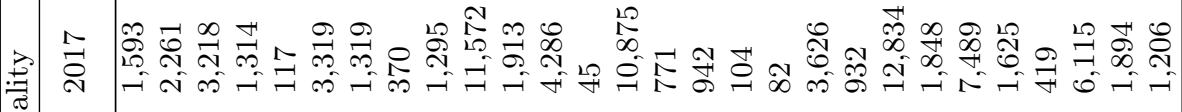

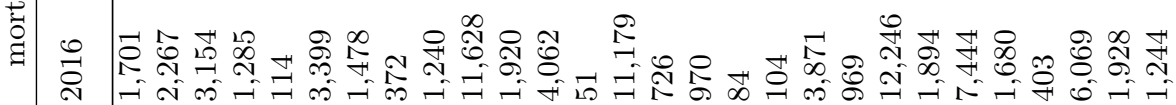

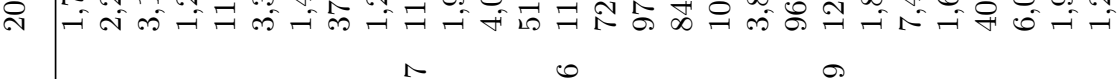
息

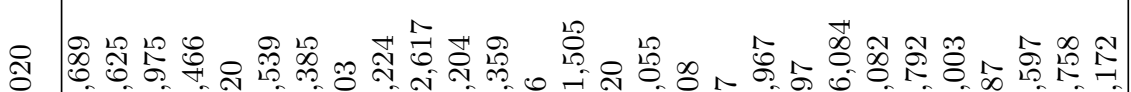
虫

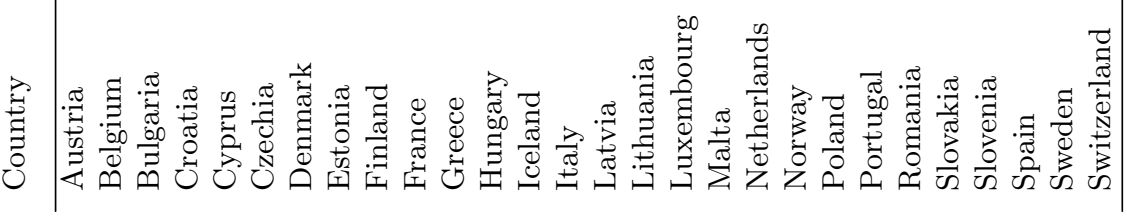




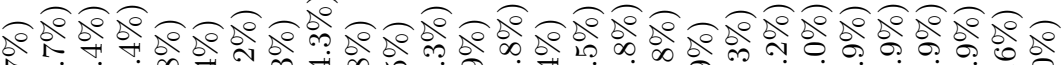

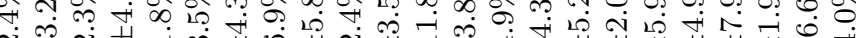

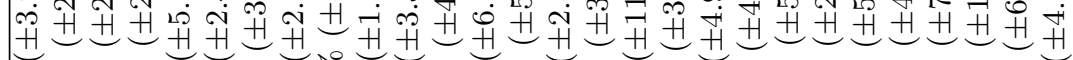

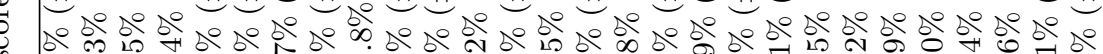

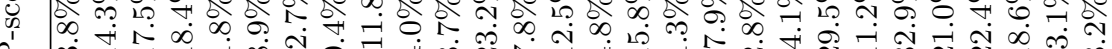
L

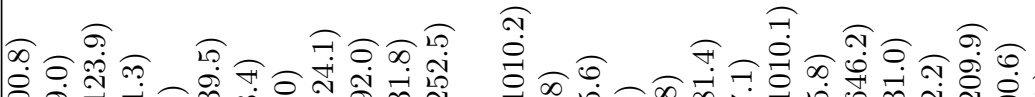

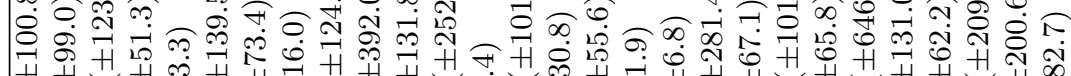

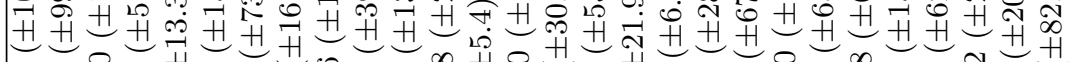

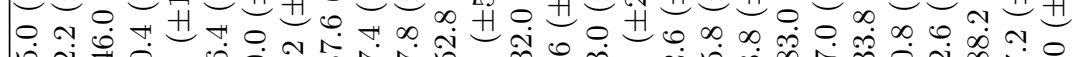

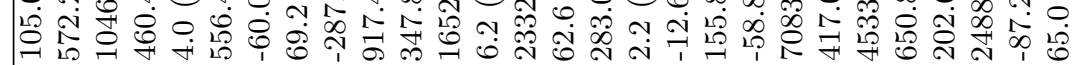

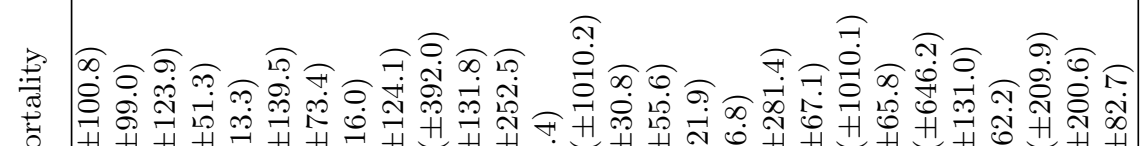

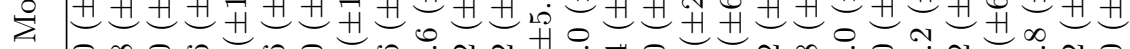

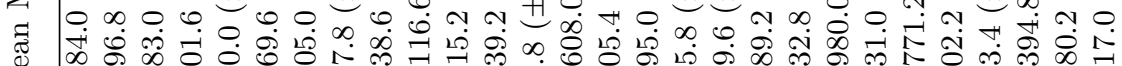

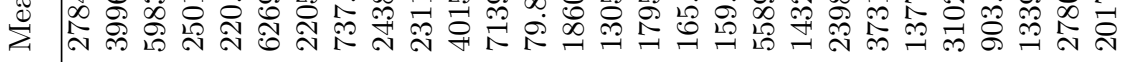

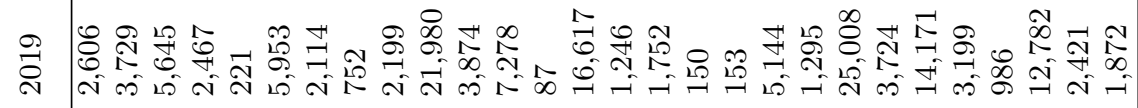

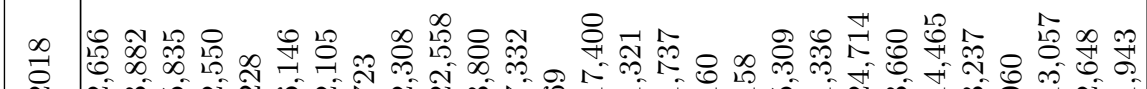
穴

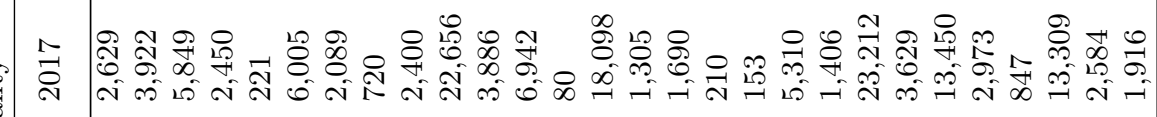

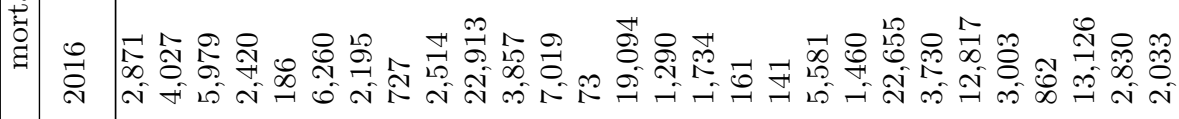
(1)

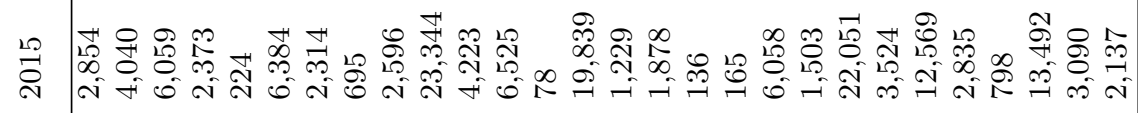
ก ส

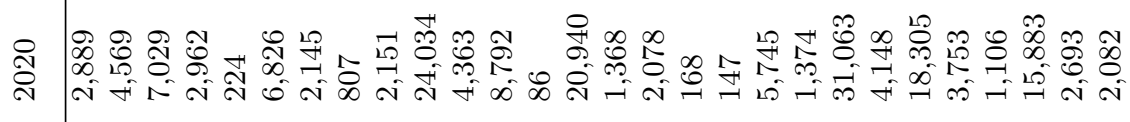

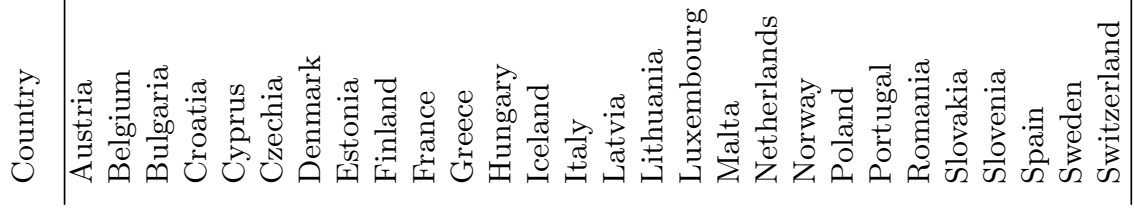




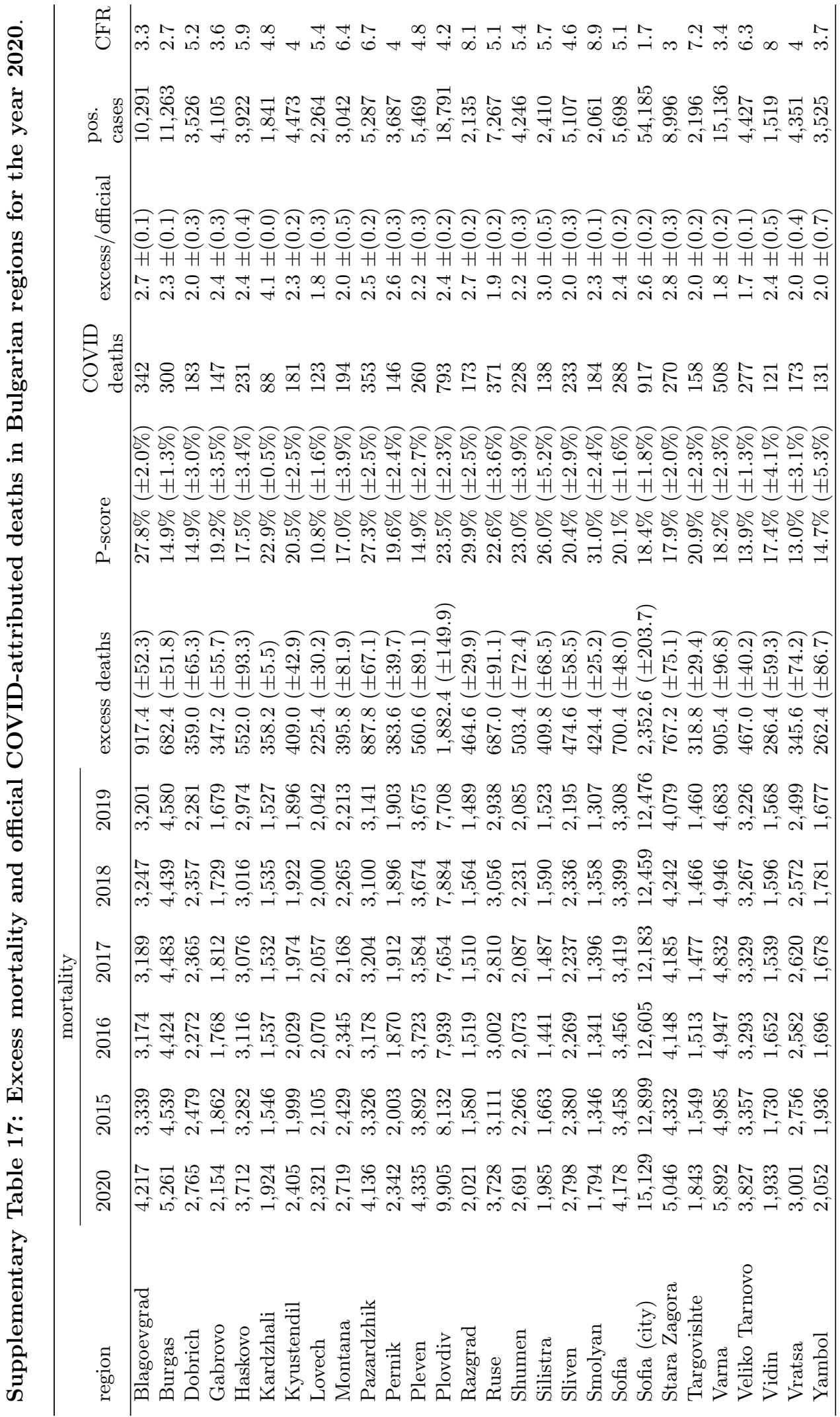


medRxiv preprint doi: https://doi.org/10.1101/2021.04.06.21254958; this version posted April 10, 2021. The copyright holder for this preprint (which was not certified by peer review) is the author/funder, who has granted medRxiv a license to display the preprint in perpetuity.

It is made available under a CC-BY-NC-ND 4.0 International license .

Supplementary Table 18: Excess mortality in Bulgarian regions for females ages 40-64 for the year 2020.

\begin{tabular}{|c|c|c|c|c|c|c|c|c|}
\hline \multirow[b]{2}{*}{ region } & \multicolumn{6}{|c|}{ mortality } & \multirow[b]{2}{*}{ excess deaths } & \multirow[b]{2}{*}{ P-score } \\
\hline & 2020 & 2015 & 2016 & 2017 & 2018 & 2019 & & \\
\hline Blagoevgrad & 281 & 187 & 169 & 181 & 194 & 178 & $96.8( \pm 7.4)$ & $52.6 \%( \pm 5.9 \%)$ \\
\hline Burgas & 356 & 302 & 300 & 270 & 288 & 299 & $59.4( \pm 10.4)$ & $20.0 \%( \pm 4.0 \%)$ \\
\hline Dobrich & 207 & 158 & 139 & 158 & 151 & 136 & $54.6( \pm 8.2)$ & $35.8 \%( \pm 6.9 \%)$ \\
\hline Gabrovo & 106 & 70 & 82 & 94 & 84 & 72 & $24.8( \pm 7.6)$ & $30.5 \%( \pm 11.1 \%)$ \\
\hline Haskovo & 207 & 172 & 187 & 151 & 141 & 168 & $40.8( \pm 14.2)$ & $24.5 \%( \pm 9.8 \%)$ \\
\hline Kardzhali & 113 & 89 & 93 & 79 & 73 & 79 & $30.4( \pm 6.4)$ & $36.8 \%( \pm 9.8 \%)$ \\
\hline Kyustendil & 143 & 113 & 116 & 95 & 102 & 91 & $38.8( \pm 8.6)$ & $37.2 \%( \pm 10.4 \%)$ \\
\hline Lovech & 120 & 99 & 93 & 105 & 102 & 92 & $20.2( \pm 4.4)$ & $20.2 \%( \pm 5.0 \%)$ \\
\hline Montana & 140 & 113 & 119 & 124 & 117 & 108 & $23.8( \pm 4.7)$ & $20.5 \%( \pm 4.7 \%)$ \\
\hline Pazardzhik & 273 & 192 & 183 & 201 & 198 & 196 & $76.6( \pm 5.4)$ & $39.0 \%( \pm 3.7 \%)$ \\
\hline Pernik & 141 & 121 & 94 & 103 & 99 & 112 & $31.2( \pm 8.4)$ & $28.4 \%( \pm 9.1 \%)$ \\
\hline Pleven & 217 & 189 & 205 & 181 & 191 & 164 & $27.8( \pm 11.7)$ & $14.7 \%( \pm 6.7 \%)$ \\
\hline Plovdiv & 561 & 441 & 484 & 428 & 419 & 388 & $122.6( \pm 27.4)$ & $28.0 \%( \pm 7.6 \%)$ \\
\hline Razgrad & 125 & 103 & 102 & 110 & 77 & 73 & $28.8( \pm 13.1)$ & $29.9 \%( \pm 15.5 \%)$ \\
\hline Ruse & 185 & 176 & 166 & 160 & 179 & 159 & $13.8( \pm 7.2)$ & $8.1 \%( \pm 4.4 \%)$ \\
\hline Shumen & 190 & 170 & 133 & 158 & 132 & 127 & $42.0( \pm 14.8)$ & $28.4 \%( \pm 11.7 \%)$ \\
\hline Silistra & 130 & 97 & 72 & 96 & 85 & 73 & $43.8( \pm 9.4)$ & $50.8 \%( \pm 14.8 \%)$ \\
\hline Sliven & 204 & 177 & 148 & 175 & 145 & 141 & $42.8( \pm 13.6)$ & $26.6 \%( \pm 9.9 \%)$ \\
\hline Smolyan & 90 & 90 & 66 & 66 & 78 & 74 & $14.4( \pm 7.8)$ & $19.0 \%( \pm 11.1 \%)$ \\
\hline Sofia & 215 & 175 & 221 & 182 & 210 & 175 & $19.2( \pm 16.8)$ & $9.8 \%( \pm 8.7 \%)$ \\
\hline Sofia (stolitsa) & 907 & 871 & 888 & 856 & 884 & 760 & $37.6( \pm 41.4)$ & $4.3 \%( \pm 4.7 \%)$ \\
\hline Stara Zagora & 292 & 260 & 267 & 243 & 240 & 215 & $43.0( \pm 15.9)$ & $17.3 \%( \pm 7.1 \%)$ \\
\hline Targovishte & 132 & 89 & 98 & 82 & 98 & 101 & $35.2( \pm 6.2)$ & $36.4 \%( \pm 8.2 \%)$ \\
\hline Varna & 372 & 306 & 312 & 304 & 304 & 273 & $66.6( \pm 12.0)$ & $21.8 \%( \pm 4.6 \%)$ \\
\hline Veliko Tarnovo & 180 & 184 & 174 & 190 & 181 & 172 & $-3.4( \pm 5.8)$ & $-1.9 \%( \pm 3.0 \%)$ \\
\hline Vidin & 79 & 73 & 77 & 79 & 70 & 83 & $2.6( \pm 3.9)$ & $3.4 \%( \pm 5.0 \%)$ \\
\hline Vratsa & 170 & 164 & 168 & 165 & 156 & 130 & $10.2( \pm 12.2)$ & $6.4 \%( \pm 7.6 \%)$ \\
\hline Yambol & 119 & 114 & 80 & 93 & 92 & 81 & $25.4( \pm 10.7)$ & $27.1 \%( \pm 13.0 \%)$ \\
\hline
\end{tabular}


medRxiv preprint doi: https://doi.org/10.1101/2021.04.06.21254958; this version posted April 10, 2021. The copyright holder for this preprint (which was not certified by peer review) is the author/funder, who has granted medRxiv a license to display the preprint in perpetuity.

It is made available under a CC-BY-NC-ND 4.0 International license .

Supplementary Table 19: Excess mortality in Bulgarian regions for males ages 40-64 for the year 2020.

\begin{tabular}{|c|c|c|c|c|c|c|c|c|}
\hline \multirow[b]{2}{*}{ region } & \multicolumn{6}{|c|}{ mortality } & \multirow[b]{2}{*}{ excess deaths } & \multirow[b]{2}{*}{ P-score } \\
\hline & 2020 & 2015 & 2016 & 2017 & 2018 & 2019 & & \\
\hline Blagoevgrad & 597 & 508 & 476 & 487 & 471 & 451 & $108.8( \pm 16.5)$ & $22.3 \%( \pm 4.0 \%)$ \\
\hline Burgas & 720 & 679 & 610 & 621 & 633 & 640 & $69.0( \pm 20.7)$ & $10.6 \%( \pm 3.4 \%)$ \\
\hline Dobrich & 395 & 378 & 356 & 347 & 320 & 327 & $42.2( \pm 18.2)$ & $12.0 \%( \pm 5.5 \%)$ \\
\hline Gabrovo & 246 & 214 & 180 & 185 & 163 & 191 & $53.0( \pm 14.6)$ & $27.5 \%( \pm 9.0 \%)$ \\
\hline Haskovo & 477 & 431 & 395 & 392 & 410 & 388 & $61.0( \pm 13.8)$ & $14.7 \%( \pm 3.7 \%)$ \\
\hline Kardzhali & 228 & 205 & 216 & 201 & 219 & 203 & $13.6( \pm 6.4)$ & $6.3 \%( \pm 3.0 \%)$ \\
\hline Kyustendil & 311 & 268 & 268 & 258 & 260 & 267 & $41.2( \pm 3.8)$ & $15.3 \%( \pm 1.6 \%)$ \\
\hline Lovech & 264 & 255 & 273 & 229 & 229 & 227 & $15.0( \pm 16.1)$ & $6.0 \%( \pm 6.4 \%)$ \\
\hline Montana & 325 & 252 & 308 & 249 & 250 & 260 & $57.2( \pm 19.6)$ & $21.4 \%( \pm 8.3 \%)$ \\
\hline Pazardzhik & 595 & 480 & 418 & 444 & 416 & 422 & $147.8( \pm 21.2)$ & $33.1 \%( \pm 6.1 \%)$ \\
\hline Pernik & 305 & 265 & 260 & 256 & 279 & 241 & $40.0( \pm 10.9)$ & $15.1 \%( \pm 4.6 \%)$ \\
\hline Pleven & 486 & 432 & 424 & 379 & 428 & 409 & $69.2( \pm 16.9)$ & $16.6 \%( \pm 4.5 \%)$ \\
\hline Plovdiv & 1218 & 1056 & 1069 & 937 & 1052 & 952 & $184.0( \pm 49.6)$ & $17.8 \%( \pm 5.4 \%)$ \\
\hline Razgrad & 276 & 224 & 225 & 259 & 210 & 196 & $50.8( \pm 18.4)$ & $22.6 \%( \pm 9.3 \%)$ \\
\hline Ruse & 461 & 372 & 387 & 367 & 368 & 358 & $77.8( \pm 8.3)$ & $20.3 \%( \pm 2.5 \%)$ \\
\hline Shumen & 361 & 328 & 299 & 260 & 323 & 304 & $53.4( \pm 21.0)$ & $17.4 \%( \pm 7.5 \%)$ \\
\hline Silistra & 269 & 244 & 207 & 225 & 213 & 207 & $43.4( \pm 12.3)$ & $19.2 \%( \pm 6.1 \%)$ \\
\hline Sliven & 355 & 292 & 342 & 340 & 308 & 296 & $35.4( \pm 18.8)$ & $11.1 \%( \pm 6.2 \%)$ \\
\hline Smolyan & 241 & 201 & 172 & 190 & 188 & 195 & $50.2( \pm 8.5)$ & $26.3 \%( \pm 5.4 \%)$ \\
\hline Sofia & 589 & 463 & 464 & 470 & 459 & 426 & $126.2( \pm 13.7)$ & $27.3 \%( \pm 3.7 \%)$ \\
\hline Sofia (stolitsa) & 1885 & 1680 & 1550 & 1566 & 1512 & 1516 & $286.6( \pm 53.6)$ & $17.9 \%( \pm 3.8 \%)$ \\
\hline Stara Zagora & 646 & 534 & 597 & 483 & 536 & 503 & $98.6( \pm 33.9)$ & $18.0 \%( \pm 6.9 \%)$ \\
\hline Targovishte & 231 & 209 & 199 & 187 & 190 & 199 & $28.6( \pm 6.8)$ & $14.1 \%( \pm 3.7 \%)$ \\
\hline Varna & 778 & 688 & 698 & 640 & 632 & 631 & $110.6( \pm 25.5)$ & $16.6 \%( \pm 4.3 \%)$ \\
\hline Veliko Tarnovo & 465 & 417 & 420 & 405 & 404 & 366 & $49.8( \pm 16.9)$ & $12.0 \%( \pm 4.4 \%)$ \\
\hline Vidin & 202 & 179 & 169 & 161 & 181 & 175 & $25.8( \pm 6.4)$ & $14.6 \%( \pm 4.0 \%)$ \\
\hline Vratsa & 418 & 355 & 362 & 321 & 310 & 314 & $83.2( \pm 19.0)$ & $24.9 \%( \pm 6.8 \%)$ \\
\hline Yambol & 250 & 221 & 228 & 216 & 239 & 203 & $24.6( \pm 10.5)$ & $10.9 \%( \pm 4.9 \%)$ \\
\hline
\end{tabular}


medRxiv preprint doi: https://doi.org/10.1101/2021.04.06.21254958; this version posted April 10, 2021. The copyright holder for this preprint (which was not certified by peer review) is the author/funder, who has granted medRxiv a license to display the preprint in perpetuity.

It is made available under a CC-BY-NC-ND 4.0 International license .

Supplementary Table 20: Excess mortality in Bulgarian regions for females ages 65-69 for the year 2020.

\begin{tabular}{|c|c|c|c|c|c|c|c|c|}
\hline \multirow[b]{2}{*}{ region } & \multicolumn{6}{|c|}{ mortality } & \multirow[b]{2}{*}{ excess deaths } & \multirow[b]{2}{*}{ P-score } \\
\hline & 2020 & 2015 & 2016 & 2017 & 2018 & 2019 & & \\
\hline Blagoevgrad & 157 & 106 & 101 & 97 & 115 & 106 & $48.8( \pm 5.3)$ & $45.1 \%( \pm 6.8 \%)$ \\
\hline Burgas & 194 & 187 & 154 & 171 & 163 & 171 & $24.0( \pm 9.6)$ & $14.1 \%( \pm 6.1 \%)$ \\
\hline Dobrich & 123 & 103 & 116 & 91 & 106 & 85 & $22.8( \pm 9.6)$ & $22.8 \%( \pm 10.8 \%)$ \\
\hline Gabrovo & 70 & 77 & 67 & 71 & 54 & 65 & $3.2( \pm 6.7)$ & $4.8 \%( \pm 9.6 \%)$ \\
\hline Haskovo & 140 & 124 & 91 & 102 & 102 & 105 & $32.8( \pm 9.4)$ & $30.6 \%( \pm 10.5 \%)$ \\
\hline Kardzhali & 78 & 51 & 56 & 59 & 48 & 54 & $24.4( \pm 3.3)$ & $45.5 \%( \pm 8.4 \%)$ \\
\hline Kyustendil & 82 & 66 & 66 & 63 & 69 & 51 & $19.0( \pm 5.5)$ & $30.2 \%( \pm 10.5 \%)$ \\
\hline Lovech & 63 & 85 & 61 & 52 & 82 & 71 & $-9.6( \pm 10.9)$ & $-13.2 \%( \pm 11.4 \%)$ \\
\hline Montana & 100 & 72 & 69 & 81 & 83 & 80 & $22.2( \pm 4.8)$ & $28.5 \%( \pm 7.4 \%)$ \\
\hline Pazardzhik & 166 & 124 & 113 & 110 & 106 & 110 & $50.2( \pm 5.3)$ & $43.4 \%( \pm 6.3 \%)$ \\
\hline Pernik & 68 & 62 & 77 & 73 & 68 & 62 & $-1.2( \pm 5.3)$ & $-1.7 \%( \pm 7.0 \%)$ \\
\hline Pleven & 149 & 137 & 115 & 150 & 133 & 107 & $17.4( \pm 13.6)$ & $13.2 \%( \pm 10.6 \%)$ \\
\hline Plovdiv & 331 & 264 & 270 & 281 & 254 & 244 & $64.4( \pm 11.2)$ & $24.2 \%( \pm 5.0 \%)$ \\
\hline Razgrad & 70 & 60 & 77 & 58 & 54 & 70 & $6.2( \pm 7.4)$ & $9.7 \%( \pm 11.4 \%)$ \\
\hline Ruse & 120 & 101 & 109 & 103 & 112 & 99 & $12.0( \pm 4.3)$ & $11.1 \%( \pm 4.2 \%)$ \\
\hline Shumen & 115 & 108 & 77 & 101 & 76 & 82 & $25.4( \pm 11.6)$ & $28.3 \%( \pm 14.7 \%)$ \\
\hline Silistra & 78 & 73 & 50 & 65 & 56 & 54 & $17.6( \pm 7.3)$ & $29.1 \%( \pm 13.9 \%)$ \\
\hline Sliven & 145 & 79 & 86 & 77 & 91 & 76 & $62.4( \pm 5.1)$ & $75.5 \%( \pm 10.2 \%)$ \\
\hline Smolyan & 65 & 46 & 48 & 51 & 47 & 37 & $19.2( \pm 4.1)$ & $41.9 \%( \pm 11.6 \%)$ \\
\hline Sofia & 164 & 130 & 113 & 119 & 110 & 117 & $40.6( \pm 6.0)$ & $32.9 \%( \pm 6.2 \%)$ \\
\hline Sofia (stolitsa) & 594 & 509 & 551 & 518 & 509 & 544 & $61.4( \pm 15.6)$ & $11.5 \%( \pm 3.1 \%)$ \\
\hline Stara Zagora & 178 & 148 & 130 & 167 & 168 & 142 & $26.2( \pm 12.9)$ & $17.3 \%( \pm 9.2 \%)$ \\
\hline Targovishte & 82 & 46 & 63 & 63 & 62 & 61 & $23.0( \pm 5.7)$ & $39.0 \%( \pm 12.3 \%)$ \\
\hline Varna & 241 & 164 & 172 & 175 & 201 & 177 & $60.8( \pm 10.9)$ & $33.7 \%( \pm 7.6 \%)$ \\
\hline Veliko Tarnovo & 158 & 116 & 125 & 119 & 126 & 126 & $32.4( \pm 3.6)$ & $25.8 \%( \pm 3.5 \%)$ \\
\hline Vidin & 73 & 73 & 72 & 48 & 53 & 57 & $11.6( \pm 8.9)$ & $18.9 \%( \pm 15.1 \%)$ \\
\hline Vratsa & 109 & 113 & 81 & 97 & 84 & 79 & $15.0( \pm 11.1)$ & $16.0 \%( \pm 12.3 \%)$ \\
\hline Yambol & 62 & 68 & 44 & 56 & 54 & 69 & $2.2( \pm 8.2)$ & $3.7 \%( \pm 12.5 \%)$ \\
\hline
\end{tabular}


medRxiv preprint doi: https://doi.org/10.1101/2021.04.06.21254958; this version posted April 10, 2021. The copyright holder for this preprint (which was not certified by peer review) is the author/funder, who has granted medRxiv a license to display the preprint in perpetuity.

It is made available under a CC-BY-NC-ND 4.0 International license .

Supplementary Table 21: Excess mortality in Bulgarian regions for males ages 65-69 for the year 2020.

\begin{tabular}{|c|c|c|c|c|c|c|c|c|}
\hline \multirow[b]{2}{*}{ region } & \multicolumn{6}{|c|}{ mortality } & \multirow[b]{2}{*}{ excess deaths } & \multirow[b]{2}{*}{ P-score } \\
\hline & 2020 & 2015 & 2016 & 2017 & 2018 & 2019 & & \\
\hline Blagoevgrad & 287 & 198 & 207 & 218 & 253 & 198 & $65.0( \pm 18.0)$ & $29.3 \%( \pm 9.7 \%)$ \\
\hline Burgas & 355 & 308 & 332 & 334 & 324 & 299 & $30.8( \pm 12.0)$ & $9.5 \%( \pm 3.9 \%)$ \\
\hline Dobrich & 186 & 196 & 192 & 189 & 185 & 190 & $-10.0( \pm 3.2)$ & $-5.1 \%( \pm 1.5 \%)$ \\
\hline Gabrovo & 122 & 116 & 120 & 120 & 116 & 100 & $6.0( \pm 6.5)$ & $5.2 \%( \pm 5.6 \%)$ \\
\hline Haskovo & 249 & 218 & 216 & 239 & 196 & 212 & $26.4( \pm 12.1)$ & $11.9 \%( \pm 5.8 \%)$ \\
\hline Kardzhali & 135 & 96 & 100 & 89 & 96 & 108 & $34.0( \pm 5.4)$ & $33.7 \%( \pm 6.8 \%)$ \\
\hline Kyustendil & 170 & 136 & 151 & 145 & 126 & 142 & $26.8( \pm 7.5)$ & $18.7 \%( \pm 5.9 \%)$ \\
\hline Lovech & 133 & 129 & 129 & 131 & 127 & 108 & $5.8( \pm 7.5)$ & $4.6 \%( \pm 5.9 \%)$ \\
\hline Montana & 201 & 178 & 156 & 151 & 157 & 134 & $44.2( \pm 12.4)$ & $28.2 \%( \pm 9.4 \%)$ \\
\hline Pazardzhik & 271 & 247 & 223 & 211 & 218 & 218 & $42.8( \pm 10.9)$ & $18.8 \%( \pm 5.5 \%)$ \\
\hline Pernik & 153 & 138 & 125 & 125 & 107 & 122 & $26.4( \pm 8.7)$ & $20.9 \%( \pm 7.8 \%)$ \\
\hline Pleven & 270 & 261 & 226 & 247 & 264 & 225 & $19.0( \pm 14.6)$ & $7.6 \%( \pm 5.9 \%)$ \\
\hline Plovdiv & 629 & 486 & 514 & 525 & 472 & 493 & $120.6( \pm 16.7)$ & $23.7 \%( \pm 3.9 \%)$ \\
\hline Razgrad & 165 & 124 & 117 & 100 & 120 & 131 & $44.2( \pm 9.0)$ & $36.6 \%( \pm 9.5 \%)$ \\
\hline Ruse & 237 & 215 & 194 & 169 & 237 & 199 & $31.8( \pm 19.8)$ & $15.5 \%( \pm 10.2 \%)$ \\
\hline Shumen & 179 & 157 & 155 & 157 & 148 & 164 & $22.0( \pm 4.5)$ & $14.0 \%( \pm 3.2 \%)$ \\
\hline Silistra & 137 & 119 & 111 & 116 & 107 & 106 & $22.8( \pm 4.4)$ & $20.0 \%( \pm 4.5 \%)$ \\
\hline Sliven & 200 & 175 & 170 & 160 & 190 & 145 & $29.6( \pm 13.1)$ & $17.4 \%( \pm 8.4 \%)$ \\
\hline Smolyan & 118 & 83 & 107 & 104 & 109 & 91 & $18.4( \pm 8.9)$ & $18.5 \%( \pm 9.7 \%)$ \\
\hline Sofia & 299 & 242 & 250 & 261 & 230 & 206 & $59.6( \pm 16.6)$ & $24.9 \%( \pm 8.1 \%)$ \\
\hline Sofia (stolitsa) & 951 & 830 & 823 & 733 & 790 & 769 & $147.6( \pm 31.3)$ & $18.4 \%( \pm 4.5 \%)$ \\
\hline Stara Zagora & 309 & 274 & 297 & 261 & 273 & 277 & $29.4( \pm 10.3)$ & $10.5 \%( \pm 3.9 \%)$ \\
\hline Targovishte & 130 & 113 & 122 & 110 & 72 & 84 & $26.6( \pm 16.6)$ & $25.7 \%( \pm 17.4 \%)$ \\
\hline Varna & 424 & 358 & 327 & 312 & 334 & 341 & $84.0( \pm 13.3)$ & $24.7 \%( \pm 4.7 \%)$ \\
\hline Veliko Tarnovo & 262 & 224 & 213 & 218 & 209 & 201 & $45.8( \pm 6.8)$ & $21.2 \%( \pm 3.7 \%)$ \\
\hline Vidin & 115 & 123 & 103 & 101 & 85 & 86 & $13.0( \pm 12.2)$ & $12.7 \%( \pm 12.0 \%)$ \\
\hline Vratsa & 203 & 189 & 188 & 192 & 171 & 174 & $17.8( \pm 7.5)$ & $9.6 \%( \pm 4.3 \%)$ \\
\hline Yambol & 139 & 126 & 111 & 131 & 119 & 122 & $15.6( \pm 5.9)$ & $12.6 \%( \pm 5.1 \%)$ \\
\hline
\end{tabular}

